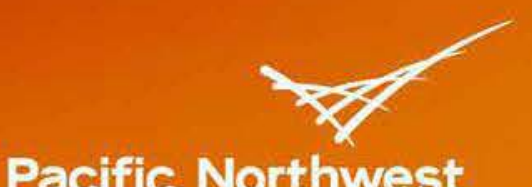

Pacific Northwest

NATIONAL LABORATORY

Proudly Operated by Batrelle Since 1965

\title{
Eddy Current Flow Measurements in the FFTF
}

\section{December 2016}

DL Nielsen

DL Polzin
RP Omberg

BJ Makenas 


\title{
DISCLAIMER
}

This report was prepared as an account of work sponsored by an agency of the United States Government. Neither the United States Government nor any agency thereof, nor Battelle Memorial Institute, nor any of their employees, makes any warranty, express or implied, or assumes any legal liability or responsibility for the accuracy, completeness, or usefulness of any information, apparatus, product, or process disclosed, or represents that its use would not infringe privately owned rights. Reference herein to any specific commercial product, process, or service by trade name, trademark, manufacturer, or otherwise does not necessarily constitute or imply its endorsement, recommendation, or favoring by the United States Government or any agency thereof, or Battelle Memorial Institute. The views and opinions of authors expressed herein do not necessarily state or reflect those of the United States Government or any agency thereof.

\author{
PACIFIC NORTHWEST NATIONAL LABORATORY \\ operated by \\ BATTELLE \\ for the \\ UNITED STATES DEPARTMENT OF ENERGY \\ under Contract DE-AC05-76RL01830
}

Printed in the United States of America
Available to DOE and DOE contractors from the Office of Scientific and Technical Information,
P.O. Box 62, Oak Ridge, TN 37831-0062;
ph: (865) 576-8401
fax: $(865)$ 576-5728
email: reports@adonis.osti.gov

\begin{abstract}
Available to the public from the National Technical Information Service, U.S. Department of Commerce, 5285 Port Royal Rd., Springfield, VA 22161 ph: (800) 553-6847 fax: $(703) 605-6900$ email: orders@ntis.fedworld.gov online ordering: http://www.ntis.gov/ordering.htm
\end{abstract}

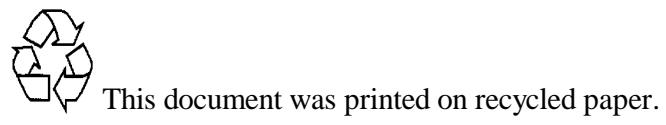




\title{
Eddy Current Flow Measurements in the FFTF
}

\author{
DL Nielsen \\ RP Omberg \\ DL Polzin \\ BJ Makenas
}

December 2016

Prepared for the TerraPower, LLC under a Commercial Work for Others Agreement with the U.S. Department of Energy under Contract DE-AC05-76RL01830

Pacific Northwest National Laboratory

Richland, Washington 99352 


\section{Executive Summary}

The Fast Flux Test Facility (FFTF) is the most recent liquid metal reactor (LMR) to be designed, constructed, and operated by the U.S. Department of Energy (DOE). The 400-MWt sodiumcooled, fast-neutron flux reactor plant was designed for irradiation testing of nuclear reactor fuels and materials for liquid metal fast breeder reactors. Following shut down of the Clinch River Breeder Reactor Plant (CRBRP) project in 1983, FFTF continued to play a key role in providing a test bed for demonstrating performance of advanced fuel designs and demonstrating operation, maintenance, and safety of advanced liquid metal reactors. The FFTF Program provides valuable information for potential follow-on reactor projects in the areas of plant system and component design, component fabrication, fuel design and performance, prototype testing, site construction, and reactor control and operations. This report provides HEDL-TC-1344, "ECFM Flow Measurements in the FFTF Using Phase-Sensitive Detectors”, March 1979. 


\section{Acronyms}

\begin{tabular}{|l|l|}
\hline ARD & Advanced Reactor Division \\
\hline CRBRP & Clinch River Breeder Reactor Plant \\
\hline DOE & U.S. Department of Energy \\
\hline ECFM & Eddy-Current Flowmeter \\
\hline FFTF & Fast Flux Test Facility \\
\hline FTR & Fast Test Reactor \\
\hline LMFBR & Liquid Metal Fast Breeder Reactor \\
\hline LMR & Liquid Metal Reactor \\
\hline
\end{tabular}




\section{Contents}

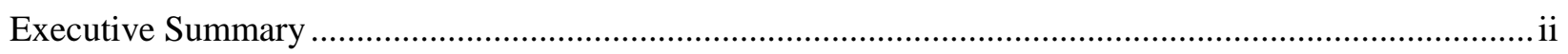

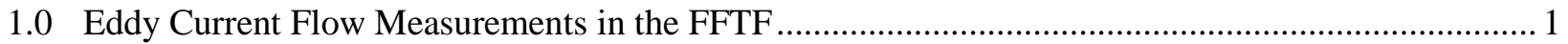




\subsection{Eddy Current Flow Measurements in the FFTF}

The Fast Flux Test Facility (FFTF) is the most recent liquid metal reactor (LMR) to operate in the United States, from 1982 to 1992.The 400-MWt sodium-cooled, low-pressure, hightemperature, fast-neutron flux, nuclear fission test reactor was designed specifically to irradiate Liquid Metal Fast Breeder Reactor (LMFBR) fuel and components in prototypical temperature and flux conditions. FFTF played a key role in LMFBR development and testing activities. The reactor provided extensive capability for in-core irradiation testing, including eight core positions that could be used with independent instrumentation for the test specimens. In addition to irradiation testing capabilities, FFTF provided long-term testing and evaluation of plant components and systems for LMFBRs.

This report provides HEDL-TC-1344, "ECFM Flow Measurements in the FFTF Using PhaseSensitive Detectors", W.T. Nutt and J.L. Stringer, Hanford Engineering Development Laboratory, March 1979. The Eddy-Current Flowmeter (ECFM) is an accurate electromagnetic device for measuring the velocity of a conductor along the longitudinal axis of the flowmeter. Misconceptions about the inherent accuracy of the flow signal resulted in the belief that the ECFM had little flow sensitivity at low flow velocities (see References 1, 2 and 3 of TC-1344). The report dispelled that notion and describes the equipment and procedures for accurately measuring very low flows in the FFTF using an Eddy Current Flowmeter. Calibration results from the Transient Test Loop were analyzed and are presented in the report. Analysis of the hardware operation in extracting a flow reading from the flowmeter signal was used to show the efficacy of the phase-sensitive detection procedure 


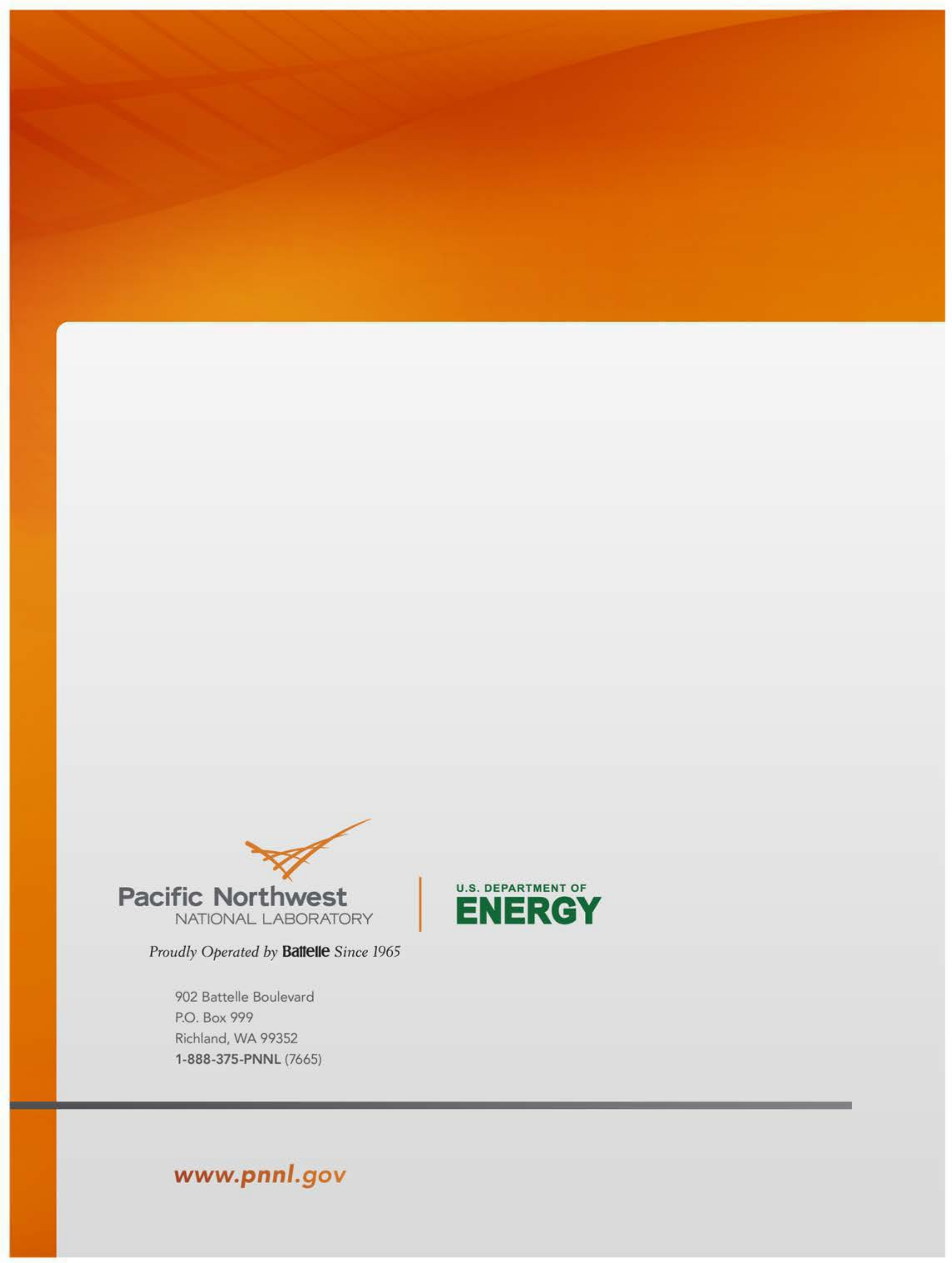


HEDL-TC-1344

\section{ECFM Flow Measurements in the FFTF Using Phase Sensitive Detectors}




\title{
ECFM FLOW MEASUREMENTS IN THE FFTF USING PHASE-SENSITIVE DETECTORS
}

\section{Hanford Engineering Development Laboratory}

\author{
W. T. Nutt \\ J. L. Stringer
}

March 1979

HANFORD ENGINEERING DEVELOPMENT LABORATORY

Operated by Westinghouse Hanford Company

P.O. Box 1970 Richland, WA 99352

A Subsidiary of Westinghouse Electric Corporation

Prepared for the U.S. Department of Energy

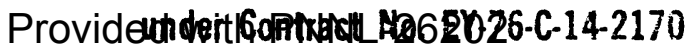




\author{
W. T. Nutt \\ J. L. Stringer
}

\begin{abstract}
The equipment and procedures for accurately measuring very low flows in the Fast Flux Test Facility using an Eddy Current Flowmeter are described. Calibration results from the Transient Test Loop are analyzed and presented. Analysis of the hardware operation in extracting a flow reading from the flowmeter signal is used to show the efficacy of the phase-sensitive detection procedure.
\end{abstract}




\section{ACKNOWLEDGEMENT}

The authors would like to express their appreciation to $W$. L. Thorne for his invaluable assistance and cooperation during the testing phase of this work. 


\section{CONTENTS}

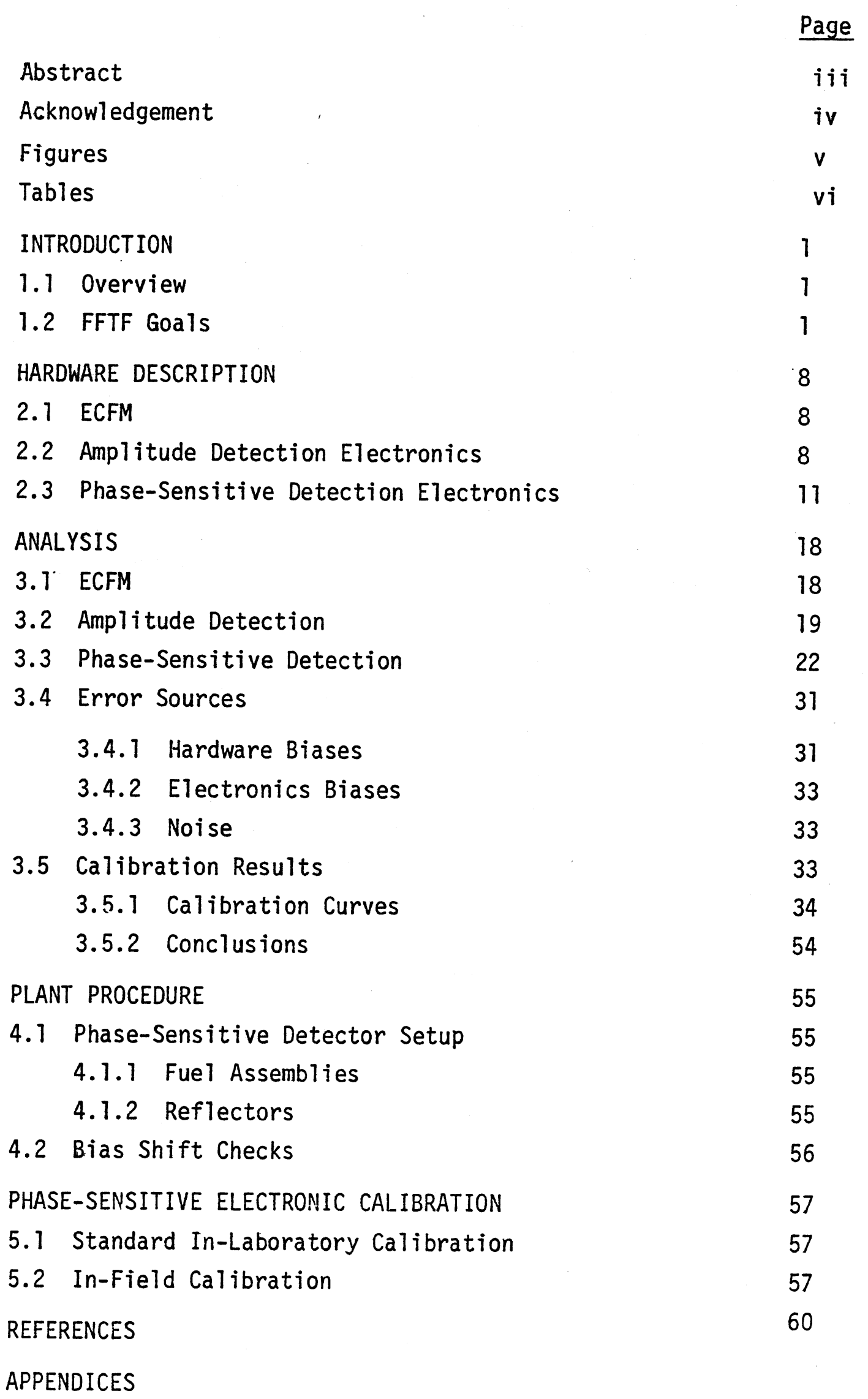




\section{FIGURES}

Figure

Page

1-1 Placement of ECFM's with Phase-Sensitive Dectection Electronics for FFTF Acceptance Testing

1-2a Open Test Assembly Types 4

1-2b. Fuels Open Test Assembly (FOTA) 5

1-3 Schematic Diagram of Typical OTA Core Arrangement 7

2-1 Photograph of a Longitudinal Cross Section of an Eddy 9 Current Flowmeter

2-2 Signal Conditioner/Current Regulator Module 10

2-3 Function Block Diagram of a Single ECFM Channel 12

2-4 Test/Calibration Station 13

2-5 Functional Block Diagram of a Single ECFM Channel 14

2-6 ECFM Channel PAR Model 128A Lock-In Amplifier 16

2-7 PAR Mode1 5204 Lock-In Analyzer 17

3-1 Ideal ECFM Amplitude-Phase Plot 20

3-2 Realistic ECFM Amplitude-Phase Plot 21

3-3 $V_{D C}$ Versus Flow for Amplitude Detection 25

3-4a Relationship of $V_{A C}$ and $Q$ for Two Flow Readings when $Q \quad 29$ has Been Properiy Adjusted.

3-4b Variation of Q with Flow When $Q$ has not been Properly 29 Adjusted

3-5 Rotation of the Direction of Measurement of $Q$ by an 30 Angle $\theta$ to make Q Flow - Independent

3-6 Graphical Method for Obtaining Q 32 


\section{TABLES}

Table

Page

3.1 S/N 052 Parameters

35

3.2 S/N 064 Parameters

36

$3.3 \quad \mathrm{~S} / \mathrm{N} 078$ Parameters

37

$3.4 \quad$ S/N 081 Parameters

38

$3.5 \quad S / N 098$ Parameters

39

3.6 S/N 109 Parameters

40

3.7 S/N 110 Parameters

41

3.8 S/N 128 Parameters

42

3.9 S/N 156 Parameters

43

$3.10 \quad$ S/N 158 Parameters

44

3.11 S/N 164 Parameters

45

$3.12 S / N 172$ Parameters $\quad 46$

3.13 S/N 191 Parameters $\quad 47$

3.14 AOTA Parameters 48

3.15 S/N 201 Parameters $\quad 49$

3.16 Calibration Curve Parameters 50

3.17 Flow and Temperature Dependence of Q for S/N 172

3.18 Parameters for Quadrature Dependence on Flow and 53

5.12 Characteristics of TTL Electronics 58

5.1b Table of Calibration Runs Versus Electronics Ident No. 59 


\subsection{INTRODUCTION}

The Eddy-Current Flowmeter (ECFM) is an accurate electromagnetic device for measuring the velocity of a conductor along the longitudinal axis of the flowmeter. While such devices have been in use for several years, misconceptions about the inherent accuracy of the flow signal have produced the notion that the ECFM has little flow sensitivity at low flow velocities (see References 1, 2 and 3). It was not until recently (see Reference 4) that the reason for the apparent loss of sensitivity at low flows was recognized. The existence of "non-flow" components in the ECFM signal was the real culprit. In this report the calibration of ECFMs using Phase-Sensitive Detection (PSD) techniques is discussed and the results of the calibration program at the Transient Test Loop (TTL) Facility at HEDL are presented.

\subsection{Overview}

The remainder of the introductory section describes the measurement goals and ECFM configurations of the Fast Flux Test Facility (FFTF). Section 2 gives a brief overview of the ECFM from a hardware point-of-view and also describes the electronic processing which produces the flow signal using either Amplitude Detection (AD) or PSD. An analys is of the general theory behind ECFMs and of AD and PSD along with a discussion of error sources and calibration results constitute Section 3. Finally, in Sections 4 and 5, procedures for the implementation of PSD in the field are discussed.

\subsection{FFTF Goals}

In the FFTF Natural Circulation Testing, the flow velocities in the fueled subassemblies will be less than $10 \%$ of full flow. In order to obtain a reasonable flow map in the core at these low flows and to be able to describe the FOTA flows, greater accuracy is required than is available with the AD System. These low flow measurements are required for code verification and model tuning from both a safety and an engineering standpoint.

There are twelve ECFMs in the instrument tree which measure the flow through the reactor, all but ten are over fueled assemblies, the last two being in the reflectors in Row 7 . These reflectors carry about $7 \%$ of the flow for 
a fueled subassembly. They have a low-flow measurement requirement even at maximum flow. Figure 1-1 shows the distribution of the PSD equipped ECFMs in the initial core load of FFTF.

This arrangement represents an effort to make use of the accurate lowflow data to characterize fuel elements in each orificing zone, power category and FOTA neighborhood.

ECFMs are present in two different configurations: The Open Test Assemblies (OTA), which have long instrument stalks extending above the core, have their ECFMs inside the instrument stalk and provide very accurate flow measurements, (see Figure 1-2). Fuel Driver Assemblies and reflectors do not extend beyond the top of the core, rather they terminate with a handling socket. The ECFMs in this case are in an instrument tree which is placed above the core. Figure 1-3 shows the two types of configuration in the FFTF. 
FTR CORE MAP

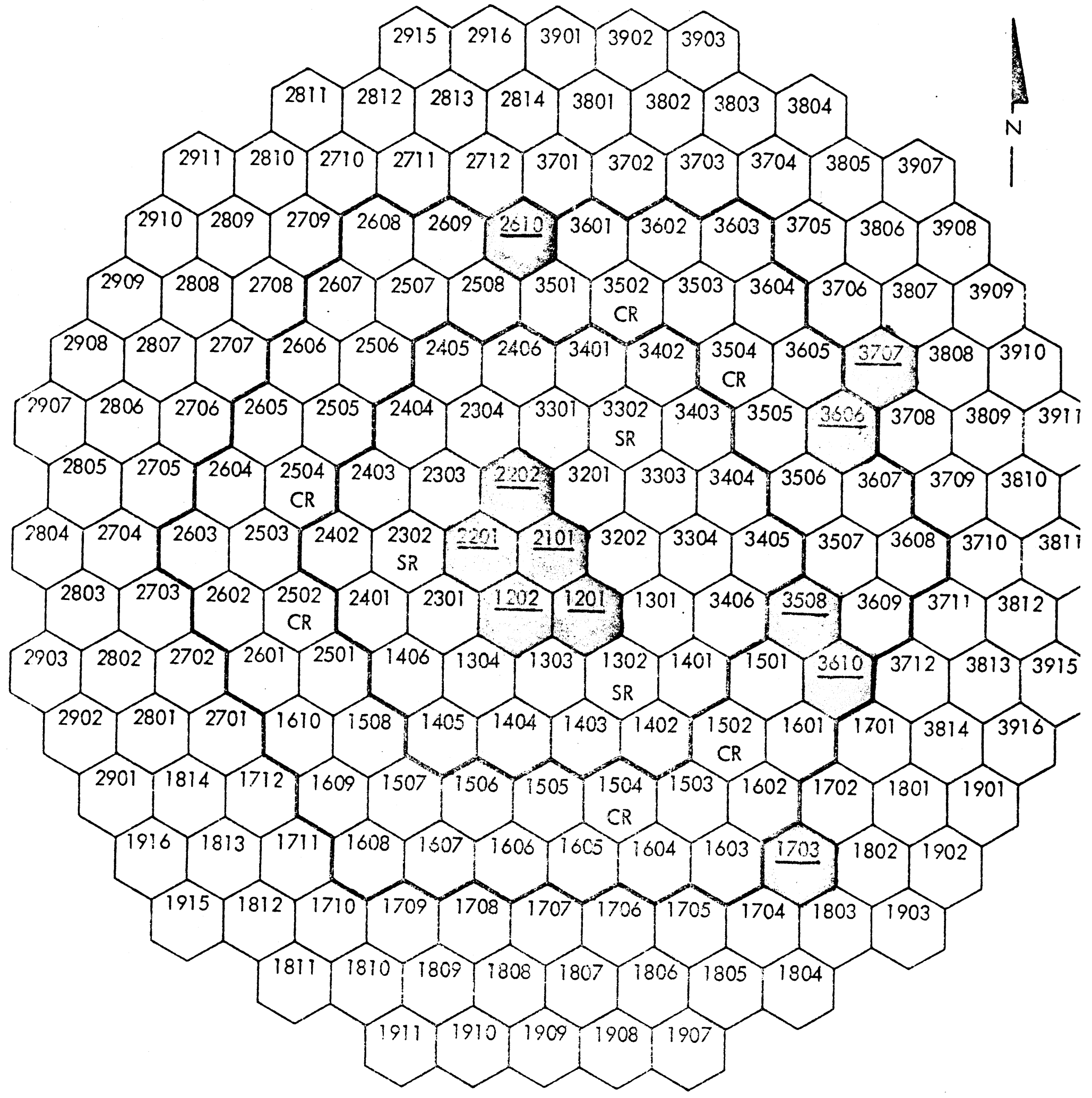

Figure 1-1 Placement of ECFMs with Phase-Sensitive Detection Electronics for FFTF Acceptance Testing. 


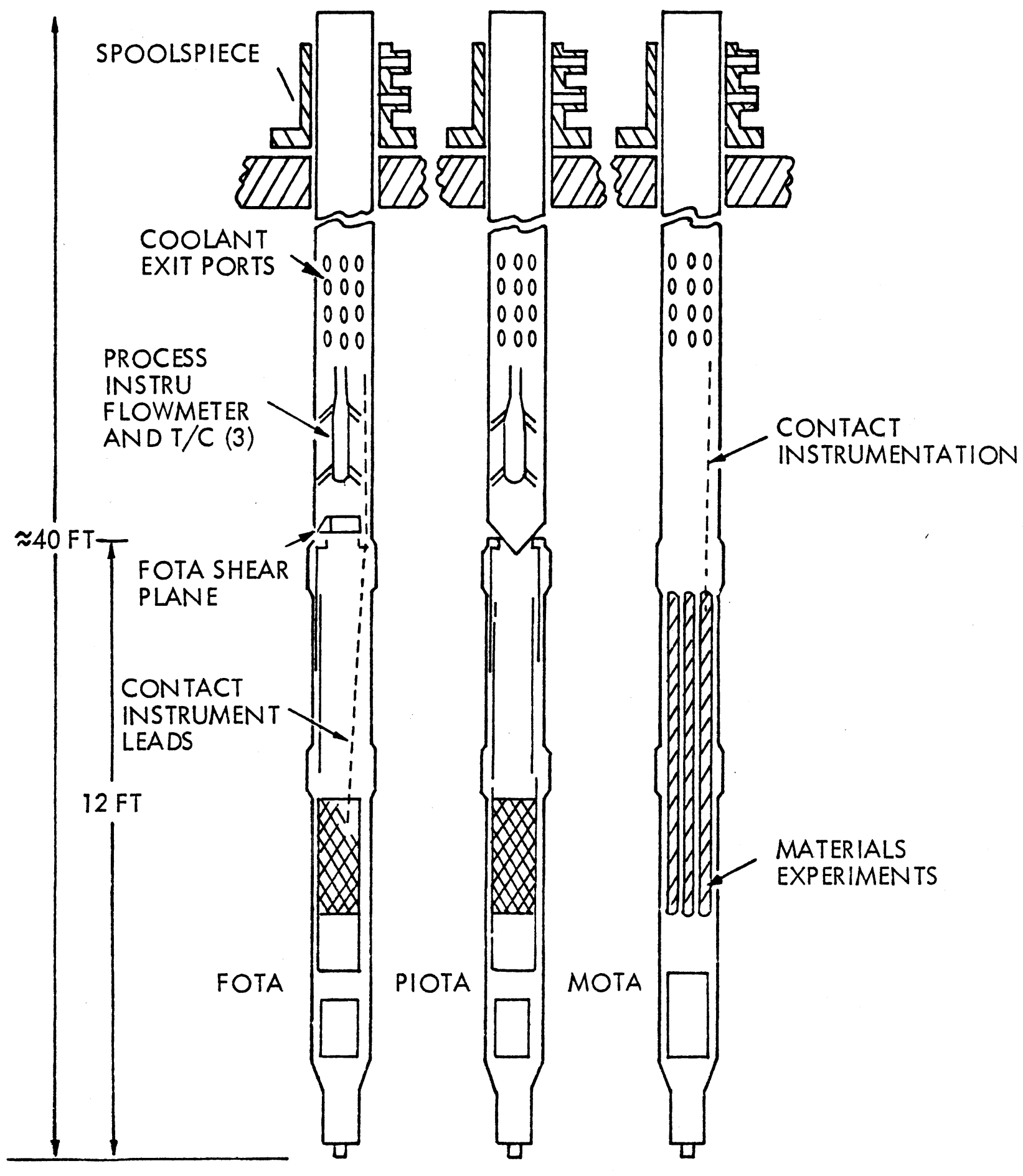

HEDL 7902-043.1

FIGURE 1-2a Open Test Assembly Types. 


\section{FUELS OPEN TEST ASSEMBLY (FOTA)}
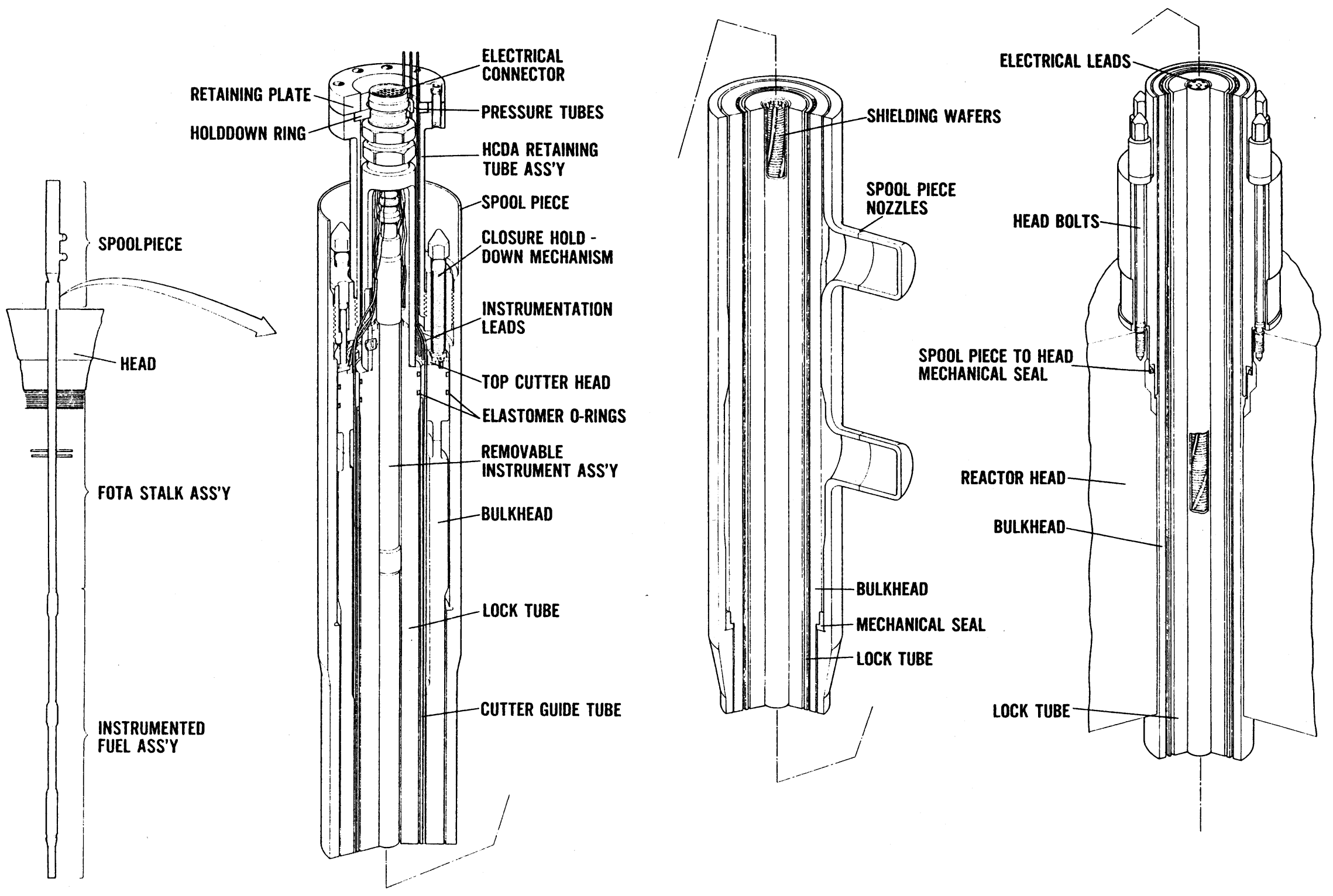

FIGURE 1-2b FUe1s OPEN TEST ASSEMBLY (FOTA) 


\section{FUELS OPEN TEST ASSEMBLY (FOTA) CONTINUED}

$a$

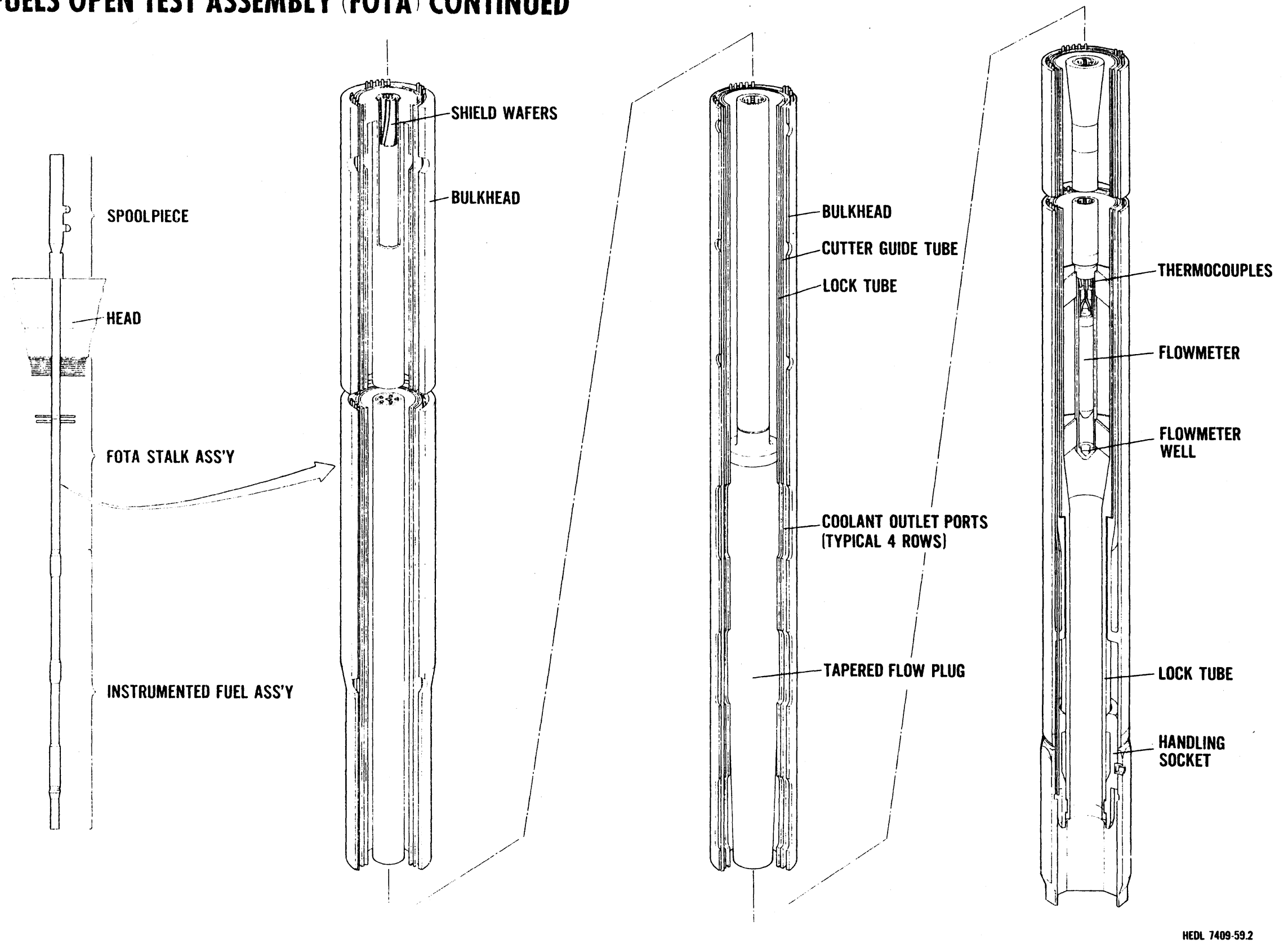

FIGURE 1-2b (Continued)

Provided with PNNL-26202 


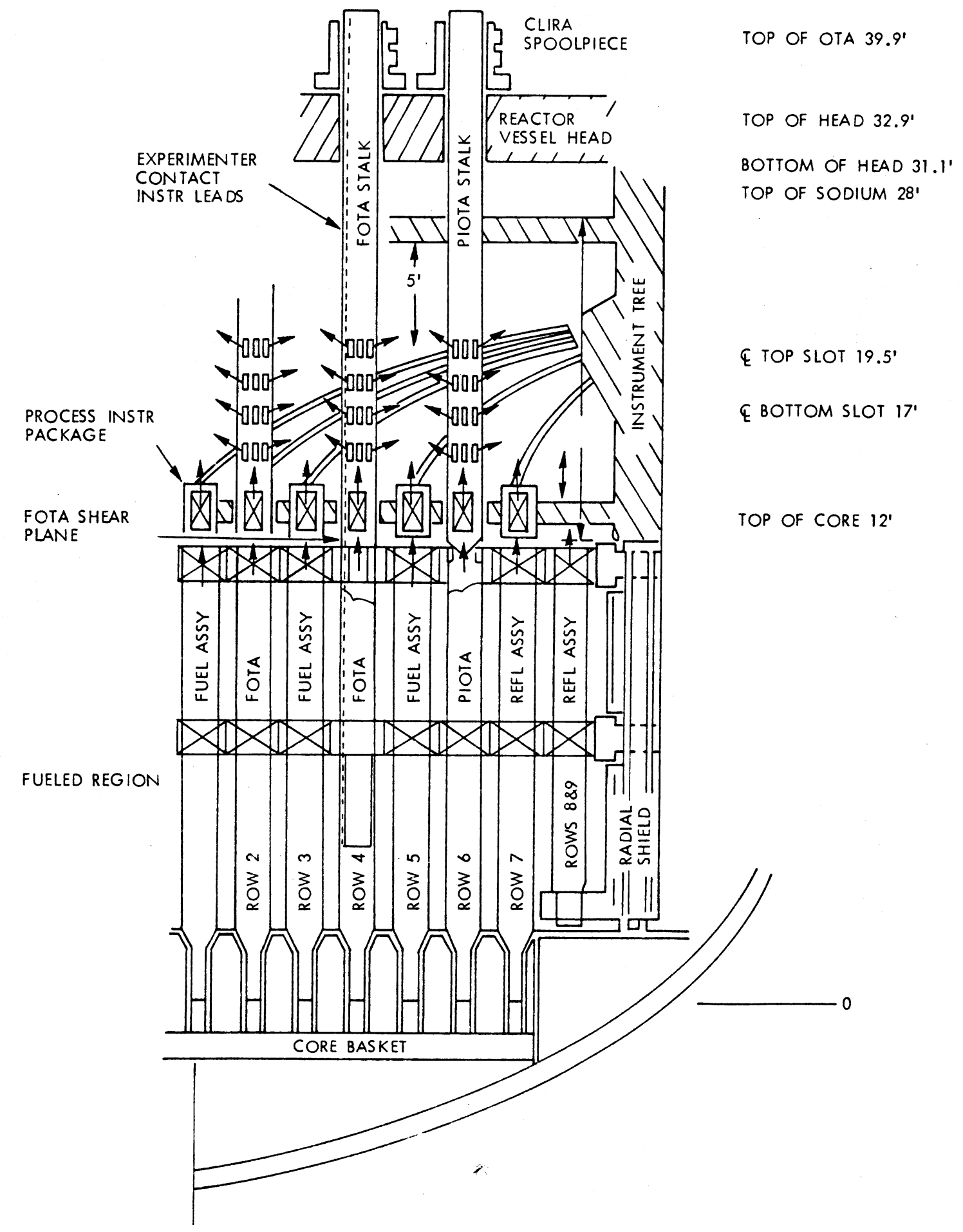

FIGURE 1-3 Schematic of Typical OTA Core Arrangement.

HEDL 7902-043.12 


\subsection{HARDWARE DESCRIPTION}

This section presents a physical description of the ECFM and the associated electronics, both AD and PSD. In operation the ECFM is placed in a stainless steel thimble which isolates it from the sodium. The thimble is oriented with respect to the flow such that the flow is along its axis.

\subsection{ECFM}

The ECFM consist of three coils placed on a single axis inside a steel container (see Figure 2-1). The middle coil in this configuration is the primary coil and the other two are secondary coils. The secondary coils are connected to provide an output which is the difference of the two induced EMFs. The physical properties of the ECFM probe were specified in Standard RDT \& C-4-7, Reference 5.

\subsection{Amplitude Detection Electronics}

The AD electronics consist of two basic modules. One module contains the system power supply and a master $1 \mathrm{KHz}$ oscillator. The second module contains a signal conditioning $(S C)$ circuit and a current regulating ( $C R$ ) circuit which provides a nominal 0.5 ampere a.c. drive current to the primary coil of the ECFM. The power supply and oscillator provide power and signal to operate six SC/CR modules housed in a standard 19" NIM Bin and are themselves housed in a standard 19" NIM Bin along with two more power supply/oscillator packages.

The power supplies are standard items manufactured by Lambda Electronics Corporation of Melville, New York. Details of the specifications for these modules are included in Operations Maintenance Manual, 0MM-092-00-002, Volume 1 and Standard RDT \& C-10-5, Reference 6 .

The SC/CR (see Figure 2-2) provides a "constant current" a.c. sine wave of 0.5 amperes rms amplitude at $1 \mathrm{KHz}$ frequency to the primary coil of the ECFM. The CR (essentialiy a non-inverting feedback amplifier) is excited by the output of the oscillator in the power supply/oscillator module. The SC section of the module has three basic circuits: 1) the differential 
FIUGRE 2-1 Photograph of a longitudinal cross section of an Eddy Current Flowmeter. The instrument lead enters at the top of the figure, where three thermocouples are located. Paired primary and secondary coils are wound around the hollow central shaft which occupies most of the picture. The truncated leads to the primary (the middle two wire pairs) and secondary (the outer pairs) coils are seen in this hollow central shaft. At the bottom of the picture is the stainless steel ogive which caps the stainless steel jacket surrounding the thermocouples and the flowmeter coils. 

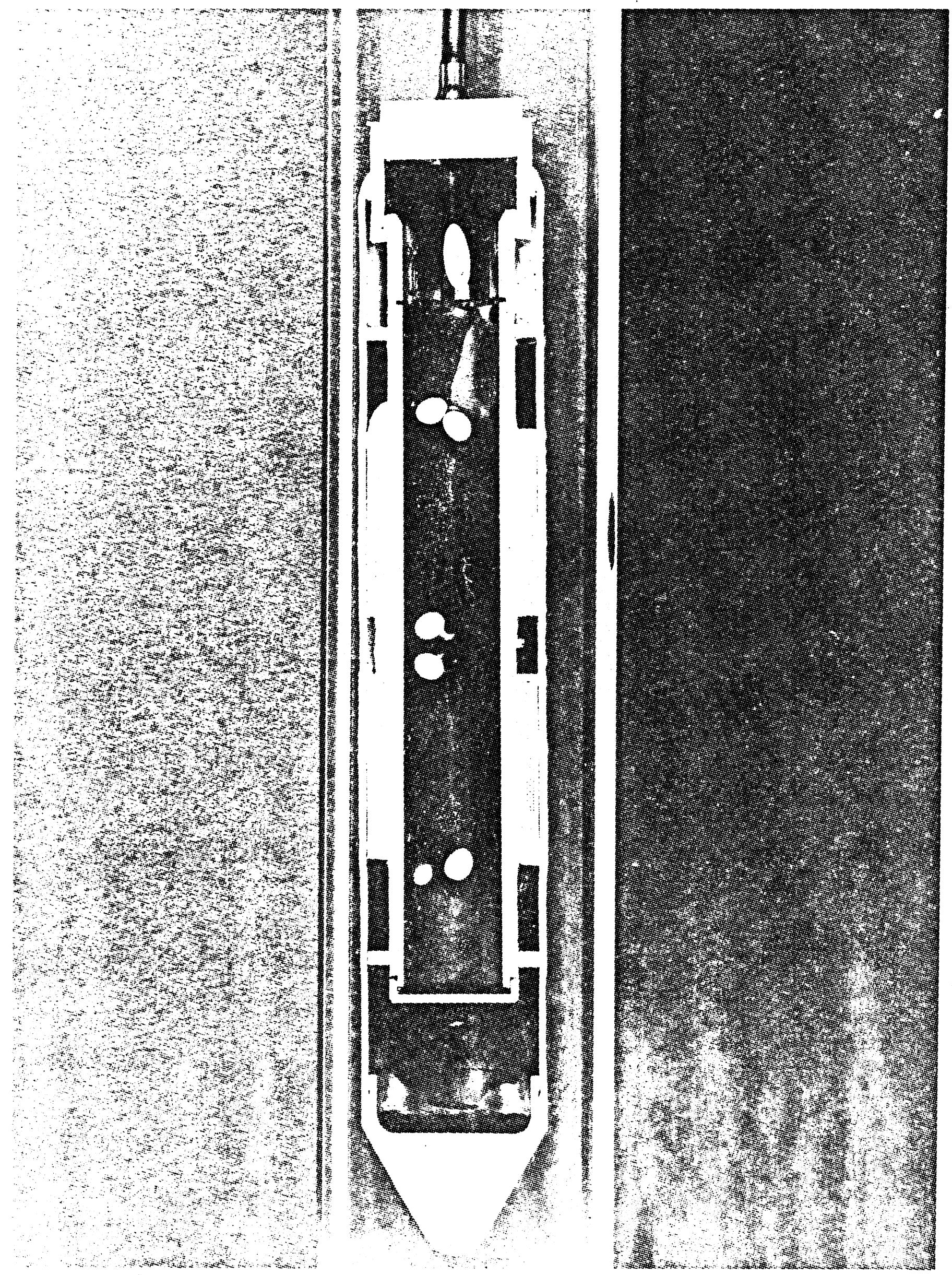

FIGURE 2.1 


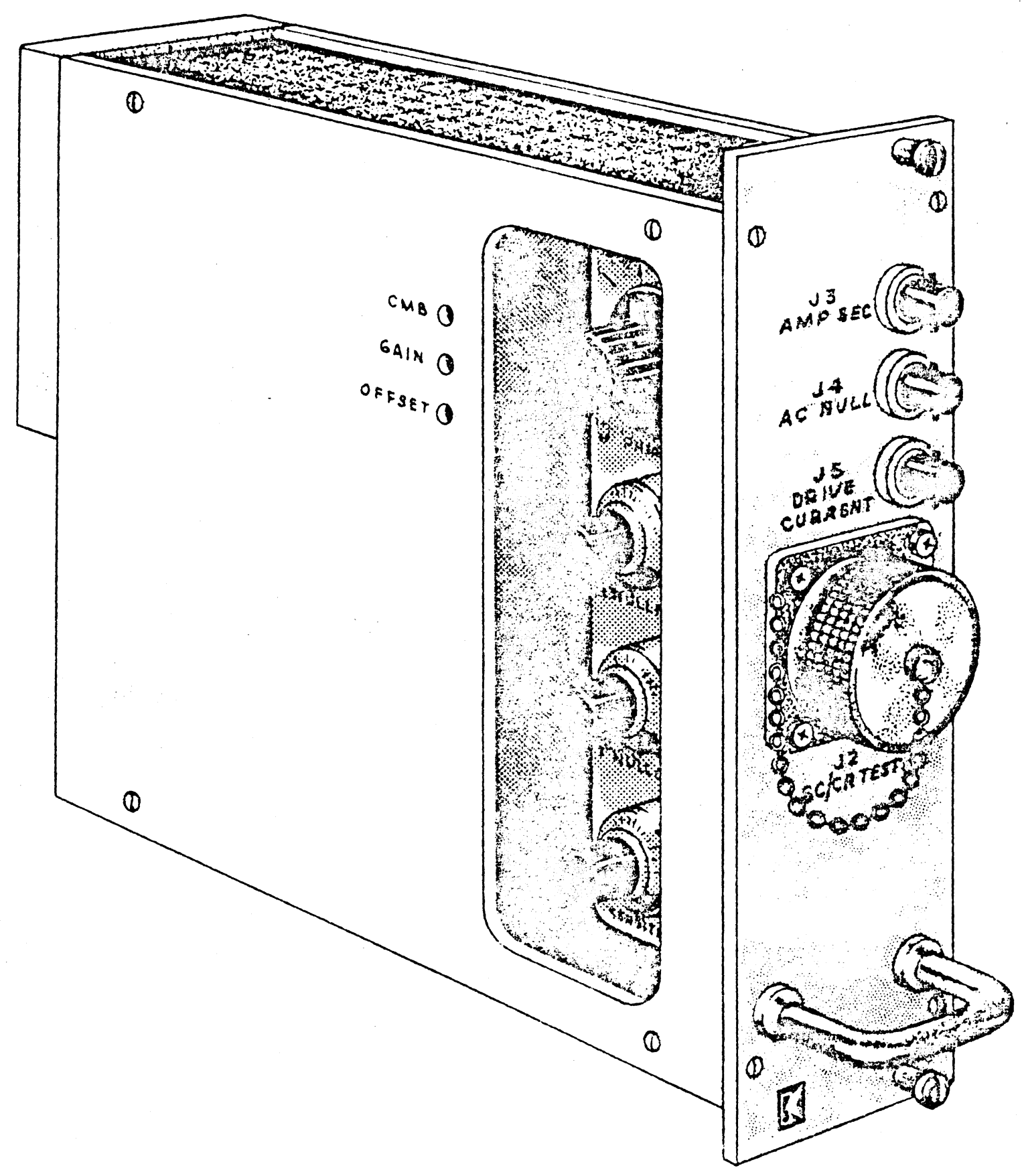

FIGURE 2-2 Signal Conditioner/Current Regulator Module 
amplifier/bandpass filter, 2) the a.c. nulling circuit and 3) the detector circuit. Emf imbalances from the ECFM secondary coils are amplified, filtered and the internally generated signal from the a.c. nulling circuit is used in the summing amplifier to remove any residual biases. Figure 2-3 provides a schematic summary of the action of the $S C / C R$ in providing the d.c. output from the coil imbalances.

The test calibration station (see Figure 2-4) incorporates the capability for testing every function of the system. It contains a built-in Fluke digital voltmeter which makes all measurements and it is designed to operate in conjunction with or independently of the flowmeter system as the station incorporates its own power supplies. The station also incorporates internal circuitry and a test switch which provides the station with a self-test capability. In operation, the station is capable of checking the ECFM by either taking d.c. resistance measurements or actual flow readings. The station further incorporates an ECFM simulator circuit which allows for simulation of the zero flow condition for an ECFM.

The zero flow signal is utilized in calibration, checkout, or adjustment of a SC module at full load by connecting the SC module to the test station. Any SC module can be adjusted to a specific ECFM via the procedure of simulating zero flow independent of the actual state of the system.

The test station also has the capability for checking the output of any power supply.

\subsection{Phase-Sensitive Detection Electronics}

The PSD electronics differ from the $A D$ electronics in that they make use of only the $C R$ aspects of the $S C / C R$ and the differential input amplifier high pass filter (See Figure 2-3). This modification bypasses most of the SC module. Typical circuitry for this "piggy-backed" system is shown in Figure 2-5. While the $A D$ circuit is not shown here, it remains intact and the PSD system is added on to expand the capabilities of the ECFM. 


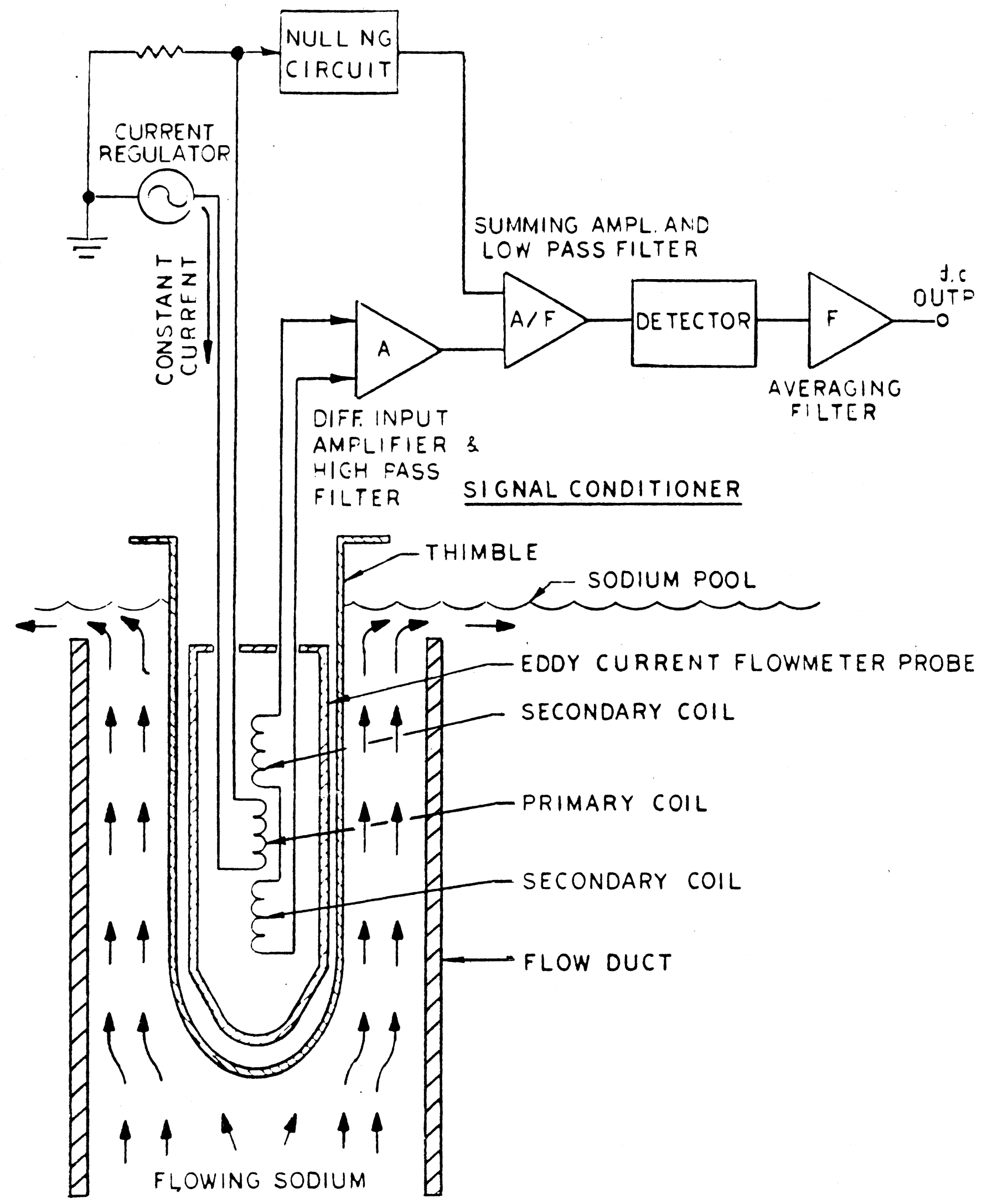

FIGURE 2-3

FUNCTIONAL BLOCK DIAGRAM OF A SINGLE ECFM CHANNEL 


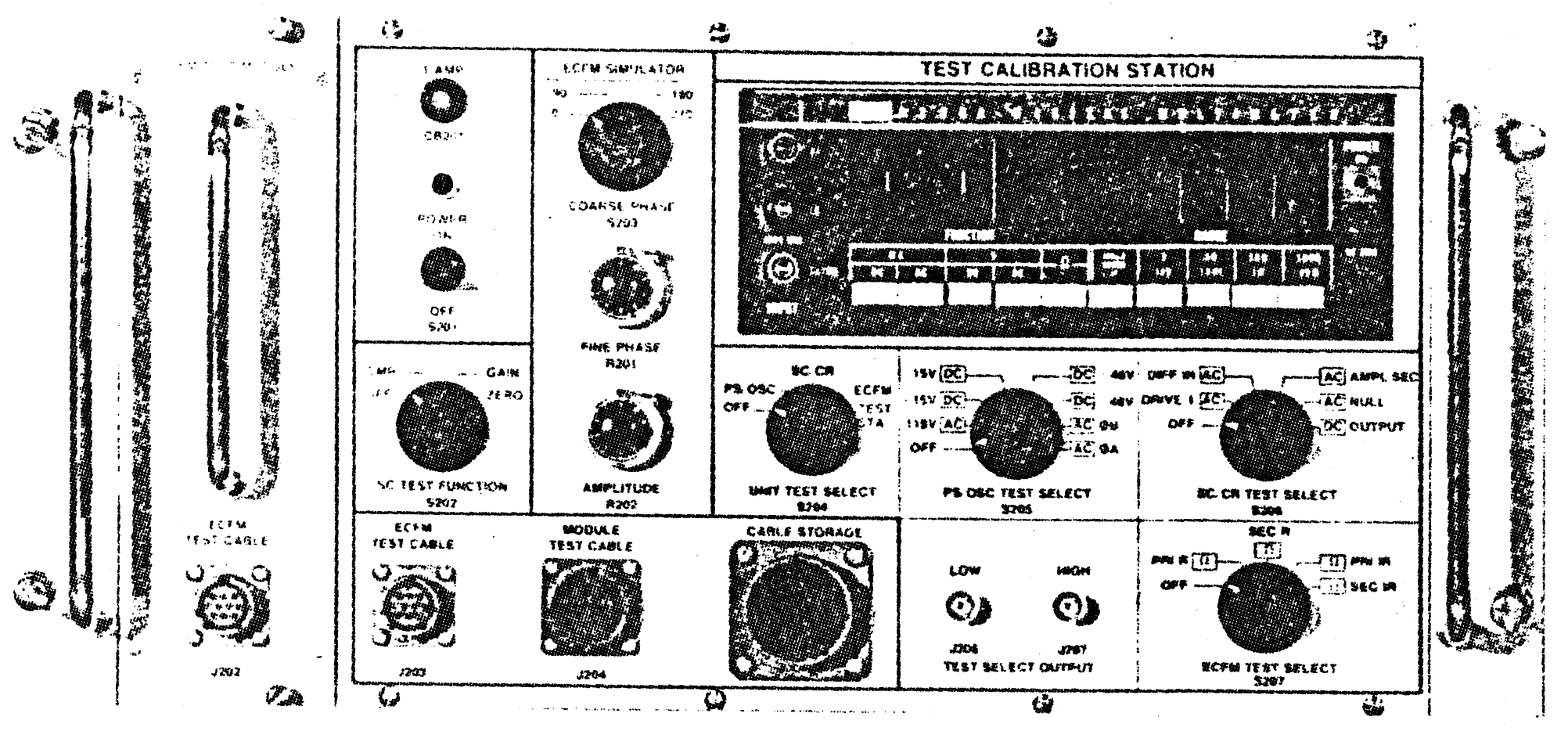

FIGURE 2-4 Test/Calibration Station 


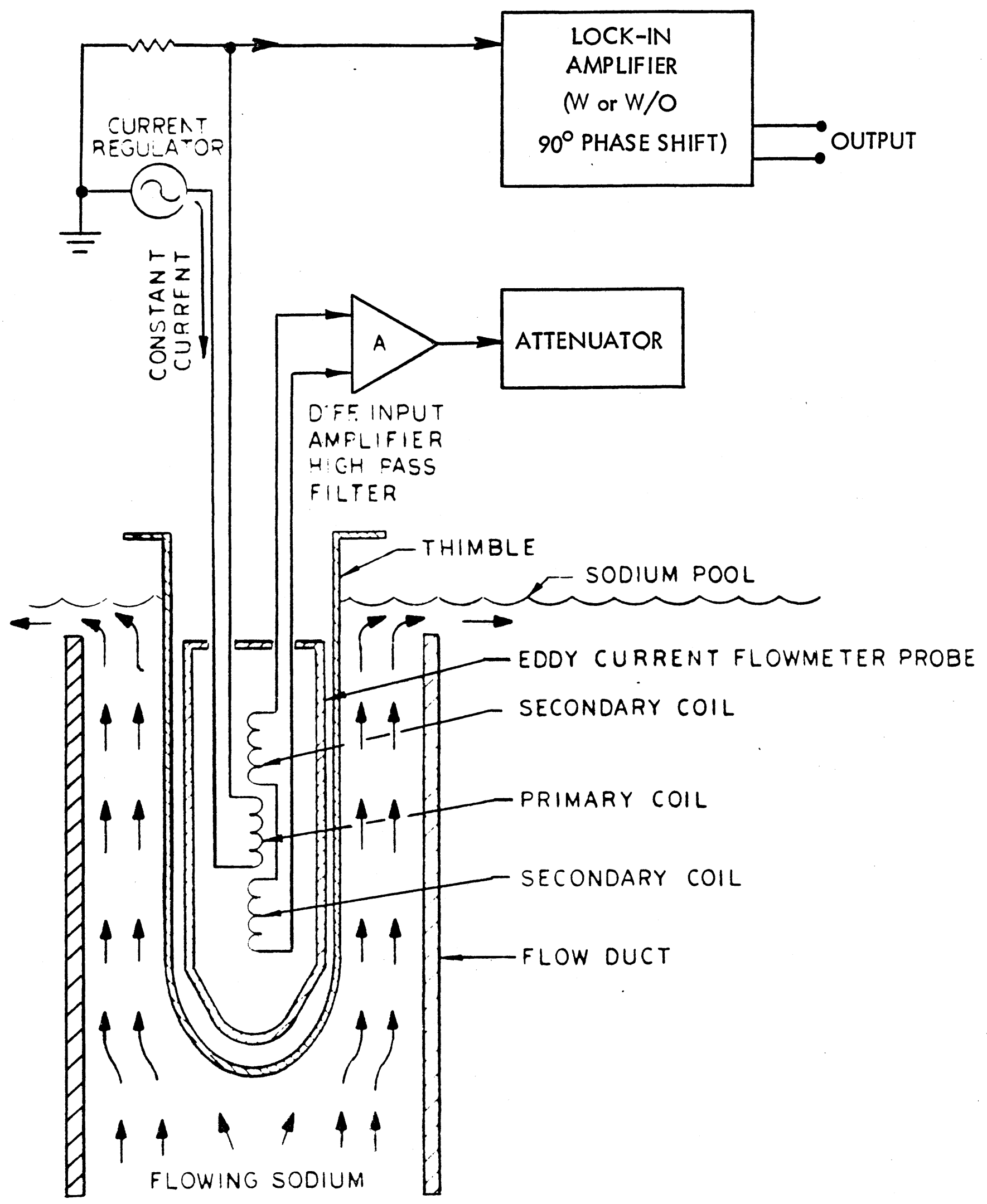

FIGURE 2-5

FUNCTIONAL BLOCK DIAGRAM OF A SINGLE ECFM CHANNEL 
Several components are common to both systems; namely, the CR, the differential input amplifier/high pass filter and the test calibration module. The additional components used in PSD are a lock-in amplifier and an ohmic attenuator to provide appropriately scaled inputs for the amplifier.

The PSD electronics are of two types: The first, used on all subassemblies except the Row 2 FOTA (HF011), employs a Princeton Applied Research (PAR) Model 128 A Lock-In Amplifier (see Figure 2-6) to provide the flow signal output using the typical circuitry in Figure 2-5. The Row 2 FOTA employs a PAR Model 5204 Lock-In Analyzer (see Figure 2-7) which is basically two lock-in amplifiers with a $90^{\circ}$ phase difference between the two channels. The output of this analyzer consists of two signals: one being the usual flow signal, the other being the component of the signal $90^{\circ}$ out-of-phase with the flow signal. Analysis of PSD measurement theory in Section 3 explains the value of this configuration and of PSD itself for low flows.

The physical characteristics of the two lock-in amplfiersare detailed in Appendix A.

As a final hardware note, the calibration program employed PAR Model 120 Lock-In-Amplifiers which differ substantively in that they have a $20 \mathrm{mv}$ setting, on which all calibration was performed, while both models used in the FFTF have a $25 \mathrm{mv}$ setting. The differences are compensated by adjusting the resistance of the attenuators as described in Section 5.2. 


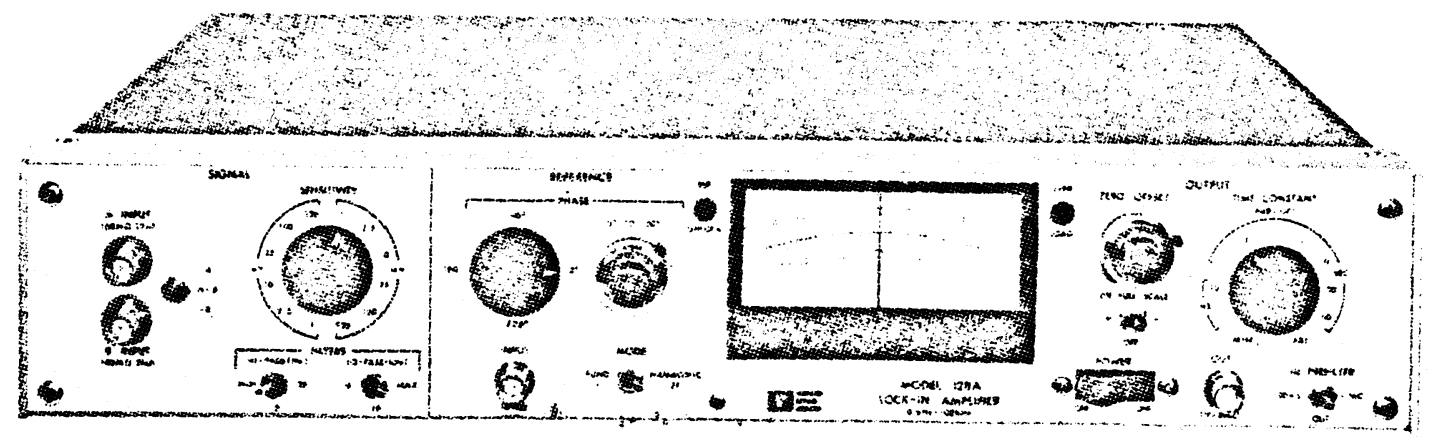

FIGURE 2-6 PAR Model 128A Lock-In Amplifier The Princton Applied Research (PAR) Model 128A Lock-In Amplifier (Front View) is used for all ECFM flow evaluation by PSD except HFO11. Specifications are presented in Appendix $A$. 


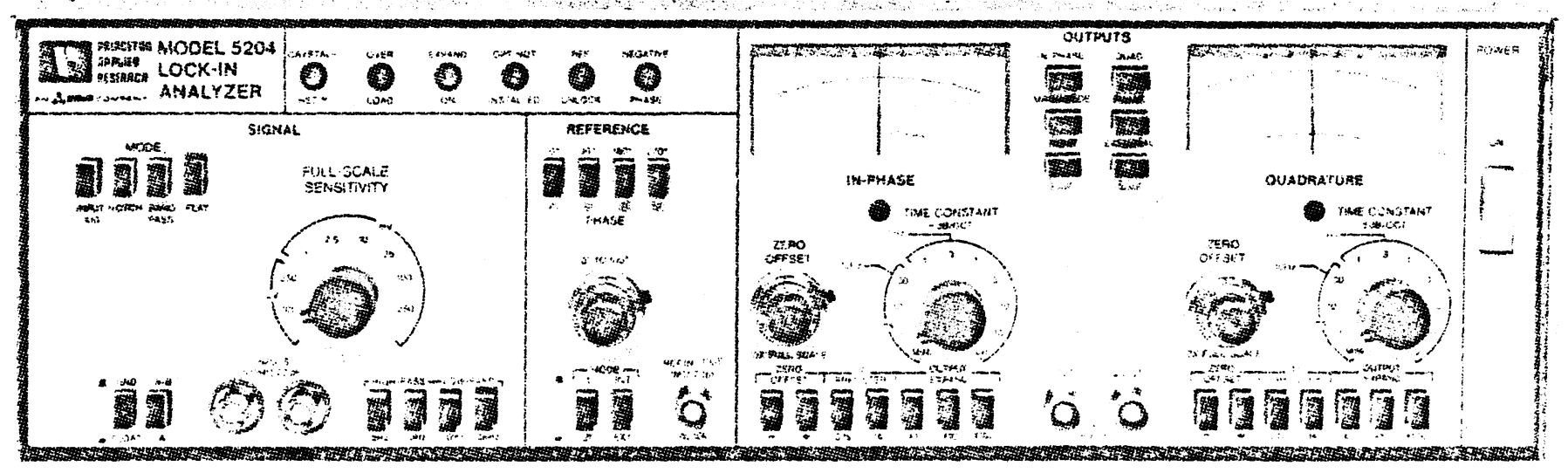

FIGURE 2-7 PAR Model 5204 Lock-In Analyzer

The Princeton Applied Research

(PAR) Model 5204 Lock-In Analyzer

used by HFOll in FFTF Acceptance

Testing. This analyzer acts as

two Lock-In Amplifiers.

Specifications are given in

Appendix A. 


\subsection{ANALYSIS}

This section presents a simplified version of the theory of ECFMs. Both $A D$ and PSD are described in order to provide the motivation for PSD. Error sources are very important in any measurement technique and Section 3.4 presents a discussion of several error sources which are present in flow measurement. Finally Section 3.5 reports the results of the calibration program and discusses errors remaining in the flow signal.

\subsection{ECFM}

A detailed discussion of the theory of operation of the ECFM is presented in both Appendix $B$ and in Reference 7 . Figure 2-3 provides a schematic picture of the operation of an ECFM immersed in flowing sodium.

An alternating current (in this case $1000 \mathrm{~Hz}$ ) is applied to the primary coil. The choice of frequency is influenced by the conductor resistivity, the use a thimble (dry) or director immersion (wet), and considerations such as lead-to-lead coupling in the electronics. The sodium penetration decreases with increasing freauency and at $1000 \mathrm{~Hz}$ the thimble alone attenuates the signal by $40 \%$. (See Refernce 8. ) The alternating current flowing in the primary induces eddy currents in the sodium which, when the sodium velocity is zero, are parallel to a plane normal to the axis of the coil, symmetric with respect to the plane in magnitude, but flow in opposite directions. If the sodium has a velocity along the axis of the coil, then the upstream eddy currents develop a damping term which is essentially bilinear in velocity and conductivity, thus introducing a skew in the EM field in the direction of flow. When the eddy currents are imbalanced by the sodium flow, a different emf is induced in each of the secondary coils. The difference in the two emfs becomes the flow signal.

There are some problems involved, in that this signal has non-flow components which arise from the variation in sodium conductivity with temperature, thermal changes in the coils (both secondary and primery), variations in permittivity of the thimble and the sodium etc. The dominant temperature variation in the non-flow component is usualiy the conductivity of the sodium although changes in the trimble and the environment can bias the low flow values in both phase and ampiitude. 
The sum of the secondary coil emfs will contain the same information except that, to first order, the flow dependence will be eliminated. Thus the temperature dependence of the signal is enhanced. This fact has been used to provide a correction for the temperature effects and improvement in the linearity for linear variable differential transformer (LVDT). (See Reference 9). In fact, when the sum of the emfs is used, it is possible to use the ECFM as a high speed temperature measuring device with good accuracy $\left(5^{\circ} \mathrm{F}\right)$. Reference 10 is a series of papers on just this topic.

\subsection{Amplitude Detection}

This technique of flow measurement assumes the non-flow components are not important and ignores the Phase, $\phi$, of the flow signal. The first assumption of $A D$ is that, while there is temperature dependence in the flow signal, all flow lines cross at a single point, $S$, in an amplitudephase $(v-\phi)$ plot at the point corresponding to zero flow.

The second assumption is that $S$ also corresponds to the origin of the $v-\phi$ plot. Thus the assumed form of a $v-\phi$ plot is that pictured in Figure 3-1.

It is clear from examining this figure that the amplitude (distance from the origin) of the flow signal for a fixed flow is independent of the temperature and vanishes when the flow vanishes. When one assumes the relationship of flow to signal is linear (a very good assumption in this case) only a gain is necessary to convert the flow signal to appropriate flow units.

In fact, both assumptions are violated to some extent by real ECFMs. Figure 3-2 represents typical $v-\phi$ plots for ECFMs. In Figure 3-2a the flow signals have all crosed at a single point, $S$, but it is not the origin and it is not zero flow. Had it been zero flow, one could have translated the origin to the zero flow point and obtained Figure 3-1. The $A D$ calibration procedure translated the origin to zero flow rather than to S. Either of these choices seems to be on equal footing, and nulling the amplitude at zero flow is easier than measuring from $S$ (which first must be determined). The consequences of the two choices are shown 


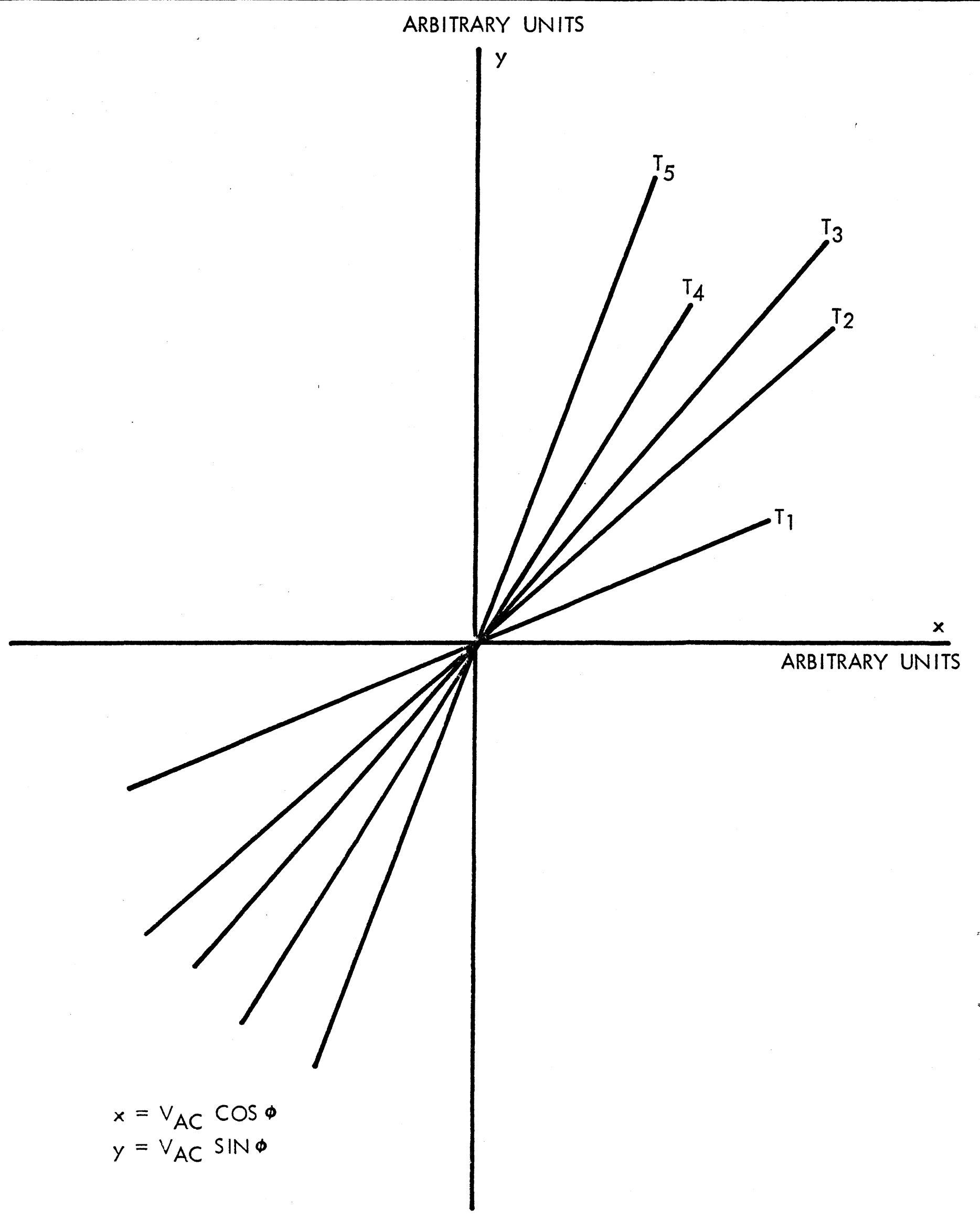

FIGURE 3-1 IDEAL ECFM Amplitude-Phase Plot

HEDL 7902-043.

Provided with PNNL-26202 


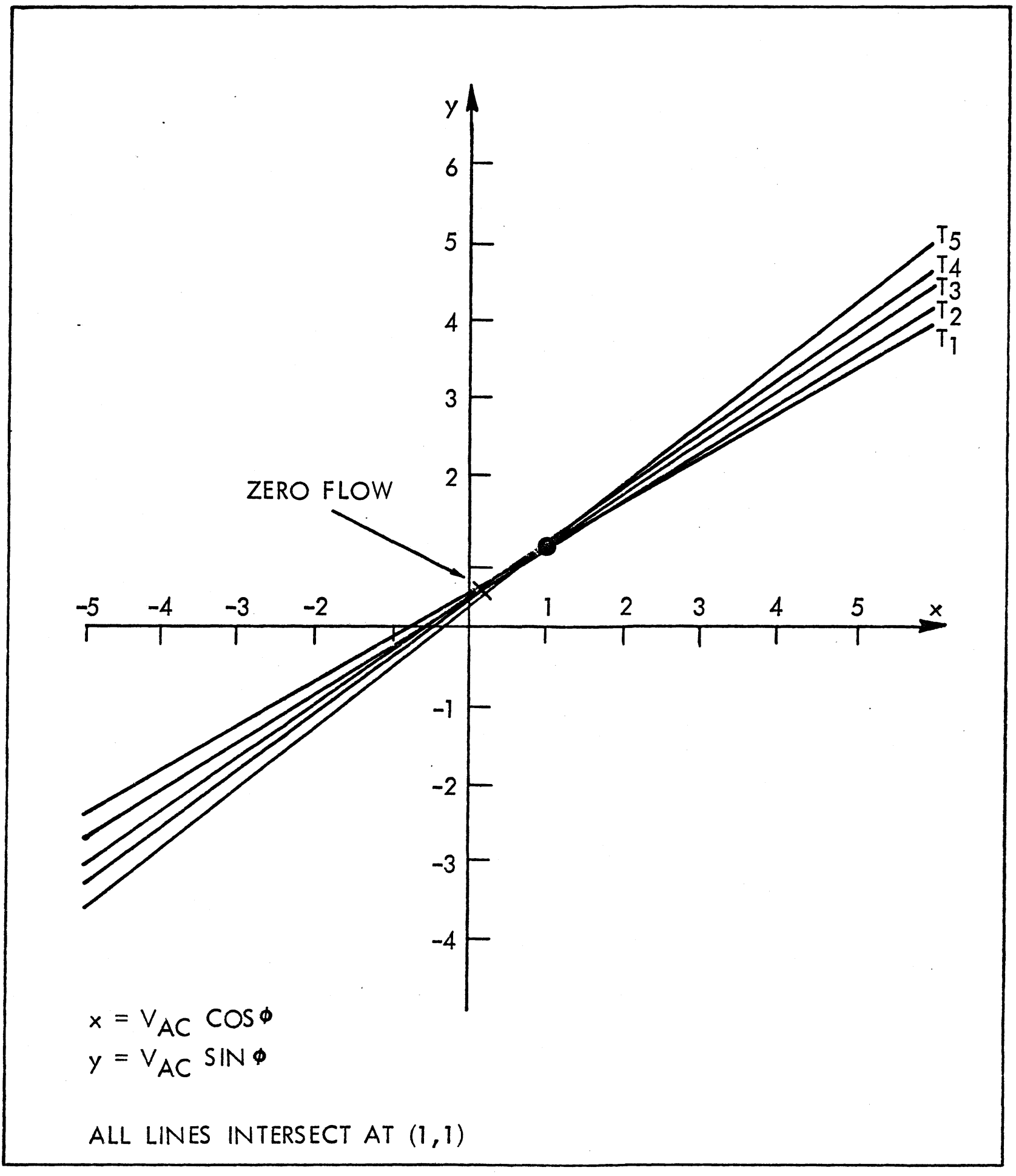

FIGURE 3-2a Realistic ECFM Amplitude-Phase Plot

HEDL 7902-043.2 
in Figure 3-3a. Note that nulling to zero flow has produced a family of curves, whereas measuring from $S$ has produced on straight line with a non-zero intercept. When nulling to zero flow, one is given the impression that some nonlinear, temperature-dependent, flow-dependent effect is entering at low flows. It is in fact just an artifact of the nulling process.

If there were no point $S$, one could get two distinct types of situations, Figure $3-2 a$ and $3-2 c$, which correspond to Figures $3-3 b$ and $3-3 c$ when one examines the flow signal versus flow. Type $b$ could be improved somewhat by measuring from an approximate $S$ value, however, Type $C$ is double valued! Nothing can be done to resolve the ambiguity at low flow using AD. Note that if the $A D$ were to null to $S$ in Type $b$ a double-valued result would result.

Use of $A D$ for higher flow is quite reliable, but the matching of the secondary coils in the ECFM is not done sufficiently well to use $A D$ in the low flow regime. Moreover, it may not be feasible to perform matching to the level of accuracy required by low flows.

\subsection{Phase-Sensitive Detection}

PSD was instituted on several ECFMs at the FFTF to ameliorate the difficulties caused by the inability of AD-calibrated ECFMs to provide the necessary low flow data. PSD, in essence, measures the distance from a line perpendicular to the reference flow line (usually $400^{\circ} \mathrm{F}$ ) and calculates the flow from the quantity. Ideally a flowmeter should be such that the flow lines for different temperature never cross. This means that the line perpendicular to the reference flow line is perpendicular to all flow lines and the distance from the line is dependent only on flow, not on temperature.

If the ideal situation were obtained, then while the flow measurements would have no temperature dependence, the change in the distance from the origin to the flow line (an easily obtained quantity) would be dependent only on the temperature. Thus it could act as a high-speed, high accuracy temperature measuring device with little post-processing of the signal.

There were approximately 140 ECFMs available at HEDL which had been calibrated using $A D$. For each flowmeter a complete file of $V_{A C}$ and $\phi$ 


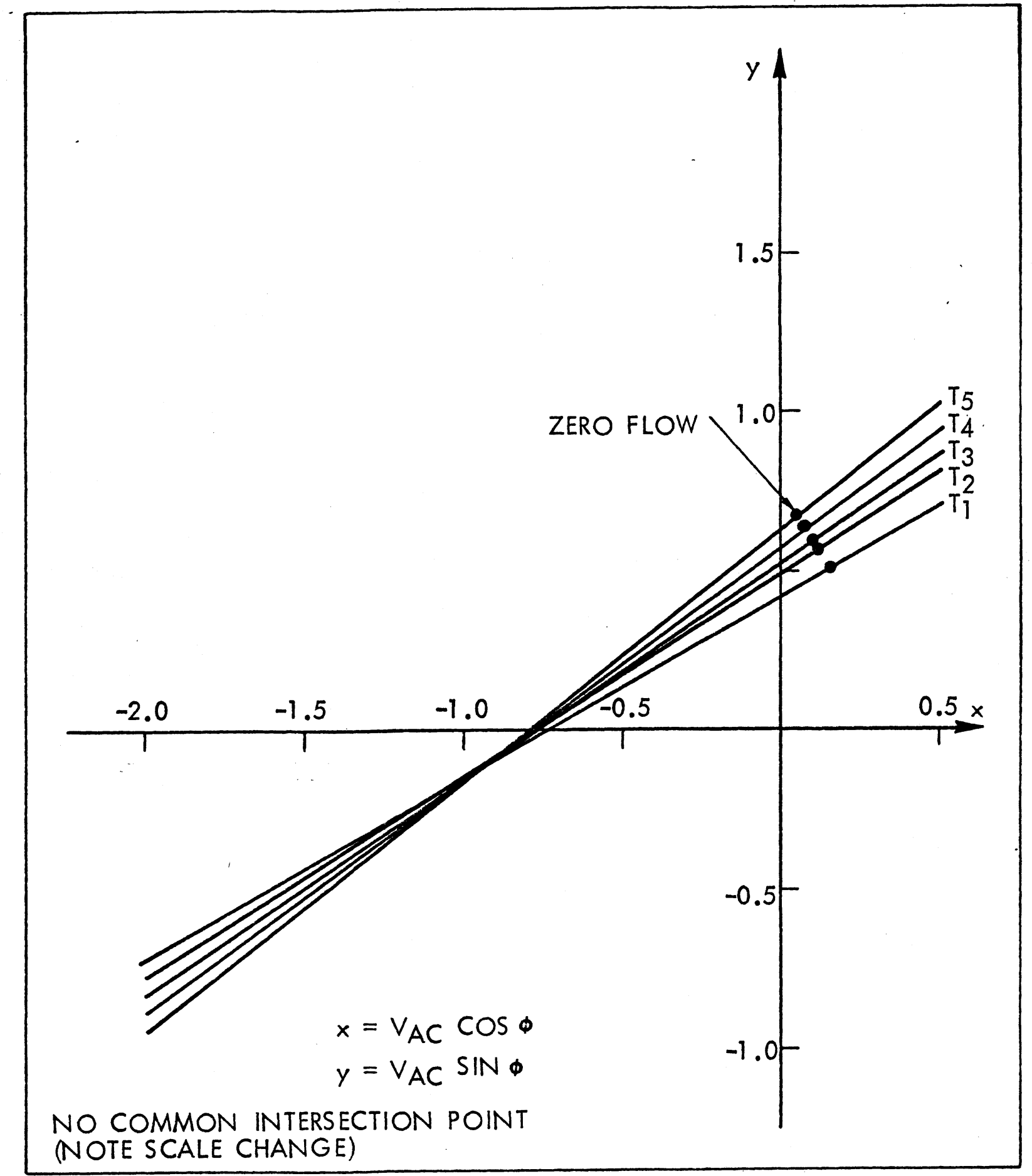

FIGURE 3-2b Realistic ECFM Amplitude - Phase Plot

HEDL 7902-043.4 


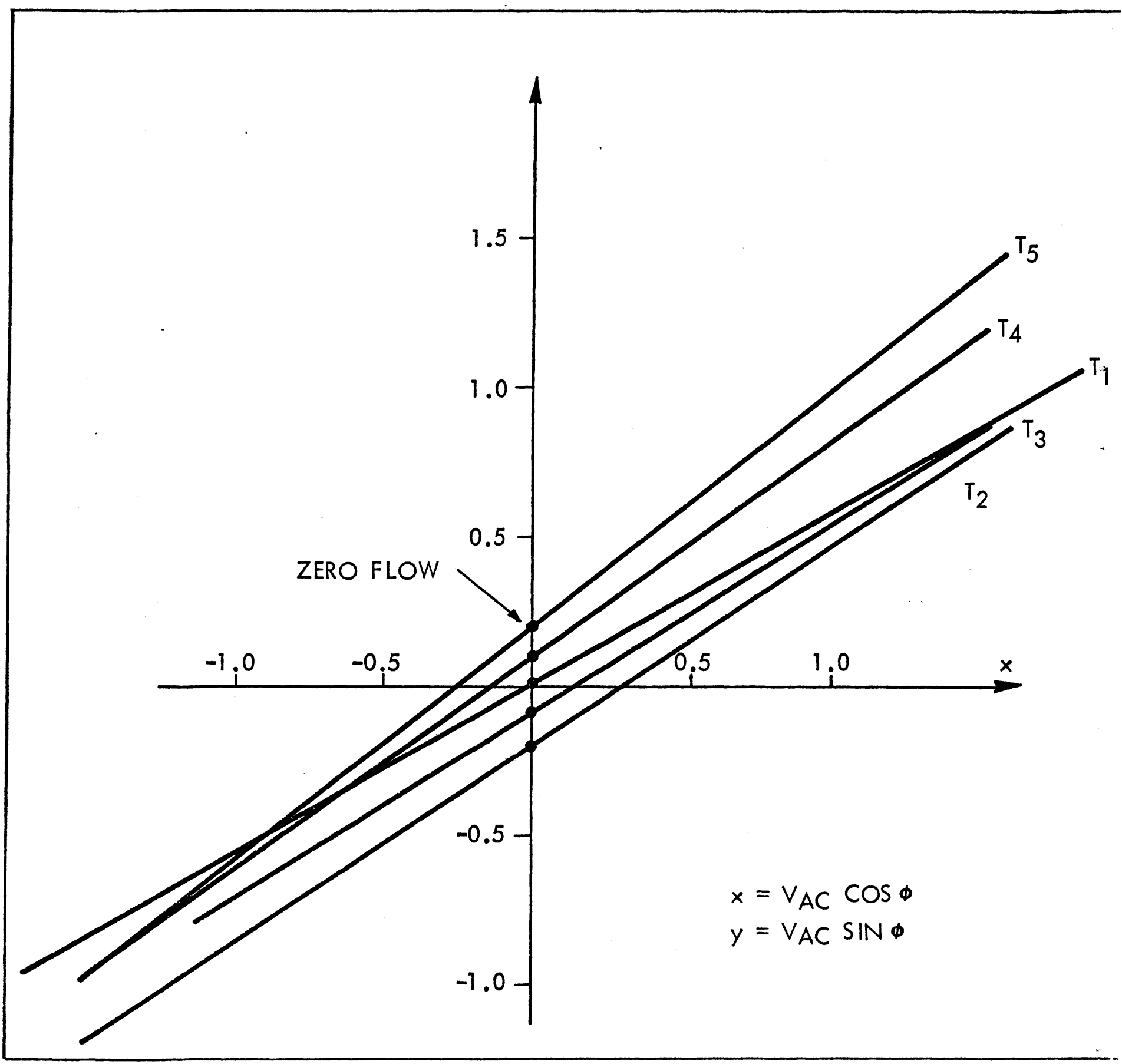

FIGURE 3-2c Realistic ECFM Amplitude - Phase Plot

HEDL 7902-043. 


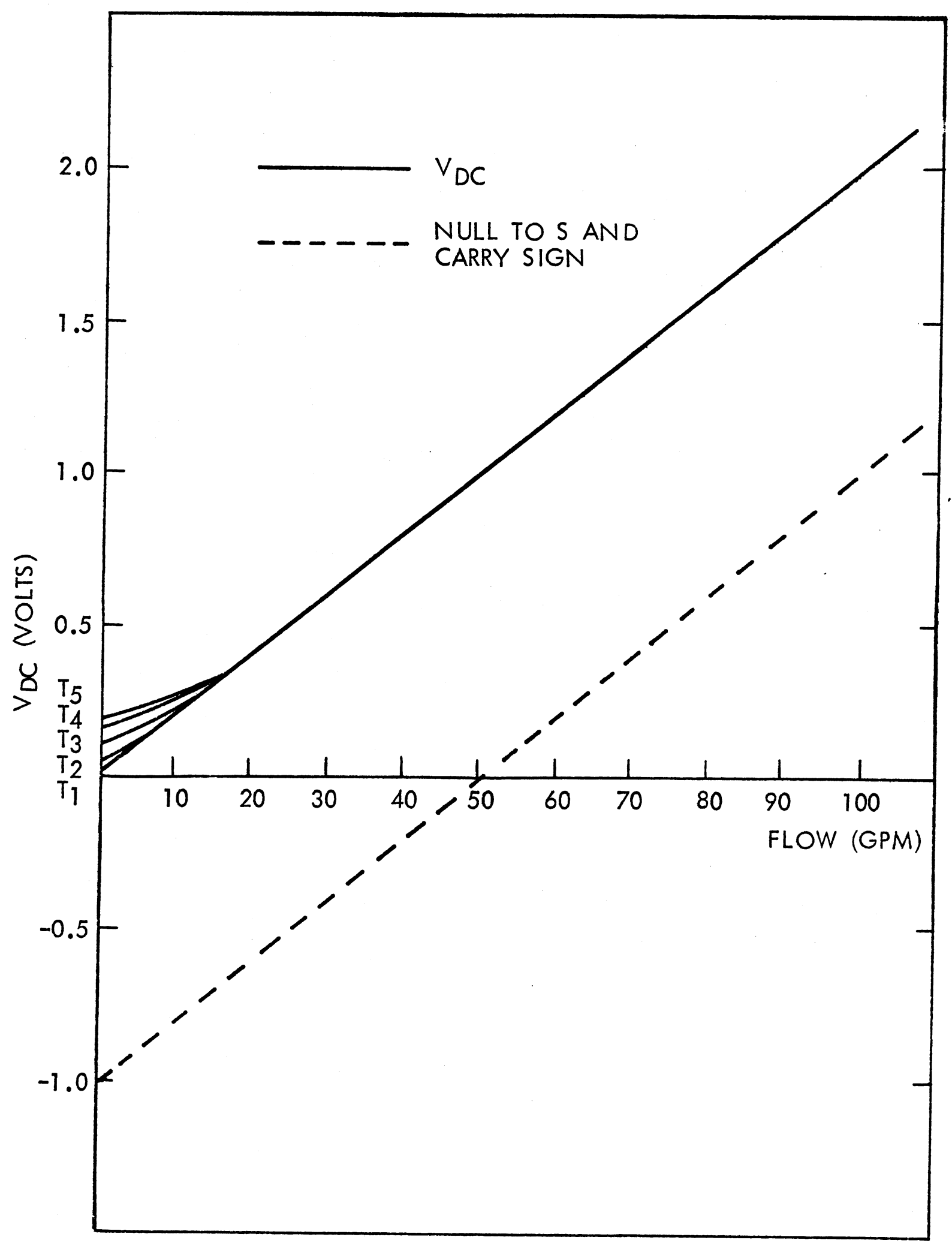

FIGURE 3-3a $V_{D C}$ Versus Flow for Amplitude Detection

HEDL 7902-043.6 


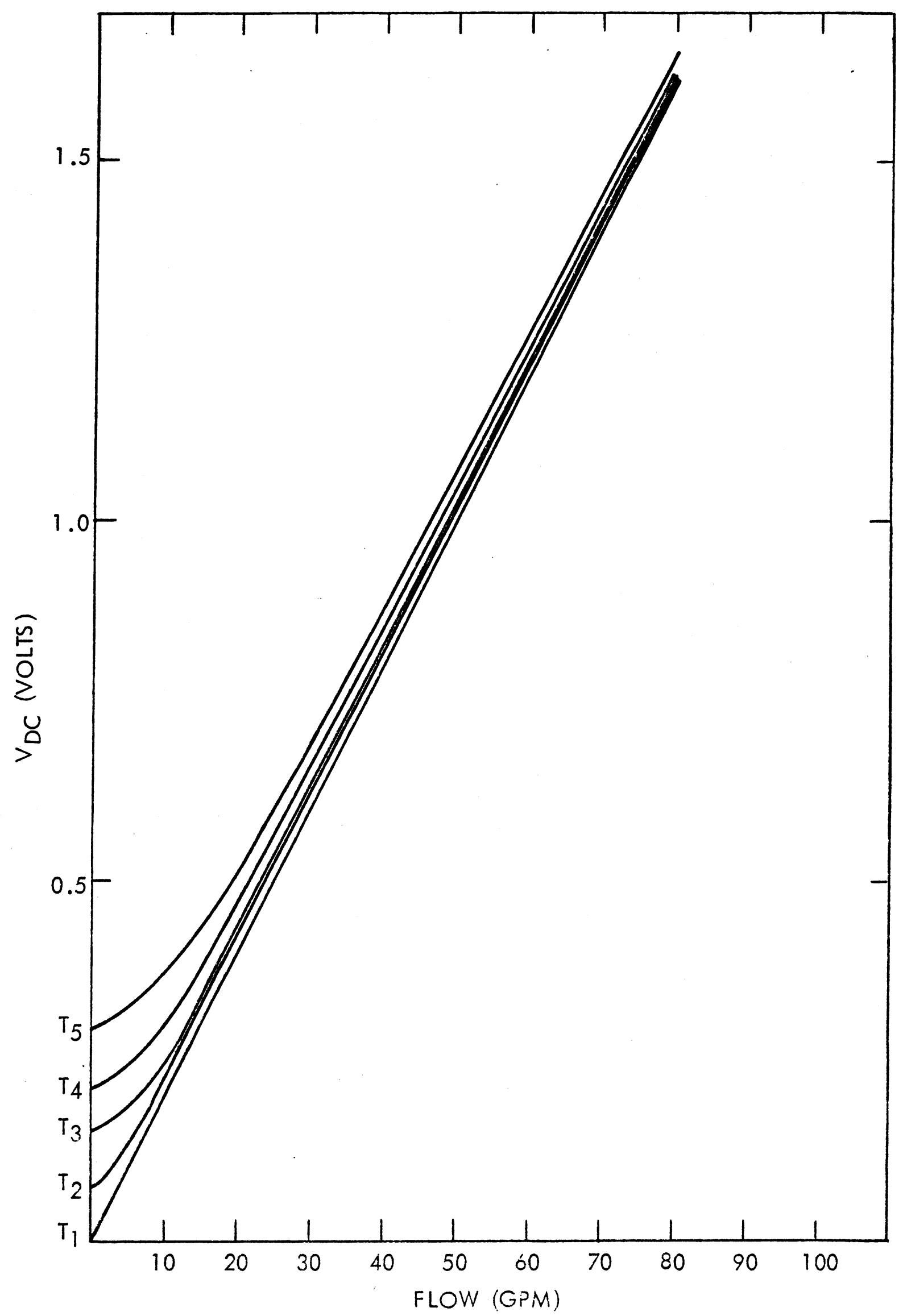

FIUGRE 3-3b $V_{D C}$ Versus Flow for Amplitude Detection

HEDL 7902-043.7 


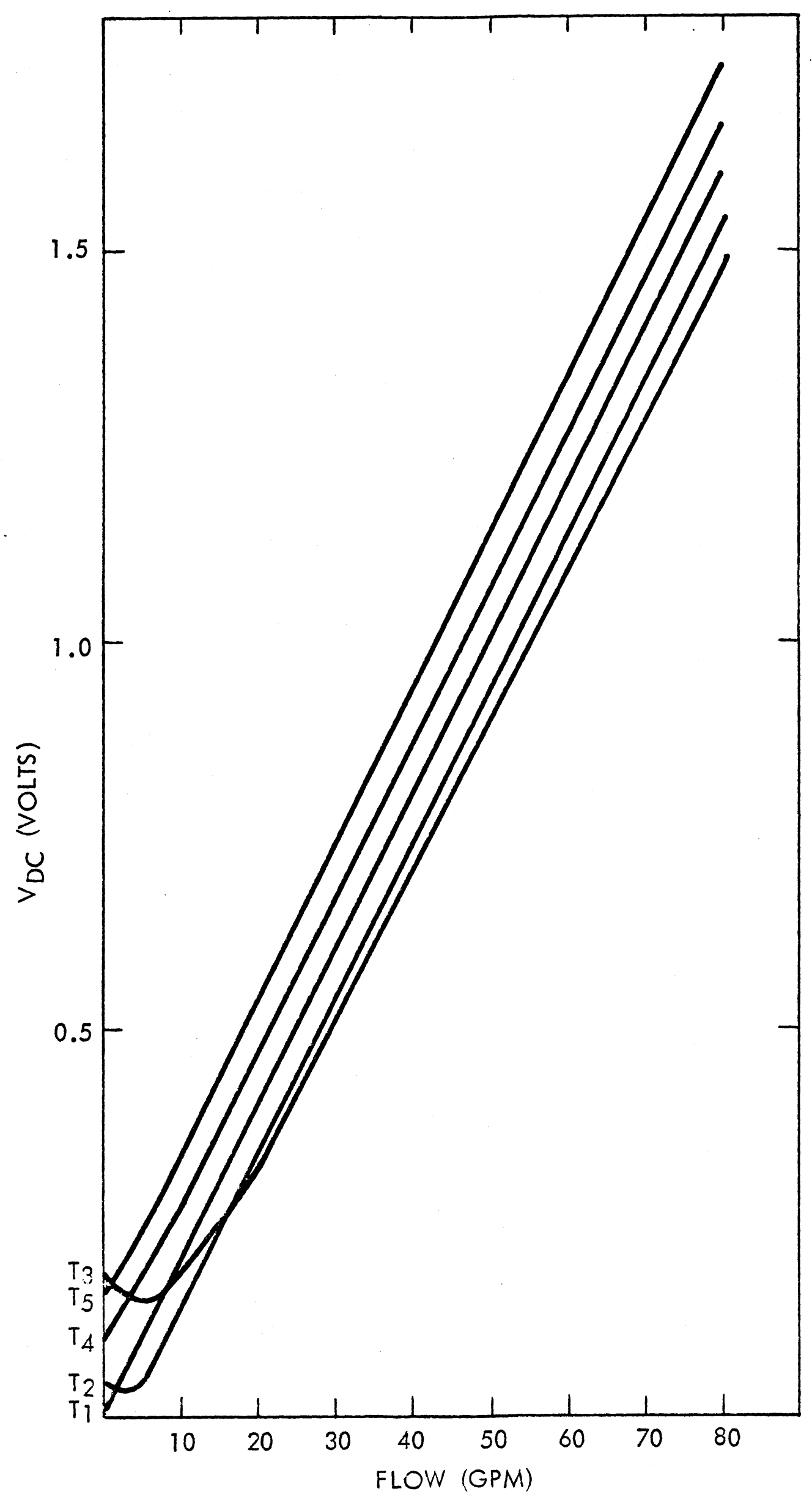

FIGURE 3-3C $V_{D C}$ Versus Flow for Amplitude Detection 
was available. Selection of ECFMs for use in low flow measurement was based on the criteria that the fixed low-flow line and the fixed temperature reference line be nearly orthogonal and that the data scatter be minimal.

In order to set up the perpendicular line using PSD, two flows (at a minimum) must be measured to find their in-phase (I) and quadrature ( $Q$ ) components at each flow. The I and $Q$ components are at $90^{\circ}$ to one another so that the amplitude $\left(V_{A C}\right)$ from the origin (as opposed to $V_{D C}$, the amplitude from the zero flow reference temperature point) is related to the two components by,

$$
V_{A C}=\left(I^{2}+Q^{2}\right)^{1 / 2}
$$

Any two flow measurements must give the same value for $Q$ if $Q$ is to represent the perpendicular distance from the origin to the flow line. Figure 3-4a shows this situation for two flows $W_{1}$ and $W_{2}$. Figure $3-4 b$ shows the case in which the two Q-components are not the same. They are measured along the same direction but they are of different length. The solution is to rotate the direction of measurement of the Q-component by an angle $(\theta)$ until the Q-components at both are equal. (See Figure 3-5.) The angle between the Q-component and the line along which $V_{A C}$ is measured is called $B$. Therefore, for $Q_{1}$ to be equal to $Q_{2}$,

$$
V_{A C} \operatorname{Cos}\left(\beta_{1}+\theta\right)=V_{A C} \cos \left(\beta_{2}+\theta\right) \text {. }
$$

The unknown voltages $V_{A C}$ and $V_{A C_{2}}$ are eliminated by the relationship,

$$
I_{n}=V_{A C} \sin \beta_{n} \text {. }
$$

Using the angle sum formula for cosines and Equation 3.3 gives,

$$
I_{1}\left(\cot \beta_{1} \cos \theta-\sin \theta\right)=I_{2}\left(\cot \beta_{2} \cos \theta-\sin \theta\right)
$$

or

$$
\theta=\tan ^{-1}\left(\frac{Q_{1}-Q_{2}}{I_{1}-I_{2}}\right) .
$$

From the two flows one can ascertain the proper Q-component, which is obtained by changing the measurement angle by an amount $\theta$. The new $Q$ is,

$$
Q=V_{A C} \cos \left(\beta_{1}+\theta\right)
$$




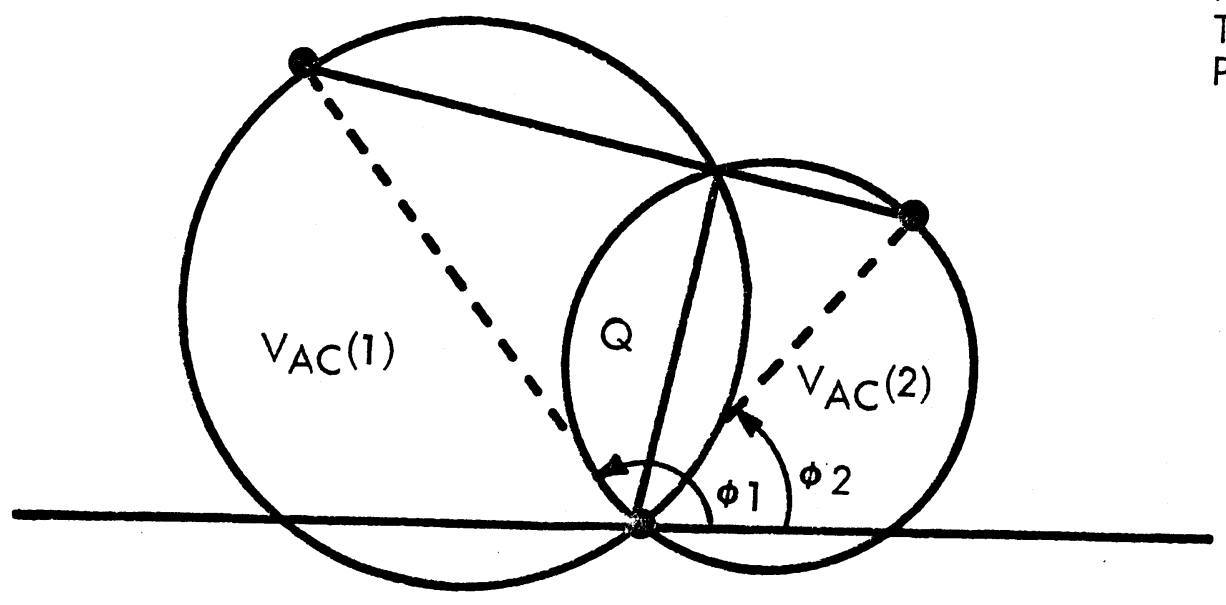
$\begin{array}{ll}\text { FIGURE 3-4a } & \text { Relationship of } V_{A C} \text { anid } Q \text { for } \\ & \text { Two Flow Readings } \\ & \text { Proper when } Q \text { has bee }\end{array}$ Properly Adjusted.

FIGURE 3-4b Variation of Q with Flow When

$Q$ has not been Properly Adjusted.

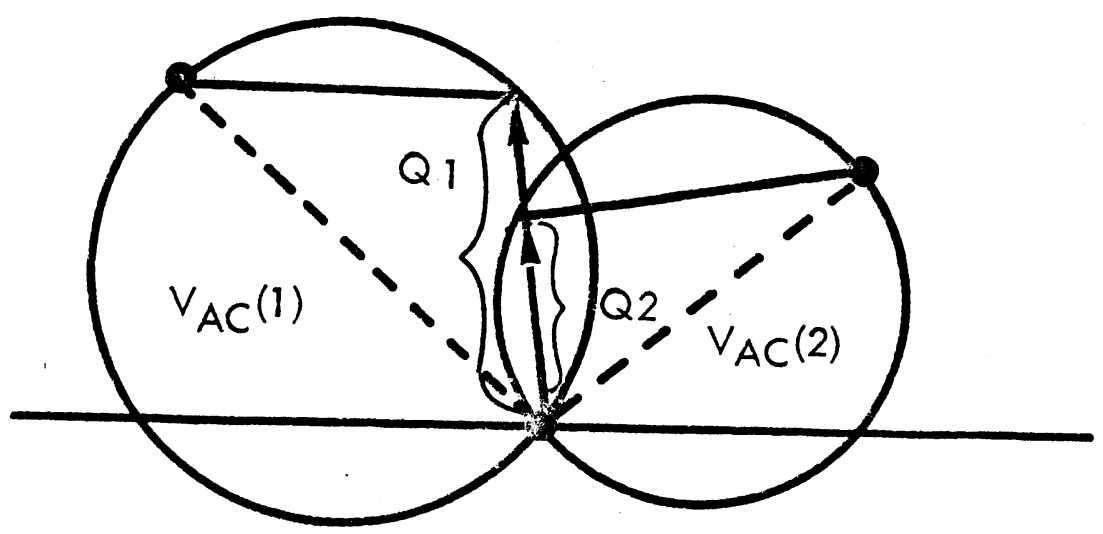

HEDL 7902-043.11 


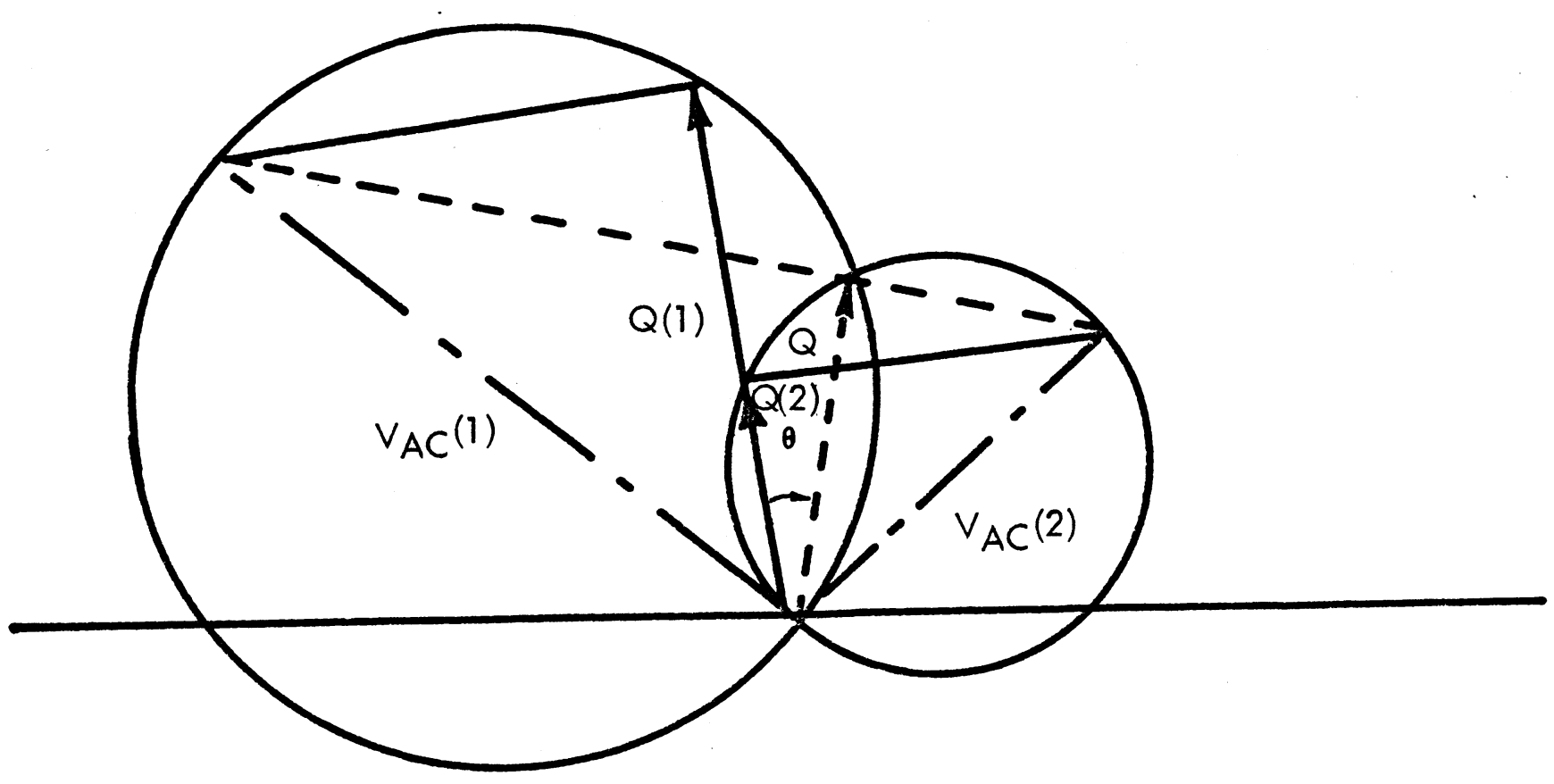

FIGURE 3-5 Rotation of the Direction of Measurement of Q by an Angle $\theta$ to Make Q Flow-Independent.

HEDL 7902-043.9 
which, making use of Equation 1.3, becomes

$$
Q=\sqrt{I_{1}^{2}+Q_{1}^{2}} \cos \left(\beta_{1}+\theta\right)
$$

In Figures 3-4 and 3-5 one flow point is on either side of the quadrature vector. A more common occurrence is to have both flow points on the same side of $Q$. The procedure for finding $Q$ is unchanged, however the readings obtained in this case will seem hard to interpret at first glance. A valuable tool for avoiding this confusion is the graphical method. This method gives an approximate value for $Q$ which can be used to verify the more precise algebraic solution outlined above.

Plot the flow point, given by the guadrature and in-phase components for each flow on a Q-I grid. Connect the two flow points with a straight line. A line from the origin, perpendicular to the flow line, is the correct Q. Figure 3-6 shows the graphical method.

Error arising from the fact that the flow lines do cross one another are sma11, because the correction is dependent on the sine of the crossing angle, which is small. Thus all of the realistic cases in Figures 3-2 can be treated with a high degree of accuracy using PSD.

\subsection{Error Sources}

In addition to the errors introduced by the lack of an ideal ECFM (which may be processed out) there are certain error sources which can give rise to errors that limit the ultimate accuracy of the flow measurement. There are three basic sources: (1) hardware-related biases, (2) electronicsbiases, and (3) noise, each of which will be discussed in the next three sections.

\subsubsection{Hardware Biases}

This category of biases includes the thimble related environment changes, the sodium channel changes, wire routing changes, etc. The net effect of these changes is to alter $V_{A C}$ and $\phi$ in such a fashion that a rotation and a shift of the flow/temperature grid on the $v-\phi$ plot occurs. The sensitivities $\left(\frac{\partial I}{\partial W}\right.$ and $\frac{\partial I}{\partial T}$ ) can be affected by these changes. When the ECFM is setup in the FFTF, only two flows are required and if one is known (i.e., zero flow), the shift and rotation of the flow/temperature grid can be processed out during the setup. The sensitivity changes, though small, will remain.

Provided with PNNL-26202 


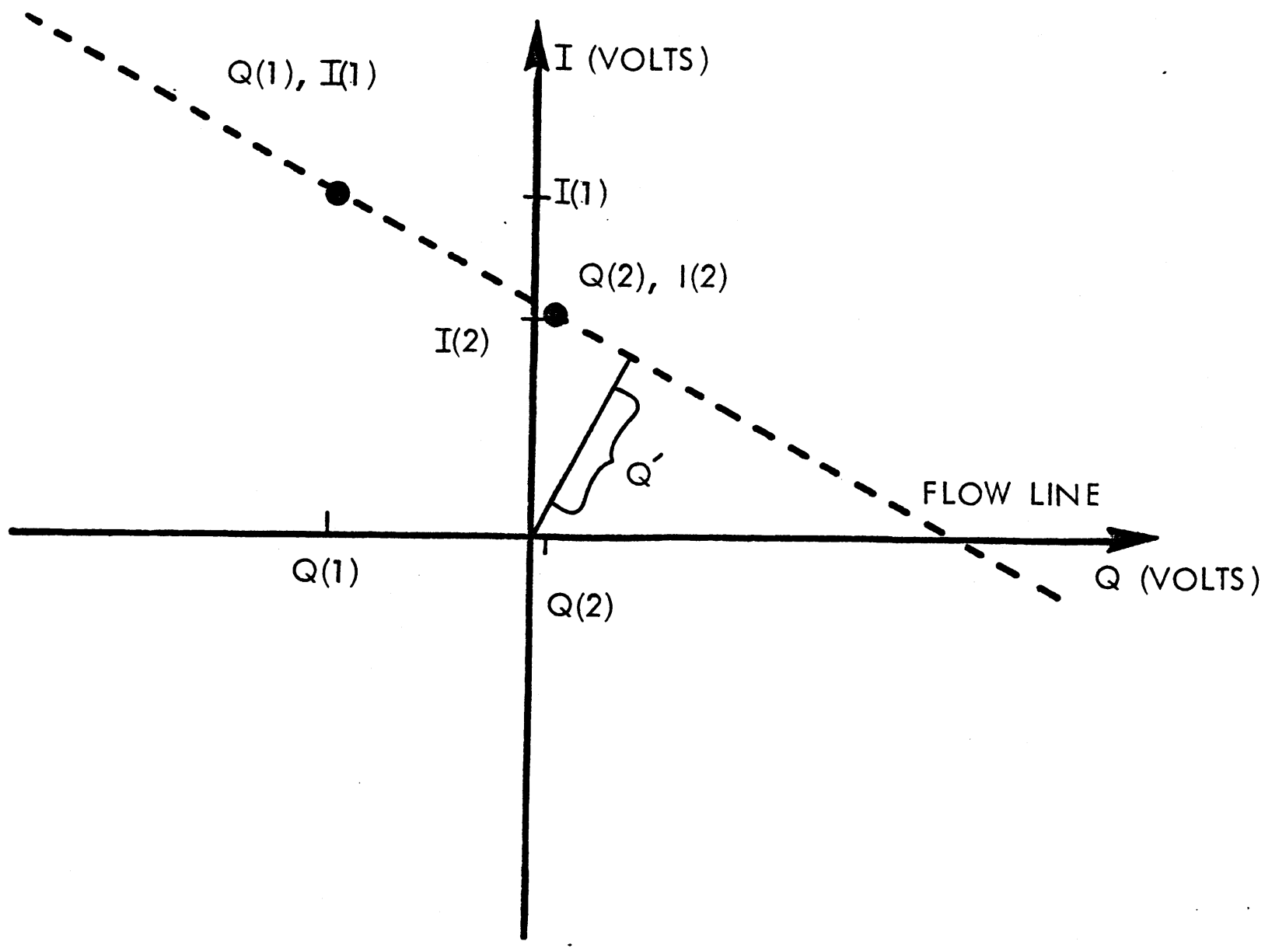

FIGURE 3-6 Graphical Method for Obtaining Q.

The length $Q^{\prime}$ is an estimate of the correct quadrature $Q$,

HEDL 7902-043.8 given two sets of measurements $[Q(1), I(1)]$ and $[Q(2), I(2)]$, at different flows. The new coordinate system is obtained by rotating the old system until the $Q$ value becomes $Q]$. The rotational angle will be determined better at flow \#1, because $\left|Q(1)-Q^{\prime}\right|>$ $\mid Q(2)$ - Q' $\mid$. After rotation, al1 Q-yalues will be constant. 


\subsubsection{Electronics Biases}

After the calibration program, variations in the electronics components were observed (see Table 5-1). In the calibration program a PAR Model 120 lock-in amplifier was used in conjunction with external attenuation and Signal Conditioning/Current Regulator Modules (SC/SR), the latter being calibrated to plant specifications. (See Reference 10.) The variations in the components are scaled by the input voltage column and renresent a small error on the order of 1/4 GPM at zero flow. In plant calibration includes compensation for these variation. In effect the sensitivities $\left(\frac{\partial I}{\partial W}\right.$ and $\left.\frac{\partial I}{\partial T}\right)$ are also perturbed, but again, only very slightly.

\subsubsection{Noise}

The TTL facility and the recording apparatus constitute a generator of random signals of a variety of frequencies and amplitudes. An analys is of the noise on the measured data is probably the best estimate of this error.(see next section). It will be present in the FFTF as well as the TTL.

\subsection{Calibration Results}

This section presents a summary of the results of processing the ECFM calibration runs at the TTL using the PSD. The discussion addresses the biases which arose in repeat runs when the test thimble and the electronics were changed, the noise level on the data and the flow/temperature calibration curves for each ECFM. For S/N 172, which is in the Row 2 FOTA and has both $I$ and $Q$ output, both the temperature and flow calibrations are reported.

The ECFM response obtained in the TTL may differ from the ECFM response in the FFTF. The effect on the calibration curve can be expressed in terms of the changes which can occur in the $v-\phi$ plot. Three separate changes to the calibration grid can occur: (1) it can be rotated around the origin in the $v-\phi$ plot, (2) it can be scaled and (3) it can be translated with respect to the origin.

The rotation is easily adjusted out Juring the setup of the quadrature. The scaling has not occurred during test station changes at TTL and is not expected to enter in any significant way. 
The translation with respect to the origin has occurred during testing at the TTL. When the quadrature vector is adjusted, there is a residual difference between the length of the in-phase vector at zero flow in the two cases. Such differences will almost certainly occur when the ECFMs are calibrated in the FFTF. Two solutions present themselves: (1) select zero flow for one of the two flows used in the setup and establish procedures for obtaining zero flow, or (2) use a Kalman filter to process out the bias in the flow data after-the-fact.

\subsubsection{Calibration Curves}

The summary of the flow calibration curves for the ECFMs calibrated at the TTL are presented in Tables3.1 to 3.15. These curves are functions of both temperature and flow. While the voltage biases for each run are included, the absolute bias is a function of many variables and will be redetermined in the plant. The temperature sensitivity of the bias is also a function of the environment.

The calibration curves are straight lines and satisfy;

$$
\text { Flow }=\left(V_{D C}-\text { Bias }\right) / \text { Slope }
$$

where $V_{D C}$ is the in-phase component I,

$$
\text { Slope }=S 1+S 2: T \text {, }
$$

and

$$
\text { Bias }=B 1+B 2 \cdot T
$$

The values of S1, S2, B1 and B2 are included in Tables 3.1 to 3.15. Several tables show different signs for $\mathrm{S1}$ fordifferent runs. This is a result of the relative phase setting on the lock-in amplifier and as a matter of convention all of these parameters are multiplied by the sign of S1. Table 3.16 is a summary of parameters. Note that all of the parameters listed in Table 3.16 are scaled by a factor of 10 . This difference is due to a change in amplifier gain between the TTL and the FFTF. As described in the next paragraph, several runs were discounted because of obvious data acquisition errors. 
Table 3.1

- S/N 052 Parameters

$\begin{array}{lclll}\text { Run \#1 } & \mathrm{T}^{\circ} \mathrm{F} & \text { Bias }(\mathrm{V}) & \text { Slope }(\mathrm{V} / \mathrm{GPM}) & \text { RMS (GPM) } \\ 400.0 & .404926 & .030161 & .504612 \\ 500.0 & .348626 & .030347 & .512748 \\ 600.0 & .294221 & .030197 & .579480 \\ 700.0 & .242743 & .029889 & .510724 \\ 800.0 & .258666 & .030155 & .322982 \\ 900.0 & .187046 & .029754 & .602076 \\ 1000.0 & .094759 & .028569 & .368891 \\ 1100.0 & -.009830 & .027804 & .379466 \\ \mathrm{~B} 1= & & & \\ \mathrm{B} 2= & .627486 & \mathrm{~S} 1=.031972 & \end{array}$

$\begin{array}{lclll}\text { Run \#2 } & T^{\circ} \mathrm{F} & \text { Bias }(\mathrm{V}) & \text { Slope }(\mathrm{V} / \mathrm{GPM}) & \text { RMS (GPM) } \\ & 400.0 & .726265 & .030086 & .161921 \\ 600.0 & .649766 & .030529 & .223428 \\ 700.0 & .610819 & .030238 & .167526 \\ 800.0 & .563427 & .030038 & .197729 \\ 900.0 & .535142 & .029281 & .174214 \\ 1000.0 & .486676 & .029423 & .139064 \\ 1100.0 & .462778 & .028033 & .216970 \\ \mathrm{B1} & .878950 & & & \\ \mathrm{~B} 2=-.0003850504 & \mathrm{~S} 1=.031860 & \end{array}$


Table 3.2

- S/N 064 Parameters

\begin{tabular}{|c|c|c|c|}
\hline$T^{\circ} \mathrm{F}$ & Bias (V) & Slope (V/GPM) & RMS (GPM) \\
\hline 400.0 & -2.568879 & .032198 & .229671 \\
\hline 600.0 & -2.772457 & .032167 & .218910 \\
\hline 700.0 & -2.866239 & .032581 & .198361 \\
\hline 800.0 & -2.940135 & .032583 & 209953 \\
\hline 900.0 & -2.977041 & .031044 & .436393 \\
\hline 1000.0 & -3.013686 & .030752 & .262611 \\
\hline 1100.0 & -3.035866 & .029937 & .495312 \\
\hline
\end{tabular}
$B 1=-2.361937$
$S 1=.034255$
$B 2=-.0006619543$.
$S 2=-.0000033672$ 
Table 3.3

\section{S/N 078 Parameters}

$\begin{array}{lllll}\text { Run \#1 } & \mathrm{T}^{\circ} \mathrm{F} & \text { Bias }(\mathrm{V}) & \text { Slope }(\mathrm{V} / \mathrm{GPM}) & \text { RMS (GPM) } \\ 400.0 & 2.188090 & -.031698 & -.218712 \\ 600.0 & 2.241499 & -.032069 & -.192551 \\ 700.0 & 2.184301 & -.031365 & -.260619 \\ 800.0 & 2.126020 & -.031545 & -.232035 \\ 900.0 & 2.152527 & -.030803 & -.357274 \\ 1000.0 & 2.332331 & -.030313 & -.848971 \\ 1100.0 & 2.480885 & -.029544 & -.342618 \\ & & & \\ \text { B1 }=1.999355 & \mathrm{~S} 1=-.033570 & \\ \mathrm{~B} 2=.0003109407 . & \mathrm{S} 2=.0000032093 & \end{array}$

$\begin{array}{cclll}\text { Run \#2 } & \mathrm{T}^{\circ} \mathrm{F} & \mathrm{Bias}(\mathrm{V}) & \text { Slope }(\mathrm{V} / \mathrm{GPM}) & \text { RMS (GPM) } \\ 400.0 & 2.146267 & -.031146 & -.106323 \\ 600.0 & 2.245697 & -.031372 & -.162133 \\ 700.0 & 2.273608 & -.031151 & -.163994 \\ 800.0 & 2.283862 & -.031305 & -.102806 \\ 900.0 & 2.261030 & -.029935 & -.327723 \\ 1000.0 & 2.229798 & -.029733 & -.209881 \\ 1100.0 & 2.179137 & -.028967 & -.378781 \\ & & & \\ \mathrm{B1}=2.199941 & \mathrm{~S} 1=-.033144 & \\ \mathrm{~B} 2=.0000399663 & \mathrm{~S} 2=.0000033454 & \end{array}$


Table 3.4

- S/N 081 Parameters

\begin{tabular}{|c|c|c|c|c|}
\hline \multirow{10}{*}{ Run \#1: } & $\mathrm{T}^{\circ} \mathrm{F}$ & Bias (V) & Slope (V/GPM) & RMS (GPM) \\
\hline & 400.0 & .410214 & .032570 & .222756 \\
\hline & 600.0 & .398231 & .033076 & .255634 \\
\hline & 700.0 & .396138 & .032933 & .236419 \\
\hline & 800.0 & .393234 & .032531 & .285982 \\
\hline & 900.0 & .381666 & .032131 & .152998 \\
\hline & 1000.0 & .395459 & .030983 & .245714 \\
\hline & 1100.0 & .392174 & .030308 & .302498 \\
\hline & \multicolumn{2}{|c|}{$B 1=.415375$} & \multicolumn{2}{|l|}{$S 1=.034841$} \\
\hline & \multicolumn{2}{|c|}{$B 2=-.0000255475$} & \multicolumn{2}{|l|}{$S 2=-.0000035194$} \\
\hline \multirow[t]{10}{*}{ Run \#2 } & $\mathrm{T}^{\circ} \mathrm{F}$ & Bias* (V) & STope * (V/GPM) & RMS * (GPM) \\
\hline & 400.0 & .103007 & .018785 & .202367 \\
\hline & 600.0 & .083521 & .018436 & .401982 \\
\hline & 700.0 & .036582 & .018577 & .541246 \\
\hline & 800.0 & -.034214 & .018064 & .149819 \\
\hline & 900.0 & -.029699 & .017627 & .744082 \\
\hline & 1000.0 & .120951 & .017115 & 1.185363 \\
\hline & 1100.0 & .177189 & .016776 & 1.053693 \\
\hline & \multicolumn{2}{|c|}{$B 1=.021728$} & \multicolumn{2}{|l|}{$S 1=.020277$} \\
\hline & \multicolumn{2}{|c|}{$B 2=.0000554978$} & \multicolumn{2}{|l|}{$S 2=-.0000030103$} \\
\hline
\end{tabular}

*An extra $5 k_{s}$ resistor in the circuit introduced a factor of 0.6 in this run. 
Table 3.5

i S/N 098 Parameters

$\begin{array}{lclll}\text { Run \#1 } & T^{\circ} \mathrm{F} & \text { Bias }(\mathrm{V}) & \text { Slope }(\mathrm{V} / \mathrm{GPM}) & \text { RMS (GPM) } \\ & 400.0 & -1.311786 & .028660 & \\ 500.0 & -1.366640 & .028993 & 1.053677 \\ 600.0 & -1.400477 & .028789 & 1.226408 \\ 700.0 & -1.426069 & .029917 & 1.204226 \\ 800.0 & -1.413824 & .028758 & 3.007165 \\ 900.0 & -1.428041 & .028385 & .370252 \\ 1000.0 & -1.439349 & .027707 & .414818 \\ 1100.0 & -1.491043 & .027271 & .218730 \\ & & & .319585 \\ \text { B1 }=-1.258869 & \mathrm{~S} 1=.030214 & \\ \text { B2 }=-.0002010465 & \mathrm{~S} 2=-.0000022048 & \end{array}$

Run \#2

$\begin{array}{cll}T^{\circ} \mathrm{F} & \text { Bias* }(\mathrm{V}) & \text { Slope }^{*}(\mathrm{~V} / \mathrm{GPM}) \\ 400.0 & 1.066116 & -.018344 \\ 600.0 & 1.147484 & -.018264 \\ 700.0 & 1.177093 & -.019053 \\ 800.0 & 1.182087 & -.018385 \\ 900.0 & 1.200562 & -.018347 \\ 1000.0 & 1.222890 & -.017859 \\ 1100.0 & 1.257483 & -.017709 \\ & & \\ B 1=.984941 & & S 1=-.019065 \\ B 2=.0022471134 & S 2=.0000009996\end{array}$

${ }^{*}$ An extra $5 K_{\Omega}$ resistor in the circuit introduced a factor of 0.6 in this run. 
Table 3.6

- S/N 109 Parameters

$\begin{array}{ccll}T^{\circ} \mathrm{F} & \text { Bias }(\mathrm{V}) & \text { Slope }(\mathrm{V} / \mathrm{GPM}) & \text { RMS (GPM) } \\ 400.0 & .064128 & .031058 & .185080 \\ 600.0 & .082627 & .030825 & .156914 \\ 700.0 & .079259 & .030689 & .233051 \\ 800.0 & .086858 & .030424 & .318283 \\ 900.0 & .106634 & .030055 & .508100 \\ 1000.0 & .166253 & .029039 & .292469 \\ 1100.0 & .188966 & .028874 & .347757 \\ & & & \\ B 1=-.028108 & S 1=.032769 \\ \text { B2 }=.0001766325 & S 2=-.0000033496\end{array}$


Table 3.7

1. S/N 110 Parameters

$\begin{array}{cccll}\text { Run \#1 } & T^{\circ} \mathrm{F} & \text { Bias }(\mathrm{V}) & \text { Slope (V/GPM) } & \text { RMS (GPM) } \\ 400.0 & -.715633 & .030730 & .482525 \\ 600.0 & -.814390 & .032592 & .354225 \\ 700.0 & -.843053 & .032730 & .521336 \\ 800.0 & -.878454 & .032705 & .799776 \\ 900.0 & -.942039 & .032877 & .684958 \\ 1000.0 & -1.048316 & .033717 & .651696 \\ 1100.0 & -1.190856 & .034785 & .674861 \\ & & & \\ \text { B1 }=-.424000 & \mathrm{~S} 1=.029110 & \\ \mathrm{~B} 2=-.0006299533 & \mathrm{~S} 2=.0000047936 & \end{array}$

\begin{tabular}{|c|c|c|c|c|}
\hline \multirow[t]{10}{*}{ Run \#2 } & $T^{\circ} \mathrm{F}$ & Bias (V) & Slope (V/GPM) & RMS (GPM) \\
\hline & 400.0 & -.517290 & .031326 & .106633 \\
\hline & 600.0 & -.433507 & .031325 & .173329 \\
\hline & 700.0 & -.383485 & .030671 & .216978 \\
\hline & 800.0 & -.348473 & .030742 & .233291 \\
\hline & 900.0 & -.305033 & .030165 & .175701 \\
\hline & 1000.0 & -.268285 & .029655 & .231682 \\
\hline & 1100.0 & -.193402 & .028739 & .190746 \\
\hline & \multicolumn{2}{|c|}{$B 1=-.698843$} & \multicolumn{2}{|l|}{$S 1=.033206$} \\
\hline & \multicolumn{2}{|c|}{$B 2=.0004440772$} & \multicolumn{2}{|l|}{$S 2=-.0000036031$} \\
\hline
\end{tabular}


Table 3.8

S/N 128 Parameters

\begin{tabular}{|c|c|c|c|c|}
\hline \multirow[t]{10}{*}{ Run \#1 } & $\mathrm{T}^{\circ} \mathrm{F}$ & $\operatorname{Bias}(V)$ & Slope (V/GPM) & RMS (GPM) \\
\hline & 400.0 & .747313 & .028916 & .149029 \\
\hline & 600.0 & .839853 & .029053 & .176245 \\
\hline & 700.0 & .892686 & .028328 & .213210 \\
\hline & 800.0 & .920184 & .028088 & .248617 \\
\hline & 900.0 & .956047 & .027646 & .285951 \\
\hline & 1000.0 & .989685 & .027294 & .155110 \\
\hline & 1100.0 & 1.046236 & .026563 & .276405 \\
\hline & \multicolumn{2}{|c|}{$B 1=.591794$} & \multicolumn{2}{|l|}{$S 1=.030732$} \\
\hline & \multicolumn{2}{|c|}{$B 2=.0004089895$} & \multicolumn{2}{|l|}{$S 2=-.0000034972$} \\
\hline
\end{tabular}

Run \#2

$\begin{array}{cll}T^{\circ} \mathrm{F} & \text { Bias }(\mathrm{V}) & \text { S1ope }(\mathrm{V} / \mathrm{GPM}) \\ 400.0 & .516283 & .030220 \\ 600.0 & .599973 & .030503 \\ 700.0 & .654381 & .030121 \\ 800.0 & .691739 & .029823 \\ 900.0 & .725340 & .029425 \\ 1000.0 & .746044 & .029018 \\ 1100.0 & .789418 & .028160 \\ \mathrm{B1}=.372474 & & \\ \mathrm{~B} 2=.0003847023 & \mathrm{~S} 1=.031967\end{array}$

RMS (GPM)

.152294

.248662

.333847

.210730

.171227

.229188

.222994

$\mathrm{B} 2=.0003847023 \quad \mathrm{~S} 2=-.0000029992$ 
Table 3.9

1 S/N 156 Parameters

$\begin{array}{lclll}\text { Run \#1 } & \text { ToF } & \text { Bias }(V) & \text { Slope (V/GPM) } & \text { RMS (GPM) } \\ & 400.0 & -1.013324 & .029825 & .202318 \\ 600.0 & -1.009467 & .029705 & .292939 \\ 700.0 & -.998643 & .029732 & .255655 \\ 800.0 & -.986815 & .029762 & .187907 \\ 900.0 & -.955683 & .029250 & .236706 \\ 1000.0 & -.934050 & .029047 & .294872 \\ 1100.0 & -.912731 & .027993 & .292973 \\ & & & \\ \text { B1 }=-1.093765 & S 1=.031086 & \\ \text { B2 }=.0001537525 & S 2=0.0000022345 & \end{array}$

\begin{tabular}{|c|c|c|c|c|}
\hline Run \#2 & $T^{\circ} \mathrm{F}$ & Bias (V) & Slope (V/GPM) & RMS (GPM) \\
\hline & 400.0 & -.826294 & .028951 & .189323 \\
\hline & 600.0 & -.798583 & .029287 & .188993 \\
\hline & 700.0 & -.766750 & .029135 & .203400 \\
\hline & 800.0 & -.733726 & .028763 & .252994 \\
\hline & 900.0 & -.693084 & .028374 & .191550 \\
\hline & 1000.0 & -.645439 & .027620 & .184455 \\
\hline & 1100.0 & -.609235 & .027029 & .181090 \\
\hline & $B 1=-$. & & $S 1=.030786$ & \\
\hline & $\mathrm{B} 2=$. & 49526 & $S 2=-.0000029$ & \\
\hline
\end{tabular}


Table 3.10

- S/N 158 Parameters

\begin{tabular}{|c|c|c|c|c|}
\hline \multirow[t]{8}{*}{ Run \#1 } & $\mathrm{T}^{\circ} \mathrm{F}$ & $\operatorname{Bias}(V)$ & Slope (V/GPM) & RMS (GPM) \\
\hline & 400.0 & -.334092 & .030159 & .178307 \\
\hline & 600.0 & -.323246 & .030187 & .172948 \\
\hline & 700.0 & -.312447 & .029578 & .248640 \\
\hline & 800.0 & -.304404 & .029603 & .222979 \\
\hline & 900.0 & -.286557 & .029105 & .422616 \\
\hline & 1000.0 & -.283594 & .028865 & .626448 \\
\hline & 1100.0 & -.268628 & .027740 & .670678 \\
\hline & \multicolumn{2}{|c|}{$\mathrm{B} 1=-.377100$} & \multicolumn{2}{|l|}{$S 1=.031847$} \\
\hline & \multicolumn{2}{|c|}{$B 2=.0000957699}$. & \multicolumn{2}{|c|}{$S 2=-.0000032175$} \\
\hline
\end{tabular}

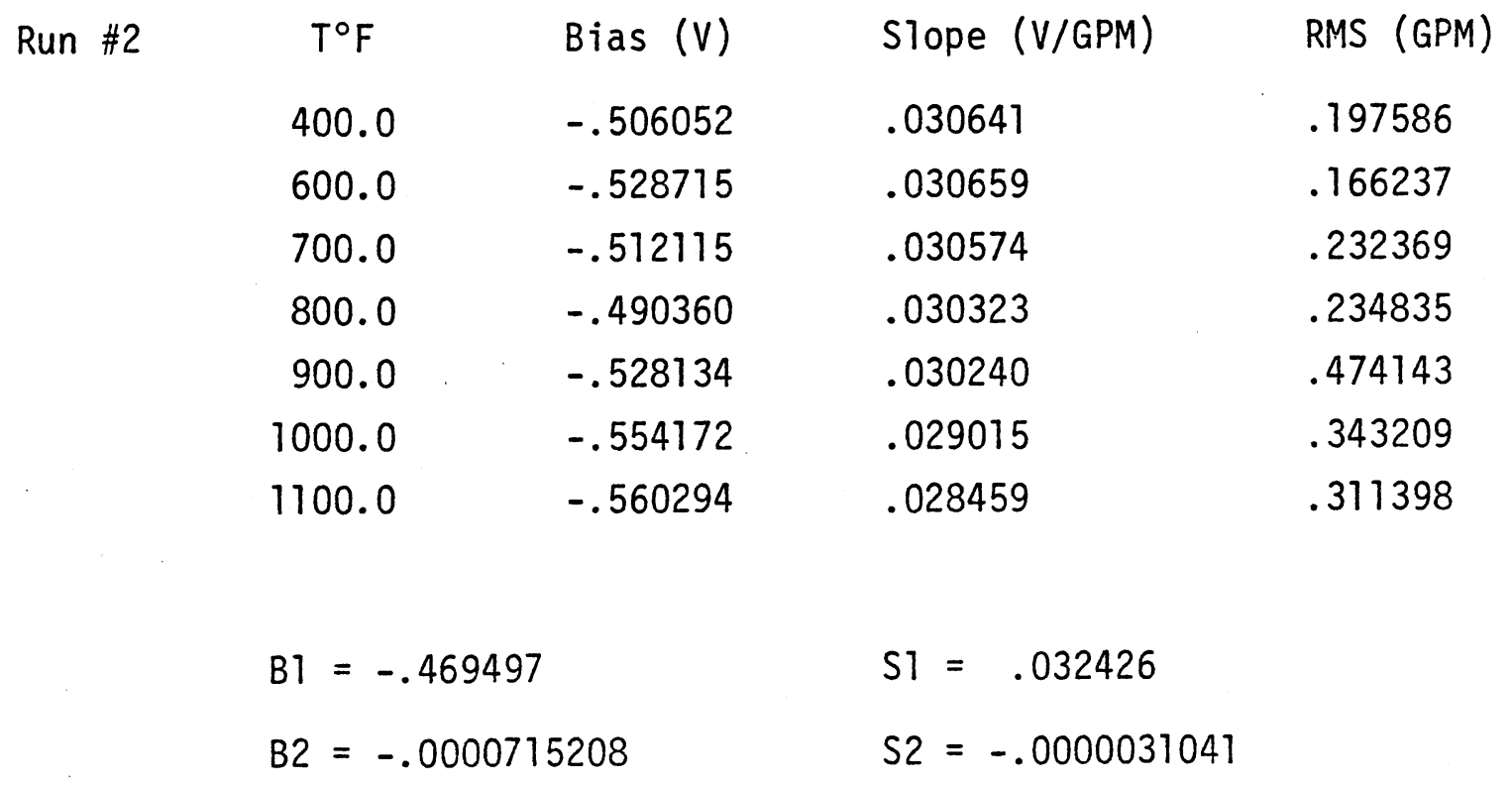


Table 3.11

- S/N 164 Parameters

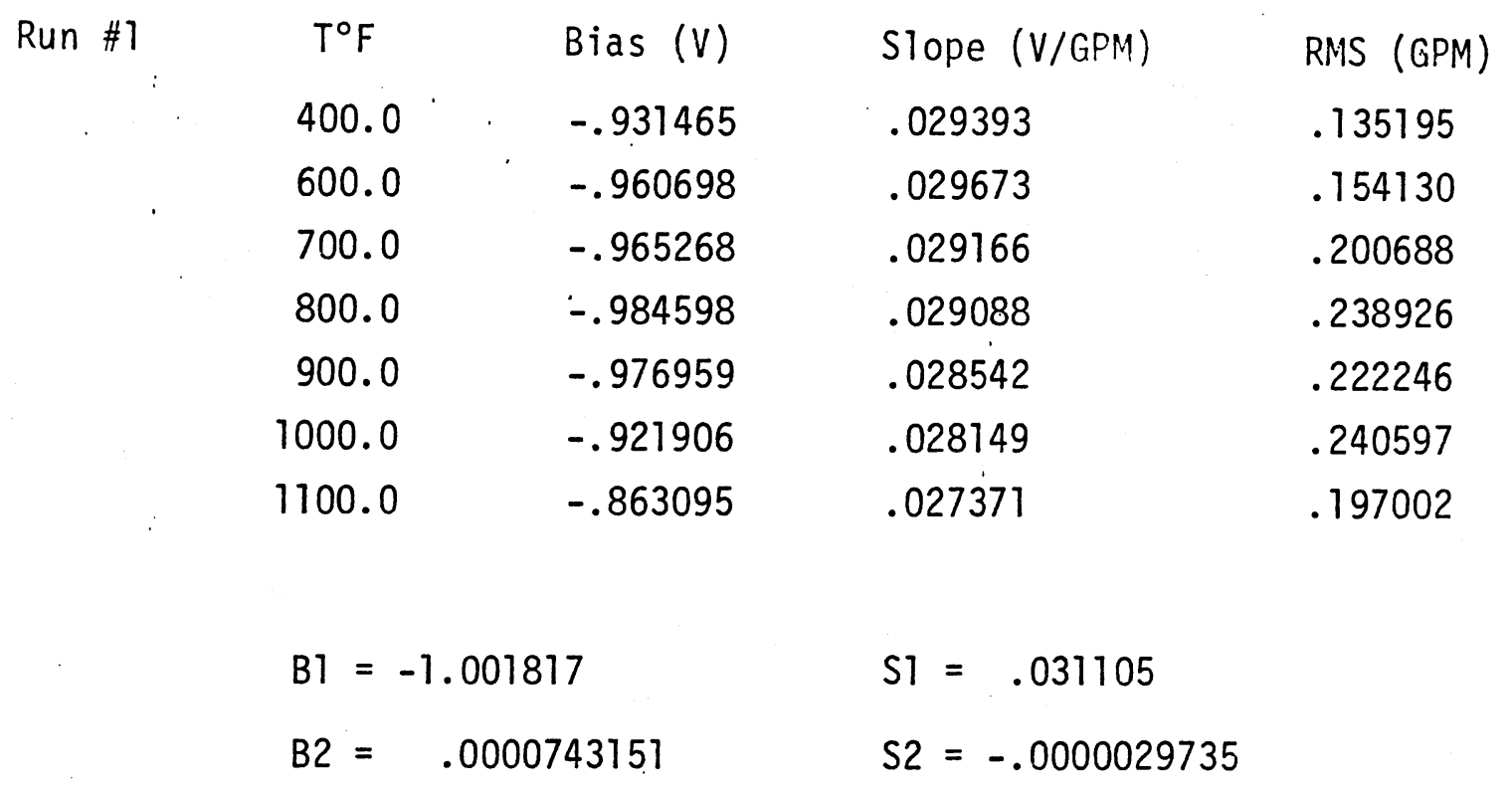

Run \#2

$\begin{array}{clll}T^{\circ} \mathrm{F} & \text { Bias }(\mathrm{V}) & \text { S1ope (V/GPM) } & \text { RMS (GPM) } \\ 400.0 & -1.238576 & .030790 & .185950 \\ 600.0 & -1.264099 & .031049 & .175565 \\ 700.0 & -1.261235 & .030462 & .333368 \\ 800.0 & -1.266589 & .030475 & .332485 \\ 900.0 & -1.269469 & .030400 & .508013 \\ 1000.0 & -1.253502 & .029670 & .269943 \\ 1100.0 & -1.231074 & .028796 & .312279 \\ B 1=-1.259242 & & \\ B 2=.0000054818 & S 1=.032343 & \end{array}$


Table 3.12

- S/N 172 Parameters

$\begin{array}{lllll}\text { Run \#1 } & T^{\circ} \mathrm{F} & \text { Bias }(\mathrm{V}) & \text { Slope }(\mathrm{V} / \mathrm{GFM}) & \text { RMS (GPM) } \\ 400.0 & 1.165144 & .023597 & .196426 \\ 600.0 & 1.172185 & .023638 & .165362 \\ 700.0 & 1.151381 & .025190 & .154781 \\ 800.0 & 1.132190 & .023827 & .101073 \\ 900.0 & 1.098150 & .023856 & .128713 \\ 1000.0 & 1.068585 & .023542 & .108390 \\ 1100.0 & 1.035932 & .022705 & .155161 \\ : \quad & \mathrm{S} 1=.024674 & \\ \text { B1 }=1.274438 & \mathrm{~S} 2=-.0000011578 & \\ \text { B2 }=-.0001995452 & \end{array}$

Run \#2

$\begin{array}{ccl}T^{\circ} \mathrm{F} & \text { Bias }(\mathrm{V}) & \text { Slope }(\mathrm{V} / \mathrm{GPM}) \\ 400.0 & 1.220693 & .032743 \\ 600.0 & 1.234435 & .034537 \\ 700.0 & 1.239034 & .033577 \\ 800.0 & 1.236476 & .032913 \\ 900.0 & 1.226639 & .031881 \\ 1000.0 & 1.176964 & .031866 \\ 1100.0 & 1.109343 & .030626 \\ \mathrm{~B} 1=1.313488 & \mathrm{~S} 1=.035644 \\ \mathrm{~B} 2=-.0001365151 & \mathrm{~S} 2=-.0000038844\end{array}$

RMS (GPM)

.216341

.531979

.238634

.184115

.454185

.301639

.342830

$B 2=-.0001365151$

Run \#3

$\begin{array}{cl}T^{\circ} \mathrm{F} & \text { Bias (V) } \\ 400.0 & 1.245072 \\ 600.0 & 1.282226 \\ 700.0 & 1.265343 \\ 800.0 & 1.215923 \\ 900.0 & 1.145447 \\ 1000.0 & 1.091266 \\ 1100.0 & 1.023844 \\ B 1=1.458393 \\ 82=-.0003526593\end{array}$

Slope (V/GPM)

RMS (GPM)

.031472

.202183

.031303

.234432

.031024

$.233 i 18$

.031303

.160429

.031380

.528557

.029388

.406395

.029730

.302421

$\mathrm{ST}=.032913$

$S 2=-.0000026885$

Provided with PNNL-26202 
Table 3.13

- S/N 191 Parameters

$\begin{array}{lllll}\text { Run \#1 } & \mathrm{T}^{\circ} \mathrm{F} & \text { Bias }(\mathrm{V}) & \text { Slope (V/GPM) } & \text { RMS (GPM) } \\ 400.0 & .148762 & .031281 & .294969 \\ 600.0 & .137557 & .032008 & .302299 \\ 700.0 & .136618 & .032107 & .334061 \\ 800.0 & .141750 & .032364 & .156915 \\ 900.0 & .163834 & .030361 & .359169 \\ 1000.0 & .179851 & .031299 & .290575 \\ 1100.0 & .192289 & .030343 & .403654 \\ & & & \\ \mathrm{~B} 1=.100691 & & \mathrm{~S} 1=.032716 & \\ \mathrm{~B} 2=.0000719682 & \mathrm{~S} 2=-.0000016824 & \end{array}$

\begin{tabular}{|c|c|c|c|c|}
\hline \multirow[t]{10}{*}{ Run \#2 } & $T^{\circ} \mathrm{F}$ & Bias (V) & Slope (V/GPM) & RMS (GPM) \\
\hline & 400.0 & .342747 & .031638 & .218153 \\
\hline & 600.0 & .352039 & .033061 & .191972 \\
\hline & 700.0 & .380906 & .032602 & .331962 \\
\hline & 800.0 & .445790 & .031913 & .263979 \\
\hline & 900.0 & .503451 & .031648 & .354667 \\
\hline & 1000.0 & .395286 & .030736 & .755003 \\
\hline & 1100.0 & .246027 & .030416 & .586130 \\
\hline & \multicolumn{2}{|c|}{$\mathrm{B} T=.390580$} & $S 1=.033789$ & \\
\hline & \multicolumn{2}{|c|}{$B 2=-.0000123296$} & $S 2=-.0000026381$ & \\
\hline
\end{tabular}


Table 3.14

i AOTA Parameters

$\begin{array}{cccll}\text { Run \#1 } & T^{\circ} \mathrm{F} & \text { Bias }(\mathrm{V}) & \text { Slope (V/GPM) } & \text { RMS (GPM) } \\ 400.0 & -.024788 & .104802 & 1.886903 \\ 500.0 & -.032325 & .103106 & 1.553797 \\ 600.0 & -.026994 & .099308 & 1.362831 \\ 700.0 & -.008825 & .094951 & 1.091018 \\ 800.0 & -.002788 & .090816 & .741955 \\ 900.0 & .039932 & .084975 & .512219 \\ 1000.0 & .074112 & .079991 & .254024 \\ 1100.0 & .112484 & .074534 & .301678 \\ & & & \\ \mathrm{~B} 1=-.135426 & \mathrm{~S} 1=.125005 & \\ \mathrm{~B} 2=.0002023695 & \mathrm{~S} 2=-.0000445925 & \end{array}$

$\begin{array}{ccccc}\text { Run \#2 } & T^{\circ} \mathrm{F} & \text { Bias }(\mathrm{V}) & \text { Slope }(\mathrm{V} / \mathrm{GPM}) & \text { RMS (GPM) } \\ 400.0 & -.135508 & .115320 & .214064 \\ 600.0 & -.089470 & .106955 & .206181 \\ 700.0 & -.067363 & .102078 & .202657 \\ 800.0 & -.043745 & .096650 & .094982 \\ 900.0 & .005329 & .090968 & .157114 \\ 1000.0 & .047434 & .084646 & .180501 \\ 1100.0 & .085842 & .077930 & .211687 \\ & & & \\ \mathrm{~B} 1=-.280185 & & \mathrm{~S} 1=.138483 & \\ \mathrm{~B} 2=.0003206936 & \mathrm{~S} 2=-.0000536057 & \end{array}$


Table 3.15

I S/N 201 Parameters

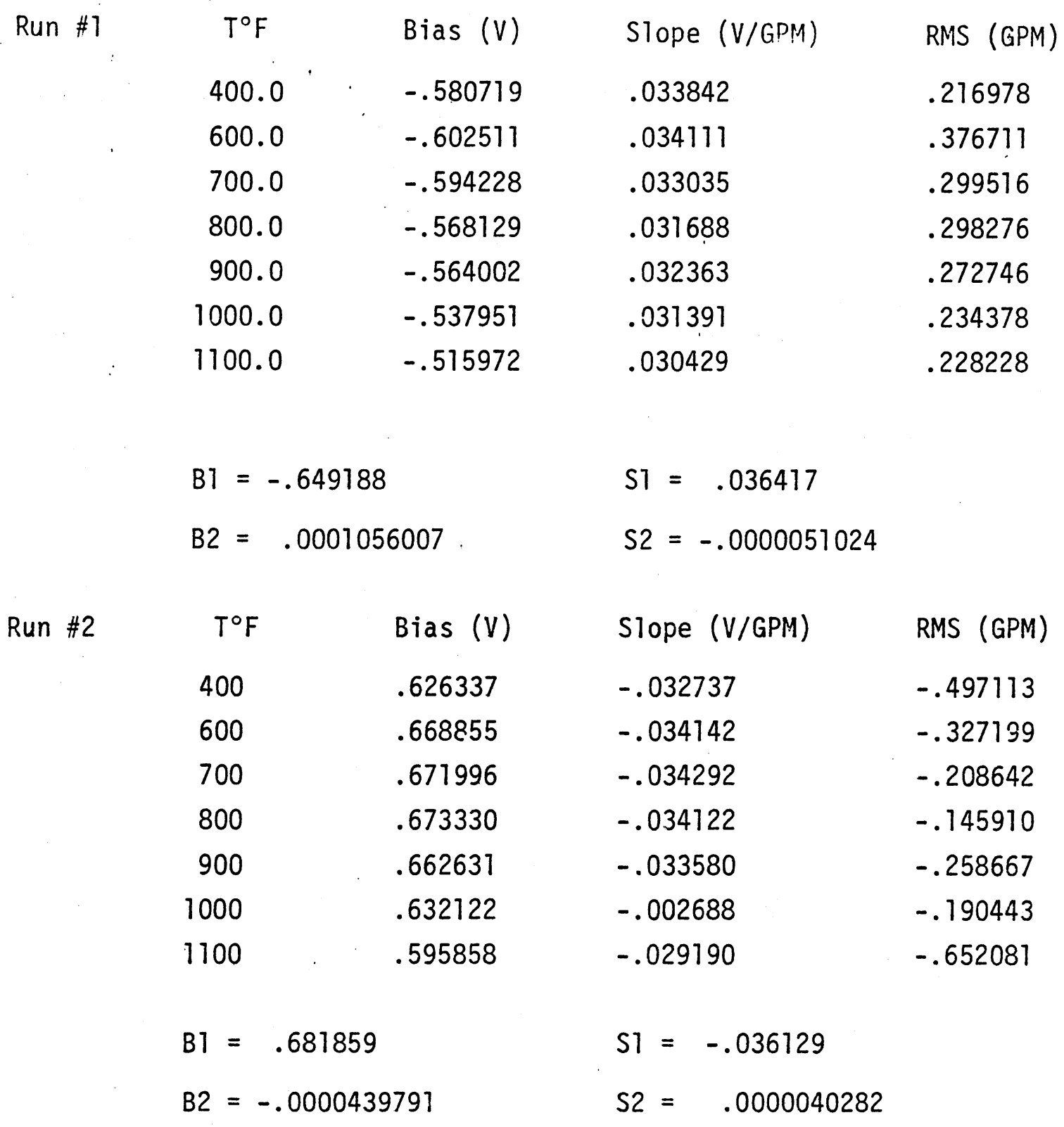


TABLE 3.16

CALIBRATION CURVE PARAMETERS

\begin{tabular}{|c|c|c|c|c|}
\hline$S / N$ & $\underset{(\text { Volt }}{\operatorname{SigPM})}\left(x 10^{+2}\right)$ & $\begin{array}{l}\text { S2 }\left(\times 10^{+7}\right) \\
\left(\text { Volt } / \text { GMP } /{ }^{\circ} \mathrm{F}\right)\end{array}$ & $\begin{array}{l}\text { B] }(x 10) \\
\text { (Volts) }\end{array}$ & $\begin{array}{l}\text { B2 }\left(\times 10^{+5}\right) \\
\left(\text { Volts } /{ }^{\circ} \mathrm{F}\right)\end{array}$ \\
\hline 052 & .319 & -2.97 & 0.75 & -4.59 \\
\hline 064 & .343 & -3.37 & -2.36 & -6.62 \\
\hline 078 & .334 & -3.28 & -2.10 & -7.75 \\
\hline 081 & .343 & -4.27 & 0.26 & -2.26 \\
\hline 098 & .310 & -1.94 & -1.45 & -3.06 \\
\hline 109 & .328 & -3.35 & -0.03 & 1.77 \\
\hline 110 & .332 & -0.36 & -0.70 & 4.44 \\
\hline 128 & .313 & -3.25 & 0.48 & 3.97 \\
\hline 156 & .309 & -2.60 & -1.04 & 2.39 \\
\hline 158 & .327 & -3.16 & -0.42 & -0.84 \\
\hline 164 & .317 & -2.83 & -1.13 & 0.40 \\
\hline 172 & .343 & -3.29 & 1.37 & -2.45 \\
\hline 191 & .333 & -2.16 & 0.25 & 0.30 \\
\hline 194 (AОTA) & 1.385 & -53.61 & -0.28 & 3.21 \\
\hline 201 & .363 & -4.57 & -0.67 & 0.75 \\
\hline
\end{tabular}


The $400^{\circ} \mathrm{F}$ to $700^{\circ} \mathrm{F}$ runs on ECFM S/Ns 052,098 and 194 (AOTA) were all run at the same time and the run suffered a computer failure producing two sets of data which led to the anomalous behavior in the rms column. Run \#1 for S/N 110 and for S/N 172 contain bad data also.

\subsubsection{Temperature and Flow Calibration}

The ECFM in the Row 2 FOTA (HFO11) is Serial Number 172 and is attached to the Model 5204 Lock-in Amplifier. This amplifier provides both $Q$ and I output. Simultaneously. A test run (Run 3C) at the TTL using flows of approximately $20 \mathrm{gpm}$ and $200 \mathrm{gpm}$ was used to find the flow and temperature dependence of the $Q$ vector for $S / N$ 172. Table 3.17 displays the results of this run, which may be summarized as follows:

$$
I=(S 1+S 2 \cdot T) \cdot F 10 w+(B 1+B 2 \cdot T)
$$

and

$$
Q=(T 1+T 2 \cdot T) \cdot F l o w+(C 1+C 2 \cdot T)
$$

where $I$ and $Q$ are the in-phase and quadrature vectors; S1, S2, B1 and B2 are given in Table 3.16 for $\mathrm{S} / \mathrm{N} 172$ and $\mathrm{T} 1, \mathrm{~T} 2, \mathrm{Cl}$ and $\mathrm{C} 2$ are defined in Table 3.18 .

Note that $\mathrm{Bl}$ and $\mathrm{Cl}$ are both functions of the location of the absolute zero flow and are subject to change. Note also, the factor of 10 scaling between TTL results and those of the FFTF. Thus the values of $\mathrm{Br}$ and $\mathrm{Cl}$ to be used in the FFTF will be derived from the zero flow values of $Q$ and I in the plant.

Solve Equation (3-11) and (3-12) for flow and $T$ (temperature in ${ }^{\circ} \mathrm{F}$ ) to obtain a pair of solutions,

$$
T_{ \pm}=1 / 2\left(\xi-\beta \pm \sqrt{\left.\beta^{2}-4 \alpha\right) / \alpha}\right.
$$

and

$$
\mathrm{FlOW}_{ \pm}=\left(\mathrm{I}_{\mathrm{p}}-\mathrm{B} 1-B 2 \cdot \mathrm{T}_{ \pm}\right) /\left(\mathrm{S} T+\mathrm{S} 2 \cdot \mathrm{T}_{ \pm}\right)
$$

where

$$
\begin{aligned}
& \alpha \triangleq \quad T 2 \cdot B 2-S 2 \cdot C 2 \\
& B \triangleq \quad B 2 \cdot T 1-S 1 \cdot C 2-T 2 \cdot(I-B 1)+S 2 \cdot(Q-C 1)
\end{aligned}
$$

and

$$
\gamma \triangleq(Q-C 1) \cdot S T-(I-B T) \cdot T 1
$$




\section{TABLE 3.17}

FLOW AND TEMPERATURE DEPENDENCE OF Q FOR S/N 172

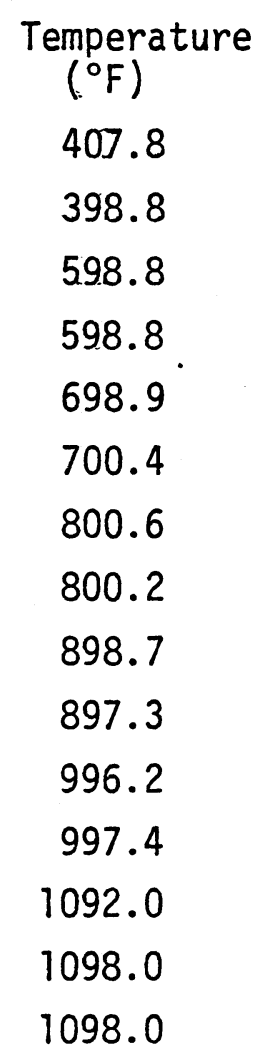

Flow
$($ GPM)
20.2
200.5
20.2
198.7
20.2
199.2
20.4
201.3
20.0
201.3
20.1
201.0
20.4
200.1
20.3

Quadrature

(Volts)

0.9322

0.9319

1.3796

$1.95 \mathrm{Fg}$

1.6224

2.5105

1.8962

2.9830

2.1631

3.4450

2.3490

3.9230

2.5117

4.2150

2.5196 


\section{TABLE 3.18}

PARAMETERS FOR QUADRATURE DEPENDENCE ON FLOW AND TEMPERATURE

$\begin{array}{ccccc} & \begin{array}{c}\text { T1 } \\ \text { (Volts } / \text { GPM })\end{array} & \begin{array}{c}\text { T2 } \\ \left(\text { Volts } / \mathrm{GPM} /{ }^{\circ} \mathrm{F}\right)\end{array} & \begin{array}{c}\mathrm{Cl} \\ (\text { Volts })\end{array} & \begin{array}{c}\mathrm{C} 2 \\ \left(\text { Volts } /{ }^{\circ} \mathrm{F}\right)\end{array} \\ \text { TTL } & -4.58 \times 10^{-3} & 1.29 \times 10^{-5} & 9.95 \times 10^{-2} & 2.07 \times 10^{-3} \\ \text { FFTF } & -4.58 \times 10^{-4} & 1.29 \times 10^{-6} & 9.95 \times 10^{-3} & 2.07 \times 10^{-4}\end{array}$


The appropriate choice of solutions corresponds to the negative root in Equation (3-13).

\subsubsection{Conclusions}

The implementation of the PSD flow measuring electronics in the FFTF allows flow measurement accuracies in the low flow regime ( $<75 \mathrm{gpm})$ of approximately $\pm 1 \mathrm{gpm}$. The success of the linear fit to the data is somewhat dependent on the low sodium velocities being measured (see Appendix B) and on the increased sensitivity of the flow signal at low flows resulting from the removal of all constant, non-flow signals by the PSD electronics.

The largest errors produced were a result of spurious data or of data recording errors. Highly repetitious measurements in the plant environment will suppress many of the larger errors and the permanent attachments to the DDH \& DS, the on-line data handling and storage computer at the FFTF, should help to minimize recording errors.

The additional instrumentation on the Row 2 FOTA (HFO11) provides, in addition to accurate flow measurement, fast temperature measurements with a sensitivity of about 2 millivolts $/{ }^{\circ} \mathrm{F}$. An accuracy of 10 millivolts (not unreasonable) in the output voltage (relative to previous readings) would allow for rapid temperature tracking with a $\pm 5^{\circ} \mathrm{F}$ uncertainty band. Thus the installation on HFO1I can provide flow measurement and temperature measurement with accuracies of $\pm 1 \mathrm{gpm}$ and $\pm 5^{\circ} \mathrm{F}$, respectively. The effects of rapid thermal transients have not been investigated and might indicate the need for post-processing of the data to account for thermal lags in the ECFM thimble.

The AOTA has considerably higher velocities at the same flow. The repeat run, unlike the other ECFMs, was made in the same thimble, as only one AOTA test station existed. The first run suffered from the computer failure and is far less believable. The second run shows the excellent accuracy of the AOTA with an rms error of $0.21 \mathrm{gpm}$ or less. This high level of linearity provides quite accurate flow measurements. 


\subsection{PLANT PROCEDURES}

This section treats the plant requirements for setting up the PSDequipped ECFMs. The procedures vary with fueled assemblies and with unfueled assemblies because of their drastically different flow rates. Finally a procedure for checking for bias shifts after a few thermal cycles is outlined in Section 4.2.

\subsection{Phase-Sensitive Detector Setup}

The in-plant setup of the PSD electronics consists of setting the correct attenuation and of obtaining a value for $Q$, the quadrature vector, which is independent of the flow. The description of the quadrature setup in the TTL given in Section 3.3 applies equally well to in-plant setup since setting the quadrature does not require knowledge of the flow value. Simulated in-plant quadrature setups were performed at the TTL in which the quadrature vector for a flowmeter was obtained using unknown flows. The results of the test indicate the knowledge of the true flow values made no difference in obtaining Q. Appendix $C$ contains the detailed procedure for the field calibration and setup.

\subsubsection{Fueled Assemblies}

Fueled assemblies are orificed to provide flows of about $500 \mathrm{gpm}$ with al1 three primary pumps at ful1 power. Three pony motors provide about $10 \%$ flow or $50 \mathrm{cpm}$. Prior to operation, the fueled assemblies produce no decay heat to speak of and it is possible to obtain nearly zero flow with an isothermal core. Hence with the fueled assemblies, the two plant flow conditions required for setup are three pony motors and no pumps. The advantage of these two flow rates are: 1) the TTL calibration was performed use 2 and $60 \mathrm{gpm}$ arid, 2) the zero flow reading provides an absolute calibration of the in-phase component, thereby lessening the uncertainty caused by the environmental feedback.

\subsubsection{Reflectors}

Most of the comments concerning the fueled assemblies apply to the reflector assemblies also. The only difference is the orificing in the reflectors: They carry about $35 \mathrm{gpm}$ with three primary pumps. Thus in 
order to accurately calibrate the reflector ECFMs, the two plant flow conditions snould be design flow and no pumps, respectively.

\subsection{Bias Shift Checks}

The stability of an ECFM appears to increase after it has undergone a few thermal cycles. In order to check for shifts in the flow zero and in the quadrature vector, the setup procedure should be performed again following the maximum isothermal (MIST) test in the ATP. 


\subsection{PHASE-SENSITIVE ELECTRONICS CALIBRATION}

The PSD electronics have been calibrated in the Standards Laboratory at HEDL prior to being installed at the FFTF. The calibrations necessary before and after arrival at the FFTF are treated in this section.

\subsection{Standard In-Laboratory Calibration}

The lock-in amplifier calibration involves adjusting the tuning of the signal amplifier of each lock-in amplifier to a high level of accuracy so that a $25 \mathrm{mv} \pm 0.2 \%$ sinusoidal input at $1 \mathrm{KHz}$ with 7 ess than $0.5 \%$ total harmonic distortion produces 1.000 volt $\pm 0.2 \%$ at the output.

After each amplifier has been adjusted on the $25 \mathrm{mv}$ scale, the attenuation ratios for the $2.5 \mathrm{mv}$ to $250 \mathrm{mv}$ ranges are recorded for each amplifier.

The procedure for this calibration is reproduced in Appendix $C$.

\subsection{In-Field Calibration}

Following calibration of the lock-in amplifiers by the Standards Lab and installation of the amplifiers in the FFTF, the attenuators were adjusted to provide full scale reading for the lock-in amplifier when a $3 \mathrm{mv}$ signal at the system $1 \mathrm{KHz}$ frequency was fed into the $S C / C R$, which in turn provided a $3.000 \mathrm{~V}_{A C}$ signal (1 KHz frequency) at the AMPL SEC (Amplified Secondary Coil Voltage) output connector located on the front of the SC/CR module. The attenuator adjustment (ADJ) potentiometer was adjusted until the lock-in amplifier, whose phase had been adjusted to obtain a maximum in-phase (zero quadrature) singal (phase shifts through the $S C / C R$ amplifier require prior adjustment of the phase switch and dial to get the maximum signal sensitivity), gives a $V_{D C}$ output corresponding to the average value obtained from Table 5-1 for the ECFM $S / N$ being calibrated.

The signal attenuator design standard is reproduced in Appendix $C$. 
TABLE 5.1.a CHARACTERISTICS OF TTL ELECTRONICS

\begin{tabular}{lcccc}
$\begin{array}{c}\text { Ident } \\
\text { No. }\end{array}$ & $\begin{array}{c}\text { SC/CR } \\
\text { S/N 5547- }\end{array}$ & $\begin{array}{c}\text { Lock-In Amplifier } \& \\
\text { Attenuator }\end{array}$ & $V_{A C}$ & $V_{D C}$ \\
\hline I & 0062 & 612953 & 3.0780 & 9.2785 \\
II & 0062 & 612480 & 3.0780 & 9.0780 \\
III & 0062 & 701584 & 3.0780 & 9.0680 \\
IV & 0019 & 612953 & 3.0440 & 9.1110 \\
V & 0079 & 612480 & 3.0455 & 8.9090 \\
VI & 0019 & 701584 & 3.0455 & 8.9000 \\
VII & 0002 & 612953 & 3.0280 & 9.0450 \\
VIII & 0002 & 612480 & 3.0280 & 8.8415 \\
IX & 0002 & 701584 & 3.0285 & 8.8300 \\
X & 0044 & 612953 & 3.0065 & 9.0650 \\
XI & 0044 & 612480 & 3.0065 & 8.8465 \\
XII & 0044 & 701584 & 3.0065 & 8.8465 \\
XIII & 0043 & 612953 & 3.0065 & 9.0485 \\
XIV & 0043 & 612480 & 3.0065 & 8.8460 \\
XV & 0043 & 701584 & 3.0065 & 8.8700 \\
XVI & 0044 & $612953+5 \mathrm{~K}$ & 3.0075 & 5.4040 \\
XVII & 0062 & $612953+5 \mathrm{~K}$ & 3.0790 & 5.5380
\end{tabular}


TABLE 5.1.b

TABLE OF CALIBRATION RUNS VERSUS ELECTRONICS IDENT. NO.

$\begin{array}{lll}\text { S/N } & \text { I.D. (1) } & \text { I.D. (2) } \\ 052 & \text { XI } & \text { XIV } \\ 064 & \text { I } & \text { XIII } \\ 078 & \text { II } & \text { XIV } \\ 081 & \text { XVI } & \text { I } \\ 098 & \text { XVI } & \text { XV } \\ 109 & \text { I } & \text { XV } \\ 110 & & \text { XIV } \\ 128 & \text { XV } & \text { I } \\ 156 & \text { II } & \text { XIV } \\ 158 & \text { XV } & \text { I } \\ 164 & \text { XV } & \text { I } \\ 172 & \text { XIII } & \text { VII } \\ 191 & \text { VII } & \text { VII } \\ \text { A0TA } & \text { XVII } & \text { XVII } \\ 201 & \text { VII } & \text { VII }\end{array}$




\subsection{REFERENCES}

1. Letter, J. W. Mitchell to W. M. Jacobi, "GPL-2 Instrument S/A Testing - Preliminary Report," W/FFTF 721426, March 1, 1972.

2. D. R. Pederson, et al., "Flowmeter Calibration Report - SLSF Flowmeters," ANL/RAS 76-16, April 1976.

3. V. DeVita, "Calibration Report for HEDL Eddy Current and PM Flowmeters - H-3-42621 and H-3-42670," LMEC TI-12-LME-009, October 1977.

4. Letter, T. T. Anderson to W. B. Klingler, "Field Installation and Operating Instructions for the FC/T Module," Argonne National Laboratory, March 10, 1977.

5. Standard RDT C-4-7, "Eddy Current Probe Type Flow Sensor for Liquid Metal Service".

6. Standard, RDT C-10-5, "Eddy Current Power Supply and Signal Conditioning Electronics."

7. M. Hirayama, "Theoretical Model of an Eddy Current Flowsensor," IEEE Transactions on Nuclear Science NS-24, 2021 October 1977.

8. L. E. Fort, Private Communication.

9. K. Ara, "A Differential Transformer with Temperature and Excitation Independent Output," IEEE Transactions on Nuclear Science, IM-21, 249, August 1972.

10. G. Hughes, "Electrical Conductivity Fluctuations in High Temperature Liquid Metals," Journal of Physics E: Scientific Instruments 5, 349, 1972 .

J. D. McCann, "Fast Response Temperature Sensor for Use in Liquid Sodium, "Journal of Physics E: Scientific Instruments 9, 298, 1975 .

B. J. Farrington and G. Hughes, "A Theoretical Analysis Applied to Electromagnetic Instruments Used in Liquid Sodium," Central Electricity Generating Board, Berkeley, Report RD/B/N275], 1975 .

B. S. Farrington and G. Hughes, "Performance of an Electromagnetic Temperature Sensor in Liquid Sodium," Journal of British Nuclear Energy 16, 347, Dctober 1977 . 


\section{APPENDIX A}

This Appendix contains the specifications for the following ECFM Components:

- Par Model 128A Lock-In Amplifier

- PAR Model 5204 Lock-In Analyzer 


\section{PAR MODEL 128A SPECIFICATIONS}

SIGNAL CHANNEL

FREQUENCY RANGE: $0.5 \mathrm{~Hz}-100 \mathrm{KHz}$

SENSITIVITY: $1 \mu \mathrm{V}$ to $250 \mathrm{mV}$ rms full scale in a 1-2.5-10 sequence.

INTERNAL NOISE: Less than $10 \mathrm{nV} / \mathrm{Hz}^{1 / 2}$ at $1 \mathrm{KHz}$.

SYSTEM GAIN STABILITY: Less than $0.1 \% /{ }^{\circ} \mathrm{C}$.

DETECTOR BIAS: Adjustable from 0 to $\pm 15 \mathrm{~V}$ by inserting divider resistors on internal preamplifier board.

SIGNAL CHANNEL: Single-ended or true differential, switch-selectable.

INPUT IMPEDANCE: 100 megohms in parallel with $20 \mathrm{pF}$.

COMMON MODE REJECTION: Better than $100 \mathrm{~dB}$ at $1 \mathrm{kHz}$.

MAXIMUM COMMON MODE VOLTAGE: $3 \mathrm{~V}$ pk-pk to $20 \mathrm{KHZ},-6 \mathrm{~dB} / 0$ ctave above.

MAXIMUM INPUT SIGNAL: 1000 times full scale up to a maximum of $1.8 \mathrm{~V}$ pk-pk before overload.

HI-PASS FILTER: A front panel switch sets the high pass characteristics to $<0.5 \mathrm{~Hz}$ (MIN. position), $5 \mathrm{~Hz}$ or $50 \mathrm{~Hz}$. These values can be easily changed in the field to suit the application.

LOW-PASS FILTER: A front panel switch sets the low pass characteristics to $100 \mathrm{~Hz}, 10 \mathrm{KHz}$ or $>100 \mathrm{KHz}$ (MAX. position). These values can be easily changed in the field to suit the application.

TUNED SIGNAL CHANNEL OPTION (128A/98): Provides a switch-selectable choice of a flat response or of a tuned bandpass (or notch charactersitic) at a set frequency with a $Q$ of 5 . The frequency can be adjusted over a 3:1 frequency range by means of a potentiometer, accessible from the rear panel, and can be changed to any frequency within the range of approximately $0.5 \mathrm{~Hz}$ to $100 \mathrm{KHz}$ by changing capacitors mounted on solderless component clips on the board. 
REFERENCE CHANNEL

FREQUENCY RANGE: $0.5 \mathrm{~Hz}-100 \mathrm{KHz}$. No range switching or tuning required. MODES OF OPERATION: Fundamental ( $f$ ) - the Model ?28A locks onto any external reference signal of the proper input characteristic. Harmonic (2f) - in this mode, the $128 \mathrm{~A}$ will respond at the second harmonic of the external reference frequency, maximum input frequency is $50 \mathrm{KHz}$.

INPUT REQUIRED: The reference channel will phase lock to virtually any external voltage waveform of at least $100 \mathrm{mV}$ pk-pk amplitude and which crosses its mean only twice each cycle. The minimum pulse duration (for asymmetrical waveforms) is $100 \mathrm{~ns}$. The front panel Reference Unlock lamp indicates the presence of a proper reference input. When using a sine wave reference, best phase accuracy is achieved at $1 \mathrm{~V}$ rms.

ACQUISITION TIME: The time required for the reference channel lock to a changed reference signal is typically 2 seconds/octave. Below $5 \mathrm{~Hz}$ the acquisition time increases to 10 seconds/octave.

PHASE ADJUSTMENT: A calibrated ten-turn potentiometer provides $0-100^{\circ}$ phase shift. The phase shift accuracy is better than $0.2^{\circ}$ over the entire frequency range. Resolution is $0.1^{\circ}$. A four-position quadrant switch provides $90^{\circ}$ phase shift increments accurate to $0.2^{\circ}$.

\section{PHASE-SENSITIVE DETECTOR}

DYNAMIC RESERVE: Asynchronous signals with amplitudes corresponding to 1000 times full scale can be applied without overload. Dynamic reserve can be greatiy increased by modification 128A/70, 128A/98, and proper setting of high pass, low pass controls. 
FILTER TIME CONSTANTS: $1 \mathrm{~ms}$ to 100 seconds plus an External position and a Minimum time position (less than $1 \mathrm{~ms}$ ). The external position allows capacitance to be added via a rear panel connector to obtain any desired time constant. A dc Pre-Filter switch is provided which inserts an additional 0.1 or 1 second time constant filter. When used in conjunction with any of the standard time constant settings, it provides a $12 \mathrm{~dB} /$ octave rolloff rate.

DC OUTPUT ZERO STABILITY: Better than $0.1 \% /{ }^{\circ} \mathrm{C}, 0.1 \% / 24$ hours at constant temperature.

OUTPUT VOLTAGE: $\pm 1 \mathrm{~V}$ full scale.

ZERO OFFSET: Calibrated ten-turn potentiometer allows up to $\pm 10 \mathrm{x}$ full scale signal to be suppressed.

OUTPUTS

METER READOUT: Zero-center taut-band meter to monitor dc output. RECORDER: $\pm 1 \mathrm{~V}$ full scale at both a front panel BNC connector and a rear panel double banana jack for driving a recorder.

GENERAL

OVERLOAD: A front panel lamp indicates overload at all critical points in the instrument.

AMBIENT TEMPERATURE RANGE: The unit can be operated at temperatures ranging from $15^{\circ} \mathrm{C}$ to $45^{\circ} \mathrm{C}$.

AUXILIARY POWER OUTPUT: Regulated $\pm 15 \mathrm{~V}$ at $20 \mathrm{~mA}$ available at a rear panel connector. 
POWER REQUIREMENTS: $100-130$ or $200-260 \mathrm{~V} \mathrm{ac} ; 50-60 \mathrm{~Hz} ; 12$ watts. Unit can also be powered from batteries by supplying \pm 20 to $30 \mathrm{~V}$ dc to a rear panel connector. Batteries must be able to supply at least $250 \mathrm{~mA}$.

SIZE: $17-3 / 4^{\prime \prime} W \times 3-1 / 2^{\prime \prime} H \times 14 " D(45 \mathrm{~cm} \mathrm{~W} \times 9 \mathrm{~cm} \mathrm{H} \times 36 \mathrm{~cm} \mathrm{D})$. WEIGHT: 14 1bs $(6.4 \mathrm{~kg})$. 


\section{PAR MODEL 5204 SPECIFICATIONS}

SIGNAL CHANNEL

FREQUENCY: $0.5 \mathrm{~Hz}-100 \mathrm{KHz}$

SENSITIVITY: 8 full-scale ranges from 100 microvolts to 250 millivolts in a 1-2.5-10 sequence. Three output expansion ranges of $\times 1, \times 10$ and $\times 100$ increase the overall sensitivity to $1 \mu \mathrm{V}$ full scale.

INPUT: Single-ended or differential input, floating or grounded.

INPUT IMPEDANCE: 100 megohms shunted by 25 picofarads.

COMMON MODE REJECTION: Better than $100 \mathrm{~dB}$ at $1 \mathrm{KHz}$.

MAXIMUM COMMON MODE VOLTAGE: $3 \mathrm{~V} \mathrm{pk-pk}$ to $20 \mathrm{KHZ}-6 \mathrm{~dB} /$ octave above $20 \mathrm{KHz}$. MAXIMUM INPUT SIGNAL: 650 millivolts $\mathrm{rms}$ sine wave before overload (1.8 V pk-pk).

DETECTOR BIAS: Adjustable from 0 to \pm 15 volts by inserting bias resistors on the internal preamplifier board.

HI PASS FILTER: A front panel switch sets high pass characteristics to $<0.5 \mathrm{~Hz}$ (both switches out), $5 \mathrm{~Hz}$, or $50 \mathrm{~Hz}$. These values can be changed in the field to suit the application. 
LO PASS FILTER: A front panel switch sets low pass filter characteristics to $100 \mathrm{~Hz}, 10 \mathrm{kHz}$, or $\max$ (greater than $100 \mathrm{kHz}$ ). These values can be changed in the field to suit the application.

INTERNAL NOISE: Less than $10 \mathrm{nV} / \mathrm{Hz}^{1 / 2}$ at $1 \mathrm{kHz}$ (see noise figure contour). SYSTEM GAIN STABILITY: Better than $0.1 \% /{ }^{\circ} \mathrm{C}$.

REFERENCE CHANNEL

FREQUENCY RANGE: $0.5 \mathrm{~Hz}$ to $100 \mathrm{kHz}$. no range switching or tuning required. MODES OF OPERATION:

Fundamental ( $f$ ): The reference channel locks onto any external reference signal having the proper reference characteristics (see below).

Harmonic (2f): The reference channel locks onto the proper external reference signal and responds to the second harmonic of the external reference.

INPUT REQUIRED: The reference channel phase locks to virtually any external voltage waveform having amplitude excursions of at least 50 millivolts on each. side of the mean crossing the mean only twice each cycle. Minimum pulse duration (for an asymmetrical waveform) is 5 microseconds. The front panel reference unlock lamp indicates the absence of a proper reference input. When using a sine wave reference, the best phase accuracy is achieved at 1 volt rms. PHASE ADJUSTMENT: A calibrated ten-turn potentiometer provides 0-100 degree phase shift. The accuracy is within 0.2 degree and the resolution is 0.1 degree. A four-position quadrant switch provides 90 degree phase shift increments accuraate to 0.1 degree.

PHASE NOISE: Less than 0.1 degree (at $1 \mathrm{kHz} ; 0.1 \mathrm{sec}, 12 \mathrm{~dB} /$ octave). ACQUISITION TIME:

$0.5 \mathrm{~Hz}$ to $50 \mathrm{~Hz}-15 \mathrm{sec}$ (typical)

$50 \mathrm{~Hz}$ to $100 \mathrm{kHz}-2 \mathrm{sec}$ (typical) 


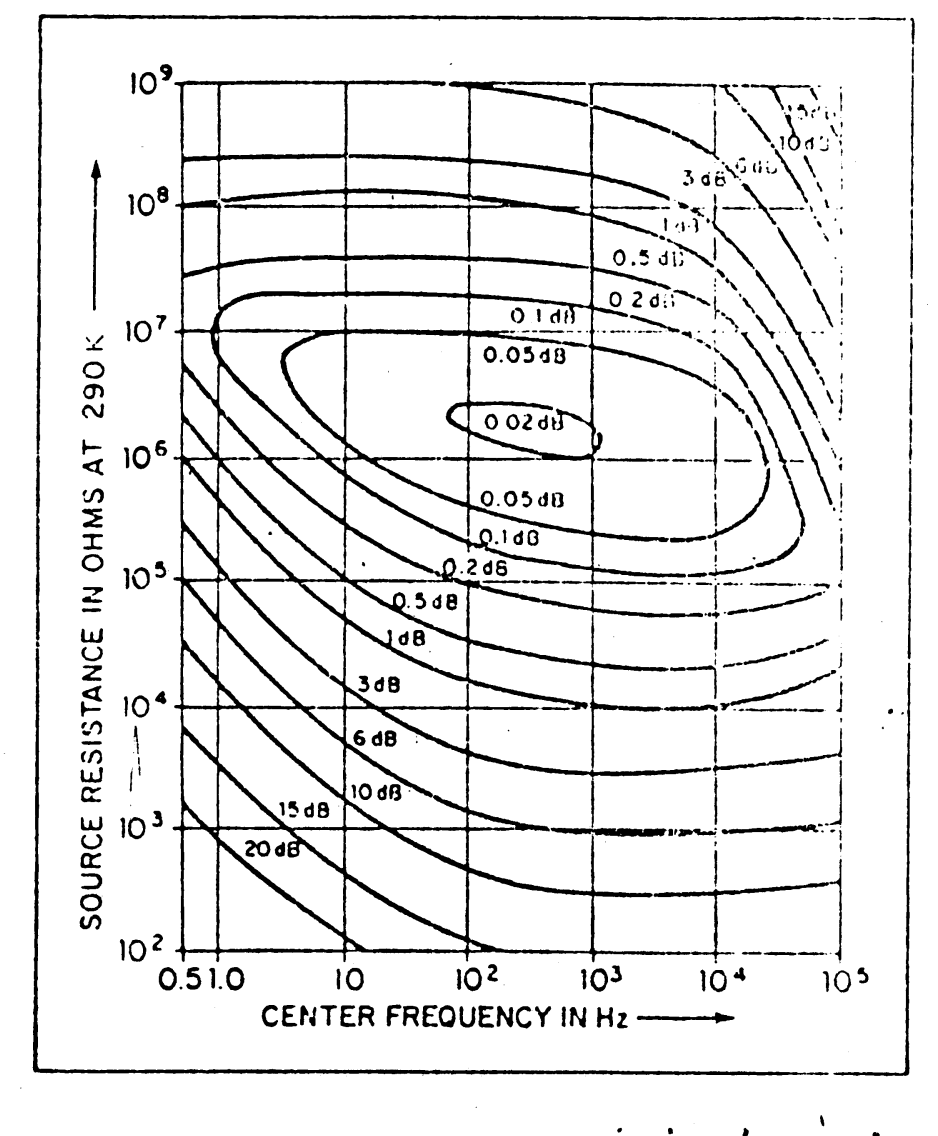

\section{OUTPUTS}

METER READOUT: Two zero-center meters provide full-scale indication for a full scale input as determined by the input sensitivity switch and the output expand switch settings. The left meter can be switched to monitor the in-phase signal or, if the appropriate option is installed, the vector magnitude or computed noise. The right meter can be switched to monitor the quadrature signal or, if the option is installed, the computed phase of the signal with respect to the reference signal. A third position allows the righr meter to monitor an external dc signal such as that available from the optional ratio output.

RECORDER OUTPUT: Front and rear panel BNC connectors are provided in parallel to interface to all standard recorders. 
OUTPUT VOLTAGE: 1 volt through 600 ohms.

METER SENSITIVITY (External Mode): 1 volt full scale. $(100 \mu \mathrm{A}$ meter movement through 10 kilohms.)

GENERAL

AMBIENT TEMPERATURE RANGE: Units can be operated at temperatures ranging from $15^{\circ} \mathrm{C}$ to $45^{\circ} \mathrm{C}$.

AUXILIARY POWER OUTPUT: Regulated \pm 15 volts at $20 \mathrm{~mA}$ available at rear panel connector.

POWER REQUIREMENTS: 100 to 130 or 200 to 260 volts ac; $50-60 \mathrm{~Hz} ; 35$ watts. Units can also be powered from batteries by supplying $\pm 24 \mathrm{~V}$ to $\pm 30 \mathrm{~V}$ and $+8 \mathrm{~V}$ dc to a rear panel connector. Batteries must be able to supply at least 1 A.

SIZE: $17-1 / 2^{\prime \prime} W \times 5-1 / 2^{\prime \prime} H \times 19-1 / 2^{\prime \prime} \mathrm{D}(44.5 \mathrm{~cm} \mathrm{~W} \times 13.9 \mathrm{~cm} \mathrm{H} \times 49.5 \mathrm{~cm} \mathrm{D})$. WEIGHT: 25 Tbs $(11.4 \mathrm{~kg})$. 


\section{APPENDIX B}

This appendix provides a detailed calculation of the behavior of the induced EMFs in an ECFM made of three single loop coils. This simplification does not affect the applicability of the qualitative results but does invalidate them for quantitative purposes.

Maxwell's field equations for the general case in which the medium is moving with a velocity, $\vec{v}$, are:

$$
\begin{aligned}
& \vec{\nabla} \times \vec{H}=\vec{J}+\sigma(\vec{E}+\vec{V}+\vec{B})+\frac{\partial \vec{D}}{\partial T} \\
& \vec{\nabla} \times \vec{E}=\partial \vec{B} / \partial T \\
& \vec{\nabla} \cdot \vec{B}=0 \\
& \vec{\nabla} \cdot \vec{D}=\rho
\end{aligned}
$$

where the only addition caused by the moving medium is the $\sigma \vec{V} \times \vec{B}$ term in Equation (B.1).

The divergence of $\vec{B}$ vanishes so, without loss of generality, $\vec{B}$ can be expressed in terms of a vector potential $A$,

$$
\vec{B}=\vec{\nabla} \times \vec{A}
$$

Where $A$ is not unique since it can be replaced by any vector function which differs from it by the gradient of some scalar function. This ambiguity does not reflect itself in the final answer and so is not considered.

Making use of Equations (B.1) - (B.5) along with the relation of $D$ to $E$ and $B$ to $H$,

$$
\begin{aligned}
& \vec{D}=\varepsilon \vec{E}, \\
& \vec{B}=\mu \vec{H},
\end{aligned}
$$


which are valid in an isotropic, homogeneous medium. The following differential equation for A may be written when the driving current is sinusoidal;

$$
\vec{\nabla}(\vec{\nabla} \cdot \vec{A})-\nabla^{2} \vec{A}=\mu \vec{J}-\mu(\sigma+i \omega \varepsilon) \frac{\partial \vec{A}}{\partial T}+\mu \sigma \vec{V} \times(\vec{\nabla}+\vec{A})
$$

which simplifies for the case in which $V$ is parallel to the Z-axis of the coil, since the current and vector potential are in the $\theta$ direction. Hence, one can write,

$$
\begin{aligned}
& \vec{V}=V \hat{z} \\
& \vec{A}=A \hat{\theta} \\
& \vec{J}=J \hat{\theta}
\end{aligned}
$$

where the caret denotes a unit vector and Equation (B.8), expressed in cylindrical coordinates becomes,

$$
\begin{aligned}
& \frac{1}{r} \frac{\partial}{\partial r}\left(r \frac{\partial A}{\partial r}\right)+\frac{\partial^{2} A}{\partial Z^{2}}-\mu \sigma V \frac{\partial A}{\partial Z} \\
= & \left(\frac{1}{r^{2}}+i \omega \mu \sigma-\omega^{2} \mu \varepsilon\right) A-\mu J .
\end{aligned}
$$

The assumption of a single loop coil of radius a at $Z=Z_{0}$ leads to,

$$
J=J_{0} \delta(r-a) \delta\left(Z-z_{0}\right)
$$

This choice means that the solution for $A$ is the Green function and can be used to create the general solution. Throughout, the assumption of invariance with respect to $\theta$ has been tacitly assumed. Define $A$ as the product of two functions,

$$
A(r, z) \triangleq \phi(r) \psi(Z)
$$


The resulting equations for $\phi$ and $\psi$ can be obtained by inserting Equation (B.13) in Equation (B.11).

$$
\begin{aligned}
& \frac{7}{\phi(r) r} \frac{\phi d}{d r}\left[r \frac{d}{d r}(r)\right]-\frac{1}{r^{2}}-\omega \mu(i \sigma-\omega \varepsilon) \\
= & -\frac{1}{\psi(z)}\left[\frac{d^{2} \psi(z)}{d z^{2}}-\mu \sigma \vee \frac{d \psi(z)}{d z}\right] \\
& -\frac{\mu J_{0}}{4(z)(r)} \delta(r-a) \delta\left(z-z_{0}\right)
\end{aligned}
$$

In order to solve Equation (B.14), it is necessary to consider the solution for $r>a$ (outside at the coil) as well as for $z>z_{0}$ and $z<z_{0}$. For these cases, the two components can be separated and written as,

$$
\begin{aligned}
& \frac{d^{2} \psi}{d z^{2}}-\mu \sigma v \frac{d \psi}{d z}=C \psi \\
& \frac{1}{r} \frac{d}{d r}\left(r \frac{d \phi}{d r}\right)-\frac{\phi}{r^{2}}=[C+\omega \mu(j \sigma-\omega \varepsilon)] \phi
\end{aligned}
$$

Because these are second order differential equations each possesses two solutions. The choice of solution is dictated by the boundary conditions. The solution of Equation (B.16) is a linear combination of first-order modified Bessel functions, however only $k_{7}$ survives because $I_{7}$ is irregular at infinity. Equation (B.15) is solved by making the ansatz that

$$
\psi=e^{-i m z}
$$

which results in

$$
M^{2}-i \sigma \mu \vee M+C=0
$$

Choose C to simplify Equation (B.18),

$$
C=\left(\alpha^{2}+i \sigma \mu \vee \alpha\right)
$$


which results in one solution, $M=-\alpha$. The second solution is obtained from,

$$
M-\alpha-i \sigma \mu v=0
$$

Again applying the appropriate boundary conditions, $\psi$ becomes

$$
\begin{array}{ll}
\psi(z)=\psi_{0} e^{i \alpha\left(z-z_{0}\right)} & z<z_{0} \\
\psi(z)=\psi_{0} e^{-i \alpha\left(z-z_{0}\right)} e^{\sigma \mu v\left(z-z_{0}\right)} & z>z_{0}
\end{array}
$$

This two solution match at $z=z_{0}$ as they should both remain finite in their respective regimes and the jump in the first derivative at $z=z_{0}$ is $\sigma \mu \vee \psi_{0}$ as it should be.

The choice of $C$ given by Equation (B.19), results in a solution for $\psi$ of,

$$
\psi(r)=\psi_{0} \cdot k_{1}\left(\alpha^{1} r\right)
$$

where

$$
\begin{aligned}
& \alpha^{\prime} \text { is given by, } \\
& \alpha^{\prime} \triangleq \sqrt{\alpha^{2}+\mu(i \sigma v \alpha+\omega(i \sigma-\omega \varepsilon))}
\end{aligned}
$$

The final solution is obtained by integrating over the arbitrary parameter $\sigma$,

$$
\begin{aligned}
& A(r, z)=A_{0} \int_{-\infty}^{\infty} k_{1}\left(\alpha^{\prime} r\right) e^{i \alpha\left(z-z_{0}\right)} d \alpha z \geq z_{0} \\
& A(r, z)=A_{0} e^{\sigma \mu v\left(z-z_{0}\right)} \int_{-\infty}^{\infty} k_{1}\left(\alpha^{\prime} r\right) e^{-i \alpha\left(z-z_{0}\right)} d \alpha z<z_{0}
\end{aligned}
$$


Where $A_{0}$ is an arbitrary normalization for $A$.

The voltage induced in the secondary coils is given by,

$$
V=\oint E \cdot d s=2 \pi b E_{\theta}=-2 \pi b \frac{\partial A}{\partial t}=-2 \pi b i \omega a
$$

where $b$ is the radius of the secondary loops $(b>a)$. Thus the EMF in the loop which is upstream of the primary $\left(z=z_{1}\right)$ is given by,

$$
v_{u s}=-i \cdot b \bar{A} \omega e^{\sigma \mu v\left(z j-z_{0}\right)} \quad \int_{-\infty}^{\infty} \cdot k_{1}\left(\alpha^{\prime} r\right) e^{-i \sigma\left(z_{1}-z_{0}\right)}
$$

Where $\bar{A}$ is a new normalization. The downstream loop $\left(z=z_{2}\right)$ sees an EMF of,

$$
v_{d s}=-i \cdot b \bar{A} \omega \int_{-\infty}^{\infty} k_{1}\left(\alpha^{1} r\right) e^{i \sigma\left(z_{2}-z_{0}\right)} d \alpha,
$$

When $\sigma \mu v\left(z_{1}-z_{0}\right)$ is not large and when $z_{1}-z_{0}=z_{0}-z_{2}$. These two potentials can be related approximately by,

$$
v_{u s} \cong v_{d s}\left[1+\sigma \mu v\left(z_{1}-z_{0}\right)\right]
$$

Hence, in the limit that $\sigma$ and $\mu$ are constant and the expansion is valid, the difference of $v_{u s}$ and $v_{d s}$ is proportional to the sodium velocity, $v$,

$$
v_{d s}-v_{u s}=v_{d s}\left(z_{0}-z_{1}\right) \sigma \mu v
$$

Fluctuations in $V_{d s}, \sigma, \mu$ and nonlinearities in $V_{u s}$ can lead to significant temperature dependent effects. $\left(V_{d s}\right.$ is not independent of $V$ since it appears in $\alpha^{\prime}$. ) Self-compensating flowmeters use the difference and the sum to eliminate $V_{d s}$. Thus they measure $R$, defined as the difference of the two potentials over the sum, which reduces to,

$$
R=\frac{1-e^{\sigma \mu v\left(z_{1}-z_{0}\right)}}{1+e^{\sigma \mu v\left(z_{1}-z_{0}\right)}} \simeq \sigma \mu v\left(z_{0}-z_{1}\right) / 2
$$


under the assumption of $\sigma \mu v\left(z_{1}-z_{0}\right)$ being small. This self-compensated flowmeter sees a more linear relationship between $R$ and flow.

In order to avoid the approximation of a small argument for the exponential, it is possible to examine the natural logarithm of the ratio of $v_{d s}$ to $v_{u s}$,

$\ln \left(v_{d s} / v_{u s}\right)=\sigma \mu v\left(z_{0}-z_{1}\right)$

Pure temperature variations affect $\sigma$ and $\mu$. Because of these effects, one can see that variations in $\sigma \mu v$ and in $\alpha^{\prime}$ (see Equation (B.23) will have much less effect on Equations (B.31) and (B.32) than on Equation (B.30). 


\section{APPENDIX C}

This appendix consists of the relevant procedures and standards for the PSD electronics:

- Setup and calibration procedure for the PAR Model 128A and 5204 Lock-In Amplifiers.

- ECFM Lock-In Amplifier System Attenuator Design.

- Field Calibration and Setup Procedure for the ECFM - Phase Sensitive Detectors. 
SET UP AND CALIBRATION PROCEDURE FOR THE

PAR MODEL 128A AND 5204 LOCK-IN AMPLIFIERS

J. L. Stringer

November 21,1978

\section{GENERAL}

These procedures cover the modifications, operational checks, and calibration for the PAR Models 128A/98 and the 5204/98 Lock-In Amplifiers. In all cases the amplifiers are new "just received" equipment whose proper operation and specific function calibration must be performed before the equipment is installed at FFTF.

\section{EQUIPMENT MODIFICATION}

A. Modifications for both $128 \mathrm{~A}$ and 5204

1. Install the rack mounting brackets on all instruments using the 07-5204-35 kit on the 5204 and brackets supplied by J. L. Stringer for the 128A's.

2. Install any hardware required to support the rear of the instrument cabinet required for mounting in the FFTF cabinets.

3. Remove the rubber feet from the bottom of all instrument chassis.

B. For only the $128 \mathrm{~A}$

Install a BNC connector in one of the rear chassis holes (selection TBD by J. L. Stringer) and connect it in parallel with the OUT connector on the front panel.

C. For only the 5204

Install a locking collet on the "Tuned Amplifier" frequency selecting patentiometer shaft (rear panel). Lock collet will be supplied by J. L. Stringer. 
III. INITIAL OPERATION CHECK

Both 5204 and 128A model lock-in amplifiers were purchased with only the "TUNED AMPLIFIER OPTION" no other options are installed.

\section{A. For the $128 \mathrm{~A}$}

Perform the instrumentation of the Section II initial checks section of the Operation and Maintenance Manual (OMM) with the following selections:

Paragraph 3.3 (3) Set tracking rate switch to FAST.

3.3 (4) $1 \mathrm{kHz}$ was the ordered frequency.

3.3 (5) Skip Option not installed.

3.3 (8) These units were to have their gain trimmed at the factory for a full scale indication on the $25 \mathrm{mV}$ range, thus, the error may be ( $1 \%$ to $2 \%$ ) larger than expected by this instruction.

\section{B. For the 5204}

Perform the instructions of Section III of the OMM "Initial Checks" with the following selections:

- Perform only the paragraph 3.3 and 3.4 instructions.

- Only the Tuned Amplifier option is installed.

IV. CALIBRATION

The calibration of the two lock-in amplifier models shall be performed only after the Initial Operation checks of the Section III have been completed and shall be performed in the sequence listed in this section.

1. Test Equipment

(a) H/P model 650B Sinewave Oscillator or equivalent with an adjustable amplitude and frequency with a $50 \mathrm{ohm}$ output impedance.

(b) 50 ohm or 75 ohm switch selected attenuator which can provide attenuation down to a ldb resolution. 
(c) Digital voltmeter such as a Fluke model $3200 \mathrm{~A}$ or equivalent.

(d) Two BNC shorting plugs.

(e) Interconnecting cables.

(f) Frequency counter with an accuracy at $1 \mathrm{kHz}$ to $\pm 0.5 \mathrm{~Hz}$ or better.

(g) General purpose oscilloscope.

\section{Preliminary Steps}

(a) Remove the top cover, which is secued by four screws, two on each side.

(b) Check and, if necessary, adjust the mechanical zero of the panel meters. Then plug in the Model 128A or 5204 turn on the power and allow a fifteen minute warm up minimum.

(c) Connect the BNC shorting plugs to both inputs.

3. Procedure for the $128 \mathrm{~A}$

Some of the instructions in this procedure will refer to the OMM for the 128 A amplifier.

\subsection{Power Supply Check}

On the power supply board, check for: (a) $+15.5 \mathrm{~V} \pm 0.1 \mathrm{~V}$ at the positive end of capacitor $\mathrm{C} 309$, (b) $-15.5 \mathrm{~V} \pm 0.2 \mathrm{~V}$ at the negative end of capacitor $\mathrm{C310}$, and (c) $+5 \mathrm{~V} \pm 0.2 \mathrm{~V}$ at the positive end of capcitor C312. If these voltages are not within the allowed variation notify J. L. Stringer (2-3418) before continuing.

Reference the OMM Section 6.4 and schematic on page VII-11. 
3.2. Amplifier Control Settings:

Input Selector Switch: A

Sensitivity: $25 \mathrm{mV}$

Lo Pass Switch: $10 \mathrm{kHz}$

Hi Pass Switch: $50 \mathrm{kHz}$

Phase

Switch: $270^{\circ}$

Dial: $90^{\circ}(9: 00)$

Reference Mode Switch: $f$ (fund.)

Time Constant: $0.3 \mathrm{sec}$.

DC Prefilter: OUT

Zero offset

Switch: OFF (center position)

Dial: 0.00 (fully counter clockwise)

Fast/Slow Switches (located on Ref. board): FAST

\subsection{Test Configuration (See Figure 1).}

3.3.1 Connect the test system together as shown in Figure 1 except that one digital voltmeter (DVM) can be used for all measurement Connection points should be provided in the test set up to allow quick connection of the DVM from point-to-point (BNC connectors)

3.3.2 Set the oscillator to $1 \mathrm{kHz} \pm 0.5 \mathrm{~Hz}$ with a nominal amplitude of $0.5 \mathrm{Vac}$ Rms. (should always be within $\pm 5 \%$ ).

3.3.3. Set the attenuator output to give $25 \mathrm{mVac} \pm 0.2 \%$ (requires approximately $26 \mathrm{db}$ of attenuation) indication on the digital voltmeter.

3.4 Set Up the Tuned Arsplifier and Lock-In Amplifier Gain.

3.4.1 Tuned Amplifier Switch Settings (Amplifier Board)

(a) Selective/Flat Switch: Selective

(b) Notch/Zandpass Switch: Notch 
Refer to OMM page IV-13, Figure IV-14.

3.4.2 Connect the oscilloscope to the Sig. Mon. BNC connector on the rear panel and set the oscilloscope to view a steady $1 \mathrm{kHz}$ waveform.

3.4.3 Alternately adjust the tuned amplifier Freq. Adj. potentiometer (rear panel hole) and the NULL potentiometer (side wall hole) to obtain a minimum amplitude signal on the oscilloscope. These controls interact so several iterations will be necessary to obtain the best minimum.

NOTE: These controls should have been preset by the vendor for $\mathrm{I} \mathrm{kHz}$.

3.4.4 Set the Notch/Bandpass switch to Bandpass.

3.4.5 Adjust the Phase Dial (and Phase Switch if required) for peak (maximum) output voltage (Vdc) on the panel meter and Digital Voltmeter.

3.4.6 Adjust the Model 128A GAIN CAL. trim poteniometer, R743, for exactly $+1.000 \mathrm{Vdc} \pm 0.0001 \mathrm{Vdc}$ on the Digital Voltmeter. Refer to OMM page V-2, Figure $V-1$ for the location of R143.

\subsection{Sensitivity Range Calibration}

This step determines the gain sensitivities of the adjacent attenuator ,ranges (250 mV, $100 \mathrm{mV}, 10 \mathrm{mV}$ and $2.5 \mathrm{mV})$.

3.5.1 Set the Sensitivity Switch to the $250 \mathrm{mV}$ position.

3.5.2 Set the attenuator for a nominal $6 \mathrm{db}$ of attenuation and .. adjust the oscillator amplitude to give a reading of 250 $\mathrm{mV} \pm 0.05 \mathrm{mV}$ at the attenuator output. 
3.5.3 Read the Model 128A output (Vdc) on the Digital Voltmeter and record this reading versus the input voltage. The output voltage should be $1.00 \mathrm{Vdc} \pm 0.02 \mathrm{Vdc}$. If not call to the attention of J. L. Stringer 2-3418.

3.5.4 Set the attenuator for a nominal $14 \mathrm{db}$ of attenuation and adjust the oscillator amplitude to give a reading of $100 \mathrm{mV}$ $\pm 0.05 \mathrm{mV}$.

3.5.5 Set the amplifier sensitivity to $100 \mathrm{mV}$ and record the $128 \mathrm{~A}$ Output voltage reading on the Digital Voltmeter versus the input voltage. Voltage should be $1.00 \mathrm{Vdc} \pm 0.02 \mathrm{Vdc}$.

3.5.6 Repeat steps 3.5.4 and 3.5.5 for the following sensitivity switch settings and inputs.

Sensitivity

$10 \mathrm{mV}$

$2.5 \mathrm{mV}$
Input

$10 \mathrm{mV} \pm 0.5 \mathrm{mV}$

$2.5 \mathrm{mV} \pm 0.5 \mathrm{mV}$
Attenuator

$34 \mathrm{db}$

$46 \mathrm{db}$

\subsubsection{Return the Sensitivity switch to $25 \mathrm{mV}$.}

This completes the calibration of the 128A Lock-In Amplifier.

\subsection{Procedure for the 5204}

Some of the instruction in this procedure will refer to the OMM for the 5204 amplifier.

4.1 Power Supply Check (DO NOT ADJUST)

In the OMM on Page VII-15 the circuit diagram 11092 and circuit board layout are shown for the power supply boards. Refer to these diagrams for the measurement locations.

4.1.1 Connect a Digital Voltmeter (DVM) across diode CR3O6 and verify a reading of $+15.00 \mathrm{Vdc} \pm 0.04 \mathrm{Vdc}$.

c 
4.1.2 Connect the DVM across diode CR307 and verify a reading of $-15.00 \mathrm{Vdc} \pm 0.04 \mathrm{Vdc}$.

4.1.3 Connect the DVM across capacitor C304 and verify $+5.0 \mathrm{Vdc}$ $\pm 0.2 \mathrm{Vdc}$.

NOTE: If any of the voltages fall outside the limits call J. L. Stringer (2-3418) for further Instruction and stop the calibration.

\subsection{Amplifier Control Settings}

\subsubsection{Front Panel:}

Mode: Notch

Float/Ground: Float

A/A-B: $\quad A$

Sensitivity: $25 \mathrm{mV}$

High Pass: $50 \mathrm{~Hz}$

Low Pass: $10 \mathrm{kHz}$

Phase (Reference)

Push Button Depressed: $270^{\circ}$

Dial: $90^{\circ}(9: 00)$

$f / 2 f: f$

EXT/INT: EXT

In-Phase

Zero Offset Dial: Fully CCW

Zero Offset $P B$ : OFF (Both released)

DC Prefilter PB: $0.1 \mathrm{Sec}$ (depressed)

Output Expand PB: $X 7$ (depressed)

Time Constant: $0.3 \mathrm{sec}$.

Meter $P B$

In-Phase: depressed

Quadrature: depressed 


\section{Quadrature}

Zero Offset dial: Fully $\mathrm{CCW}$

Zero Offset PB: Off (both released)

DC Prefilter PB: $0.1 \mathrm{sec}$ (depressed)

Output Expand PB: $X I$ (depressed)

Time Constant: $0.3 \mathrm{sec}$.

\subsubsection{Rear Panel}

Tuned Amplifier

Range Switch: $1 \mathrm{kHz}$

Multiplier: Near 1 (subject to final tuning)

\subsection{Test Configuration (See Figure 1)}

\subsubsection{Repeat Steps 3.3.1 through 3.3.3}

4.3.2. Connect a DVM to the In Phase (I) Output BNC.

4.4 Set up the Tuned Amplifier and Lock-In Amplifier Gain

4.4.1 Adjust the Tuned Amplifier Range and Multiplier controls set up in 4.2.2 to achieve a decreased level on the In Phase meter and DVM.

4.4.2 Alternately adjust the Multipiier and Notch Depth controls to get the smallest indication on the In Phase meter. Increase the measurement sensitivity by first operating the output expansion $P B$ to $X 10$ then to $X 100$ and finally move the Sensitivity switch to $10 \mathrm{mV}, 2.5 \mathrm{mV}$, etc., until no further decrease can be achieved or the overload light becomes illuminated.

4.4.3 Return the Sensitivity switch to $25 \mathrm{mV}$ and the Output Expand $P B$ to $X 1$ (depressed).

4.4.4 Depress the Bandpass pushbutton the In Phase (I) meter shou?d indicate near full scale and the Quadrature (Q) meter should indicate near zero.

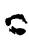

Provided with PNNL-26202 
4.4.5 Move the phase dial to get the best zero on the $Q$ meter and a maximum reading on the $I$ meter and DVM.

NOTE: Use the $Q$ meter Output Expand ranges of $\times 10$ and $\times 100$ to complete the final adjustment, then return the Output Expand to $X 1$.

4.4.6 Referring to pages VII-12 and VII-13 for the schematic and parts location on the Signal Amplifier Board, adjust RT43 Gain Adj. potentiometer to give an output on the I meter of $1.000 \mathrm{Vdc} \pm .0001 \mathrm{Vdc}$.

4.4.7 Depress the $180^{\circ}$ phase pushbutton and change the DVM to the $Q$ meter output. Verify that the $Q$ output voltage is $1.000 \mathrm{Vdc} \pm 0.0005 \mathrm{Vdc}$.

4.4.8 Return the DVM to the I meter output and depress the $270^{\circ}$ Phase pushbutton.

This completes setting up the gain of the 5204 for the $25 \mathrm{mV}$ sensitivity range to an accuracy $\pm 0.2 \%$.

\subsection{Sensitivity Range Calibration}

This step determines the relative gain sensitivities of the adjacent attenuator ranges $(250 \mathrm{mV}, 100 \mathrm{mV}, 10 \mathrm{mV}$ and $2.5 \mathrm{mV}$ ).

4.5.1 Set the Sensitivity switch to the $250 \mathrm{mV}$ position.

4.5.2 Set the attenuator for a nominal $6 \mathrm{db}$ of attenuation and adjust (trim) the oscillator amplitude to give a reading of $250 \mathrm{mV} \pm 0.05 \mathrm{mV}$ at the attenuator output.

4.5.3 Read the I meter output (Vdc) on the DVM and record the reading versus the input voltage. The output voltage should be witnin $1.000 \mathrm{Vdc} \pm 0.020 \mathrm{Vdc}$. 
4.5.4 Set the attenuator for a nominal $14 \mathrm{db}$ of attenuation and trim the oscillator amplitude to give a reading of $100 \mathrm{mV}$ $\pm 0.05 \mathrm{mV}$.

4.5.5 Set the 5204 sensitivity switch to $100 \mathrm{mV}$ and read the I meter output (Vdc) on the DVM and record this reading versus the input voltage. This voltage should be within the range of 1.000 $V d c \pm 0.020 V d c$

4.5.6 Repeat steps 4.5 .4 and 4.5 .5 for the following sensitivity switch settings and inputs.

Sensitivity

$10 \mathrm{mV}$

$2.5 \mathrm{mV}$
Input

$10 \mathrm{mV} \pm .05 \mathrm{mV}$

$2.5 \mathrm{mV} \pm .05 \mathrm{mV}$
Attenuator

$34 \mathrm{db}$

$46 \mathrm{db}$

4.5.7 Return the Sensitivity switch to $25 \mathrm{mV}$.

This completes the calibration of the 5204 Lock-In Amplifier. 


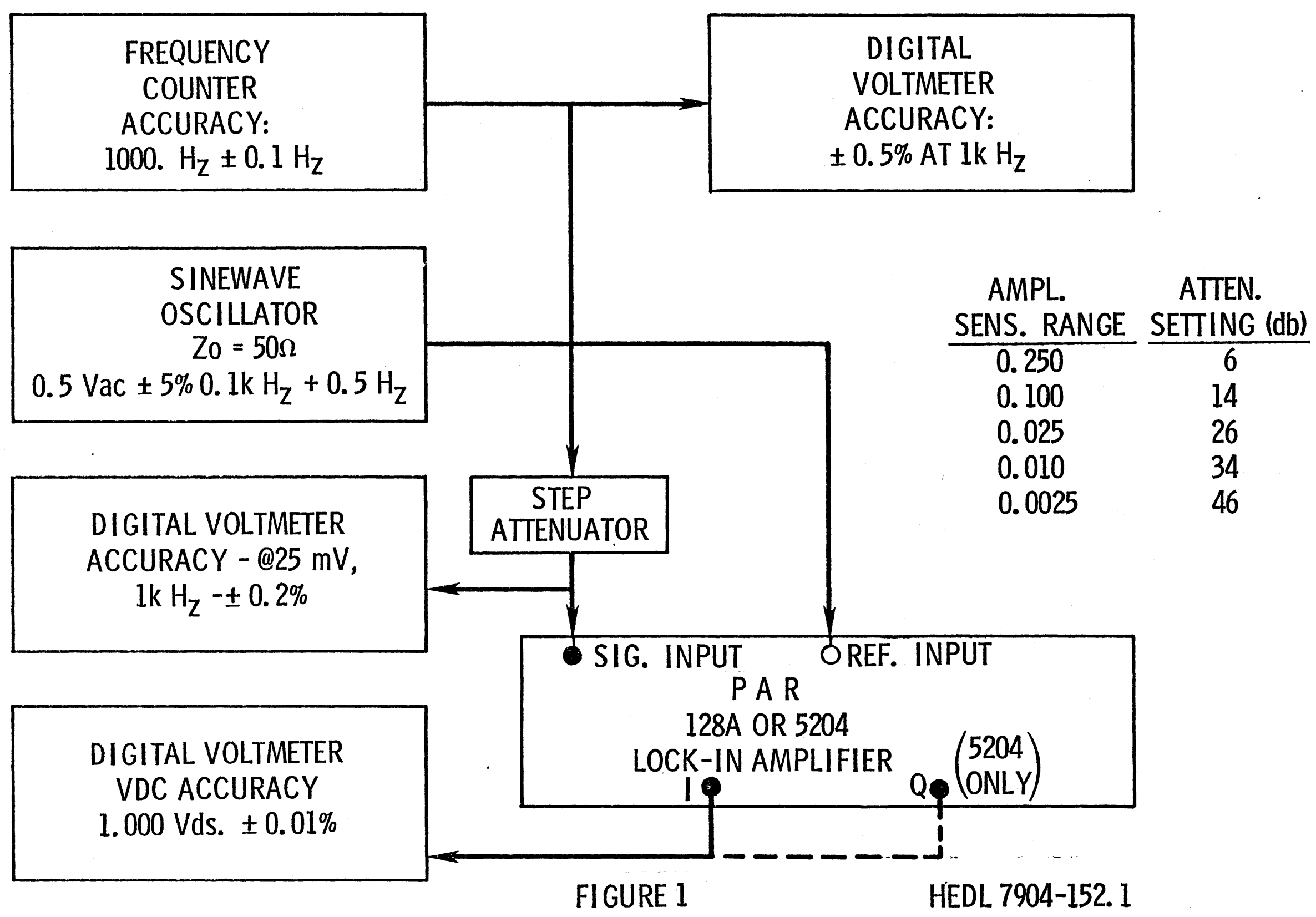


SYSTEM ATTENUATOR

ECFM LOCK-IN AMPLIFIER DESIGN

J. L. Stringer

December 4; 1978

I. DESIGN DECISIONS:

1. Since the new PAR lock-in amplifiers have a $25 \mathrm{mV}$ sensitivity range rather than $20 \mathrm{mV}$ and a $1.000 \mathrm{Vdc}$ output rather than $10.00 \mathrm{Vdc}$, it was decided to design the attenuator to match the $25 \mathrm{mV}$ input signal, but allow the factor of 10 reduction in the output (no choice).

2. The gain errors from the original calibration of the ECFM's for the lockin amplifier/attenuator combinations for each chanel is $+1.1 \%,(-) .79 \%$. The gain error between channels (Attenuator/Amplifier No. 1; Attenuator/ Amplifier No. 2$)$ is (+) $1.3 \%,(-) .78 \%$.

3. The tolerance of the 10K ohm buffer resistor in the FFT?-ECFM-SC/CR module is $\pm 5 \%$.

4. From these data the tctal variation which must be accomodated by the atteriuator is:

$$
\pm 5 \%, \pm 1.3 \%, \pm 1.1 \%
$$

Linearly combining these variations gives

$$
\pm 7.4 \%
$$

as the variation range for the adjustment, and is the design goal.

5. A variation of $\pm 10 \%$ was $\because 2$ to make the initial design choices.

6. The final design choices ware made for the components available from Rockwell Stores. 
7. A circuit design was chosen to make the attenuator input and output impedances nearly contant near the values used for the calibration attenuators.

8. The circuit ground will be carried separate from chassis ground to be consistant with the grounding practices in use at FFTF and the floating input on the PAR amplifiers.

\section{CIRCUIT DESIGN (Nominal Values)}

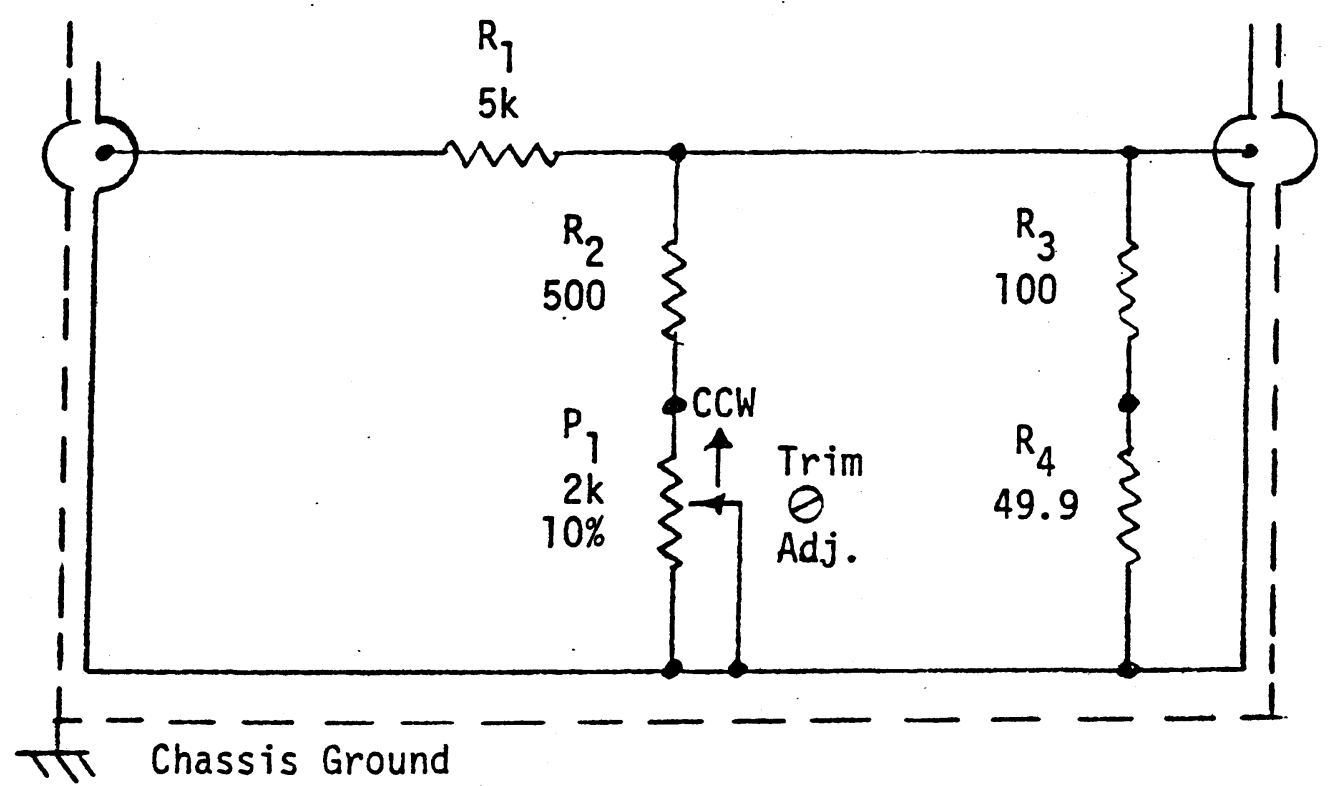

All resistor values in ohm

All resistors are $1 / 4 \mathrm{w}, 1 \%$, metal film

Potentionmeter is cermet, 20 turn

The nominal setting of $P_{1}$ to give an output of 0.0250 volts for a 1.000 $V$ input is $P_{1,0}=382$ ohms.

\section{FIGURE 1}

The equation for the nominal attenuator is:

$$
\frac{V_{0}}{V_{\text {in }}}=n=\frac{\frac{R_{s}\left(R_{2}+P_{1}\right)}{R_{s}+R_{2}+P_{1}}}{\frac{R_{s}\left(R_{2}+P_{1}\right)}{R_{s}+R_{2}+P_{1}}-R_{1}}
$$

where: $R_{s}=R_{3}+R_{4}$ 
Evaluating with the nominal values gives

$$
\text { . } R_{S}=R_{3}+R_{4}=100+50=150 \Omega
$$

and

$$
R_{2}+P_{1}=500+382=882 \Omega
$$

and

$$
\frac{R_{s}\left(R_{2}+P_{1}\right)}{R_{s}+R_{2}+P_{1}}=\frac{150(500+382)}{150+500+382}=128.2 \Omega
$$

then

$$
\frac{V_{0}}{V_{\text {in }}}=n=\frac{128.2}{5000+128.2}=.0250
$$

This result can be interpreted to mean, when 1 volt is applied to the attenuator input .0250 volts is applied to the amplifier input.

The nominal input impedance of the attenuator is

$$
5000+128.2=5.1282 \mathrm{k} \text { ohms } \pm 1 \%
$$

The ECFM calibration attenuator nominal input impedance was $5.10 \mathrm{~K}$ ohms $\pm 1 \%$.

The nominal output impedance of this attenuator design is

$$
\frac{(128.2)(5000)}{128.2+5000}=125 \text { ohms } \pm 7 \%
$$

The nominal output of the ECFM calibration attenuator was

$$
\frac{(100)(5000)}{100+5000}=98.0 \text { ohms } \pm 1 \%
$$

\section{CIRCUIT VARIATION RANGE}

Note the following circuit components and their tolerances. 


$$
\begin{aligned}
& R_{1}=5000 \Omega, \pm 1 \% \\
& R_{2}=500 \Omega, \pm 1 \% \\
& R_{3}=100 \Omega, \pm 1 \% \\
& R_{4}=50 \Omega, \pm 1 \% \\
& P_{1}=2000 \Omega \pm 10 \% \text { and } \sim 2 \Omega \text { residual resistance } \\
& R_{3}+R_{4}=150 \Omega, \pm 1 \%
\end{aligned}
$$

The attenuator circuit can be, redrawn as

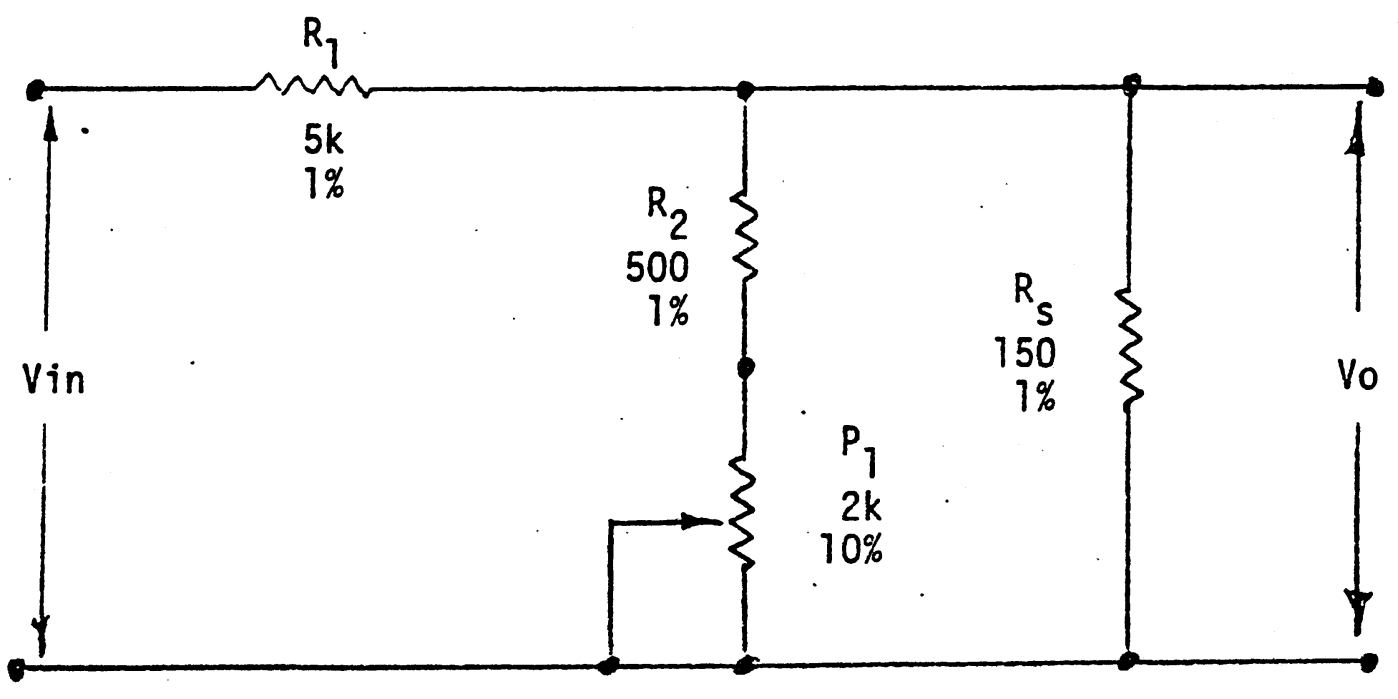

FIGURE .2

\section{Variation Analysis:}

The various circuit element combinations will be calculated for the maximum and minimum vation around the nominal attenuator value of 0.0250 .

The minimum output voltage of the $R_{T}, R_{S}$ circuit branch ocurrs when

$$
\begin{aligned}
& R_{S}=148.5(-1 \%) \text { ohm } \\
& R_{f}=5050(+1 \%) \text { ohms }
\end{aligned}
$$

The maximum output voltage of the $R_{7}, R_{S}$ circuit branch ocurrs when

$$
\begin{aligned}
& R_{s}=151.5(+1 \%) \text { ohms } \\
& R_{1}=4950(-1 \%) \text { ohms. }
\end{aligned}
$$


The $R_{2}, P_{1}$ circuit branch just modifies the $R_{s}$ circuit value, thus, when the $R_{2}, P_{1}$ circuit has its maximum value the parallel combination of $R_{s}$ and $\left(R_{2}+P_{1}\right)$. will have its maximum value, and when $\left(R_{2}+P_{1}\right)$ has its minimum value the paralle combination of $R_{s}$ and $\left(R_{2}+P_{1}\right)$ will, have its minimum value.

Thus, only four cases need to be calculated. These are:

\section{CASE I:}

$$
\begin{array}{ll}
R_{s}=148.5 \Omega & n\left(R_{1}, R_{s}\right)=\text { minimum } \\
R_{1}=5050 \Omega & R_{2}+P_{1}=\text { minimum (Adj. High) } \\
R_{2}=495 \Omega & \\
P_{1}=1800 \Omega & \\
R_{p}=\frac{R_{s}\left(R_{2}+P_{1}\right)}{R_{s}+R_{2}+P_{1}}=\frac{148.5(2295)}{148.5+2295}=139.5 \Omega & \\
\frac{V_{0}}{\text { Vin }}=\frac{R_{p}}{R_{1}+R_{p}}=\frac{139 .}{139.5+5050} & \\
\text { Minimum }(+) \text { variation } \% & \frac{.02688-.02500}{.02500} \times 100=+7.52 \%
\end{array}
$$

\section{CASE II:}

$$
\begin{array}{ll}
R_{s}=151.5 & P\left(R_{1}, R_{s}\right)=\operatorname{maximum} \\
R_{1}=4950 & R_{2}+P_{1}=\operatorname{maximum} \text { (Adj. High) } \\
R_{2}=505 & \\
P_{1}=2200 & \\
R_{p}=\frac{R_{s}\left(R_{2}+P_{1}\right)}{R_{s}+R_{2}+P_{1}}=\frac{151.5(505+2200)}{151.5+505+2200}=143.5 \mathrm{R} & \\
\frac{V_{0}}{V i n}=\frac{R_{p}}{R_{1}+R_{p}}=\frac{143.5}{4950+143.5}=.02817 . & \\
\operatorname{Max}(+) \text { variation \% }
\end{array}
$$

$$
\frac{.02817-.02500}{.02500} \times 100=+12.7 \%
$$


CASE III:

$R_{S}=148.5$

$R_{1}=5050$

$R_{2}=495$

$P_{1}=2$

$R_{p}=\frac{R_{s}\left(R_{2}+P_{1}\right)}{R_{s}+R_{2}+P_{1}}=114.3 \Omega$

$\frac{V_{0}}{V \text { in }}=\frac{R_{p}}{R_{1}+R_{p}}=\frac{114.3}{5050+114.3}=.02213$

Maximum (-) variation \%

$$
\frac{.02213-.02500}{.02500} \times 100=-11.48 \%
$$

CASE IV:

$$
\begin{array}{ll}
R_{s}=151.5 & n\left(R_{1}, R_{s}\right)=\operatorname{maximum} \\
R_{1}=4950 & R_{2}+P_{1}=\operatorname{maximum} \text { (Adj. High) } \\
R_{2}=505 & \\
P_{1}=2 & \\
R_{p}=\frac{R_{s}\left(R_{2}+P_{1}\right)}{R_{s}+R_{2}+P_{1}}=116.5 & \\
\frac{V 0}{V i n}=\frac{R_{p}}{R_{1}+R_{p}}=\frac{116.6}{4950+116.6}=.0230 \\
\text { Minimum }(-) \text { variation \% } \\
\quad \frac{.0230-.0250}{.0250} \times 100=-8.0 \%
\end{array}
$$$$
\begin{aligned}
& n\left(R_{1}, R_{s}\right)=\text { minimum } \\
& R_{2}^{-}+P_{1}=\text { minimum (Adj. High) }
\end{aligned}
$$$$
\begin{aligned}
& n\left(R_{1}, R_{s}\right)=\text { minimum } \\
& R_{2}^{-}+P_{1}=\text { minimum (Adj. High) }
\end{aligned}
$$ 
Thus, the minimum positive attenuation variation value is $+7.52 \%$ while minimum negative attenuation variation value is $-8.0 \%$.

\section{SUMMARY}

The positive and negative adjustment limits with the component tolerance chosen bracket the expected $\pm 7.4 \%$ system variation and should provide the long term stability that is necessary for the system operation. 
FIELD CALIBRATION

\section{AND SET UP PROCEDURE FOR \\ THE ECFM - PHASE SENSITIVE OETECTORS}

J. L. Stringer

December 13, 1978

GENERAL

This procedure is focused on setting the PSD external attenuator to the TTL calibration gain requirements for the specific ECFM sensor being caibrated, and to adjust the chase space position of the in-phase FSD component to coincide with the sensor's fiow vector.

PROCEDURE

1.0 Preliminary

1.1 Equipment Required

a. Interconnecting cables and adapters.

b. FLUKE - DVM in the ECFM test section for Vac measurements.

c. Hand calculator SR-50, TI-30 or equivalent.

d. Portable DVM with resolution and accuracy to $1 \mathrm{mVdc}$ on a 1-2 Vdc full scale range.

1.2 Equipment Warm Up

The equipment shall have been turned on for 30 minutes following the last 2 to 3 minute duration without power prior to performing the procedurai steps.

The attenuator calibration procedures shall be performed without power interruption.

\subsection{Assumptions}

1.3.1 This procedure assumes that the Mode? 1?84's and 5204(1) have completed the gain calibratiors in the Standarcs Laboratory $(2)$, have been installed in the appropriate ECFM cabinets at FFTF and (3) 
that the systems are interconnected per the connection diagram of Figure 1 .

1.3.2 These procedures can be performed only following compilation and certification of FTRTA - ECFM - SC/CR module gain adjustment to a procedure equivalent to that of paragraph 5.4.1.4 (Gain Adjust) page 59 of OHM-092-00-002, Vol. 1.

\subsection{Initial Control Settings}

a. Model 128A

Input Selector Switch: A

Sensitivity: 25 millivolts

Lo Pass Switch: $10 \mathrm{kHz}$

Hi Pass Switch: $50 \mathrm{~Hz}$

Phase:

Switch: $270^{\circ}$

Dial: $90^{\circ}(9: 00)$

Reference Model Switch: $f$ (fundamental)

Time Constant: $3.0 \mathrm{sec}$.

DC Prefilter: Out

Zero Offset:

Switch: Off (Center Position)

Dial: 0.00 (full ccw)

b. Model 5204

Front Panel

Mode: Bandpass (PB depressed)

Float/Ground: Float (PB depressed)

$A / A-B$ : $\quad A$ (PB depressed)

Sensitivity: $25 \mathrm{mV}$

High Pass: $50 \mathrm{~Hz}$ (PB depressed)

Low Pass: $10 \mathrm{kHz}$ (PB depressed)

Phase (Reference)

PB: $270^{\circ}$ (depressed)

Dial: $90^{\circ}(9: 00)$ 
Mode (reference)

$2 f / f: \quad f(P B$ released)

Ext/Int: Ext (PB depressed)

In-Phase

Zero Offset Dial: fully ccw

Zero Offset $P B$ : Off (both released)

DC Prefilter PB: off (both released)

Output Expand FB: $\mathrm{X} 7$ (depressed)

Time Constant: $3.0 \mathrm{sec}$.

In-Phase Meter

In-Phase PB: Depressed

Quadrature Meter

Quadrature PB: Depressed

Quadrature

Zero Offset Dial: Full ccw

Zero Offset PB: Off (both released)

DC Prefilter PB: Off (both released)

Output Expand PB: $X I$ (depressed)

Time Constant: 3.0 seconds

\section{Rear Panel}

Tuned Amplifier Range Switch: $7 \mathrm{kHz}$

\subsection{Calibrate the PSD Attenuator/Lock-In Amplifier}

2.1 Verify that the flowsensor is installed and connected to the correct $\mathrm{SC} / \mathrm{CR}$ module position.

2.2 Verify that the PSD system is interconnected per Figure 1 and that power has been turned on for at least 30 minutes.

2.3 Verify that the ECFM-SC/CR module/flowsensor have been energized for at least 30 minutes, and has been calibrated to the requirements of paragraph 1.3.2. 
2.4 Verify that the Lock-In Amplifier controls are setup per paragraph 1.4 for the appropriate Lock-In moduie.

2.5 Verify that the REF UNLOCK iight in the Reference Section of the Lock-In Amplifier is not illuminated.

2.6 Connect the Test and Readout (T\&R) cable between the Module Test Cable connector J204 on the Test/Cal Station and the Selected SC/CR module test connector.

2.7 With the T\&R cable attached, remove the SC/CR module from its operating position and insert it fully into the Test Station test slot.

2.8 Set Test/Cal Station controls as follows:

Control/Switch

Unit Test Select

SC/CR TEST SEL

SC TEST FUNCTION

AMPL CONTROL

DMM

\section{Position}

$\mathrm{SC} / \mathrm{CR}$

AMPL SEC

GAIN

$400(4.00 \mathrm{mV})$

$10 \mathrm{~V}-\mathrm{AC}$

2.9 Verify that the DMM reads $\pm 3.03 \mathrm{VaC}( \pm 1 \%)$ with the cable to $\mathrm{J3} \mathrm{SC} / \mathrm{CR}$ disconnected. Record this reading 3. Vac.

2.10 Reconnect the cable to J3 (AMPL SEC) on the SC/CR module and note that the DMM reading drops to $1.02 \mathrm{Vdc} \pm .07 \mathrm{Vdc}$.

2.11 While monitoring the OUT DC voltage with portable DVM (2 Vdc max, $100 \%$ overage of output) adjust the dial phase control and the course switch or pushbutton controls to achieve a maximum in-phase output voltage and/or a zero quadrature voltage.

NOTE: The quadrature output for the Model 5204 is read from the $Q$ outpit connector directly. For the Model 128A change the course phase dial by $90^{\circ}$ leading or lagging and read the DVM output while adjusting the phase dial to get zero $v d c$. 
2.12 Return the Lock-In Amplifier course phase controls to display the maximum in-phase'signal. Record the final phase readings. Switch Dial

2.13 Adjust the associated PSD attenuator section, adjust potentiometer to get a Vdc output from the Lock-In Amplifier determined in the following manner.

Multiply the voltage reading obtained in step 2.9 by the gain number associated with the ECFM probe being calibrated listed in the gain number column of Table I.

For example:

If the step 2.9 voltage is 3.04 and the Gain Number from Table I is 0.302 the Vdc output voltage will be:

$$
3.04 \times .302=0.918 \mathrm{Vdc}
$$

2.14 When the Lock-In Amplifier reads the calculated output voltage stop the adjustment, remove the adjustment tool, and cover the adjustment hole with an appropriate label which includes the ECFM No., and SC/CR No., serial number of associated Lock-In Amplifier, and the final output voltage measured.

2.15 Return the SC/CR module to its correct panel location and disconnect the T\&R cable.

2.16 This completes the PSD attenuator calibration for this channel.

2.17 Continue to repeat the procedure steps until eleven PSD attenuator sections are adjusted.

2.18 Proceed to setting up the PSD detector in the direction of the flow vector section 3.0 . 


\subsection{Lock-In Amplifier Phase Adjustment For Flow Measurement}

3.1 Verify that the flowsensor is connected to the correct SC/CR module position, PSD attenuator and Lock-In Amplifier.

3.2 Verify that the PSD system is connected according to Figure 1.

3.3 Verify that power has been applied to both the SC/CR module and the Lock-In Amplifier for at least 30 minutes.

3.4 Verify that section 2.0 of this procedure has been completed for this PSD system.

3.5 Verify that the Lock-In Amplifier controls are set up per paragraph 1.4 for the appropriate Lock-In module.

3.6 Verify that the REF UNLOCK light in the reference section of the Lock-In Amplifier is not illuminated.

3.7 Set up the Switch/Pushbutton and dial phase settings determined in the TTL calibration for the ECFM selected. These settings are listed in Tabie I for the selected ECFM.

3.8 Set the reactor sodium flow past the ECFM's to zero (all pumps off).

3.9 Observe the in-phase (IP) and quadrature (QP) $\left( \pm 90^{\circ}\right)$ signal magnitude and polarities, with the portable DVM, and adjust the phase switch and dial settings to get the magnitudes and polarities for IP and QP listed in Table I.

3.10 Record these magnitudes and phase settings in Section I of Addendum I.

3.i1 Repeat the procedure step 3.1 through 3.10 for a11 the Lock-In Amplifier systems being set up.

3.12 Increase the flow by operating two or three (3 proferred) of the primary system poriy motors. 
3.13 Without performing any adjustments on the phase of the Lock-In Amplifier, record the IP and QP output voltages in Section I of Addendum I for the maximum flow.

NOTE: This procedure may not be adequate for those flowsensors positioned over the reflector position. A procedure addition may result from the field measurements being made.

3.14 Following completing steps 3.7 through 3.13 for all amplifiers transfer the voltage values recorded in Section I of Addendum I to the $1_{1}, 1_{2}$, $q_{1}$, and $q_{2}$ values of Addendum II according to the following:

$1_{1}=I P$ at 3 pony motor flow, $400^{\circ} \mathrm{F}$.

$q_{1}=Q P$ at 3 pony motor flow, $400^{\circ} \mathrm{F}$.

$I_{2}=$ IP at zero flow, $400^{\circ} \mathrm{F}$.

$q_{2}=Q P$ at zero flow, $400^{\circ} \mathrm{F}$.

3.15 Perform the calculations indicated on Addendum II to get the correct 3 pony motor flow value for the $Q P$ voltage setting. Also, graph the $1_{1}$, $l_{2}, q_{1}$, and $q_{2}$ values and graphically verify the calculated value.

3.16 Record the QP calculated value in Section II Addendum I.

3.17 Repeat steps 3.14 through 3.16 for a 11 the Lock-In Amplifier systems being set up.

3.18 While the three pony motor flow continues set the phase switch on the selected lock-in system to measure QP, and slowly adjust the phase dial to get as near to the calculated $Q P$ value as possible over a 5 minute time period.

3.19 Record the IP and QP voltage values in Section II of Addendum I. 
3.20 Repeat steps. 3.18 and 3.19 for al1 lock-in systems.

3.21 If possible lower the flow back to that used in step 3.9 and 3.10 and record the QP and IP output voltage in Section II of Addendum I as zero flow.

3.22 Repeat step 3.21 for all lock-in systems.

3.23 Resume 3 pony motor or selected flow.

3.24 Remove the DVM from the outputs.

3.25 Verify that the course phase switch is set to display the IP vector component on the meter and that the output connector is connected to the DDH and DS input.

3.26 This completes set up of the Lock-In Amplifier system after MIST operation. 


\section{ADDENDUM I \\ LOCK-IN AMPLIFIER/ECFM SET UP}

Date: Trial Run No.: ECFM No.:

Reactor Position: ECFM SC/CR NO.:

DDH \& DS Channel No.: Lock-In Amp/Attn. No.: 1

NA Temp.: ${ }^{\circ} \mathrm{F}$, Name and Initial:

Calibrator

Section I

Na Flow - 3 pony motors $8400^{\circ} \mathrm{F}$

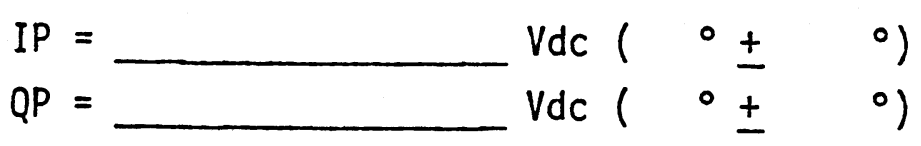

$\mathrm{Na}$ Flow - near Zero $8400^{\circ} \mathrm{F}$

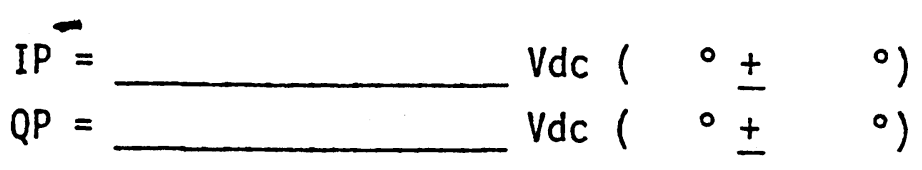

Section II

\section{CALCULATED}

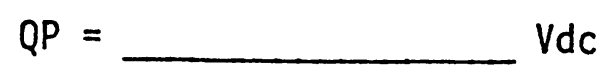

Na Flow $=3$ pony motors $0400^{\circ} \mathrm{F}$

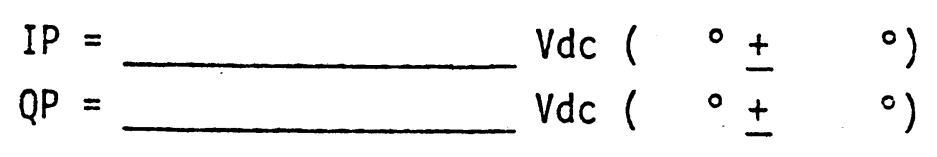

$\mathrm{Na} \mathrm{Flow} \mathrm{=} \mathrm{near} \mathrm{Zero}$

$0400^{\circ} \mathrm{F}$ (Check of QP)

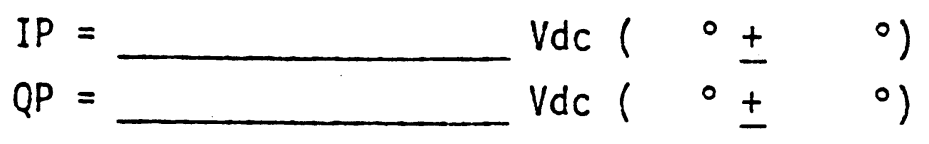


Date: Trial Run No.: ECFM No. :

Reactor Position: ECFM SC/CR No.:

DDH \& DS Channel No. Lock-In Amp/Attn. No.: 1

Na Temp.: ${ }^{\circ} \mathrm{F}$, Name and Initial:
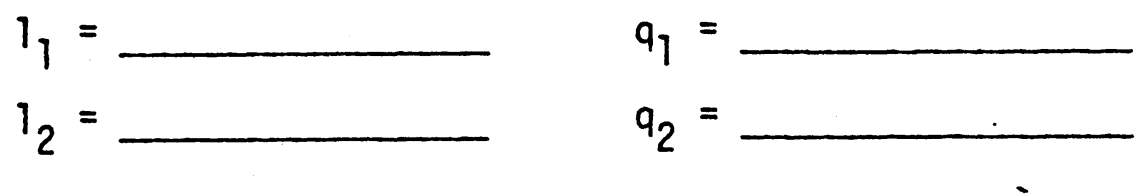

Ca)culate: (Observe Algebraic Sign Laws)

$$
\begin{aligned}
& \sqrt{1_{1}^{2}+q_{1}^{2}}= \\
& \theta=\tan ^{-1} \frac{l_{1}}{q_{1}}= \\
& \theta=\tan ^{-1}\left(\frac{q_{1}-q_{2}}{r_{1}-1_{2}}\right)= \\
& Q P=\sqrt{1^{2}+q_{1}^{2}} \cos (\theta+\theta) \\
& Q P=
\end{aligned}
$$




\section{TABLE I}

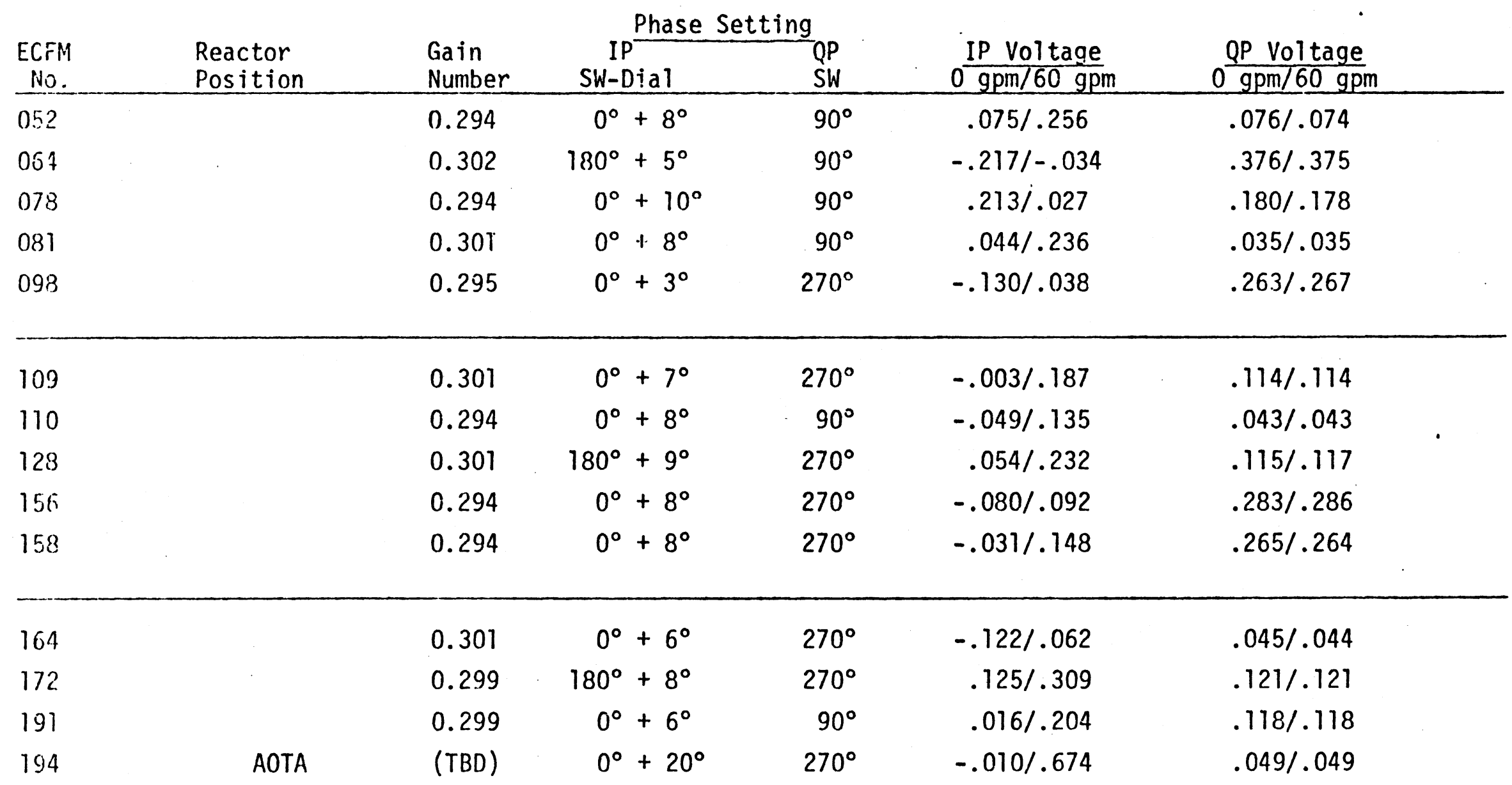


TYPICAL CHANNEL WIRE

ROUTING

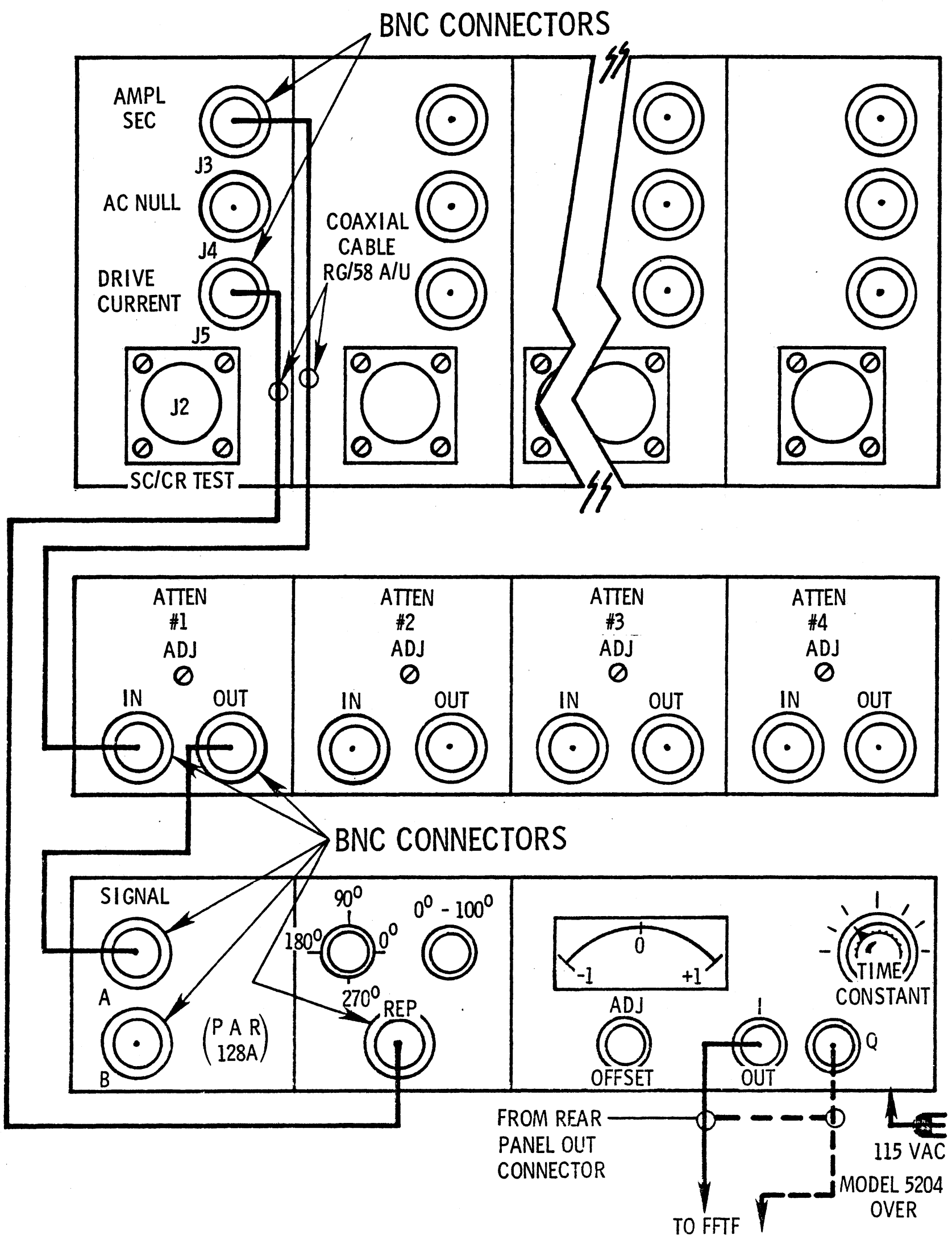

DDH \& DS SYSTEMS

HEDL 7904-152. 2

Provided with PNNL-26202 


\section{DISTRIBUTION}

\section{DOE/FFTFPO}

Director (5)

G. D. Bouchey

T. L. King

HEDL

S. L. Additon

W/B-18

T. A. Basmajian

$W / A-59$

R. A. Bennett

$W / B-43$

P. B. Bourne

J. W. Connell

W/B-118

W/D-56

D. C. Corrigan

W/C-3

E. R. Cramer

A. D. Danko

W/B-48

W/D-18

L. V. Feigenbutz

L. F. Fort

W. M. Gajewski

W/C-6

$W / D-56$

W/B-82

C. W. Hoth

$W / E-32$

R. J. Jackson

W/E-32

H. G. Johnson

W/B-43

W. L. Knecht

$W / D-66$

W. J. McShane

D. E. Mahagin

W. T. Nutt (6)

W/B-12

W/A-59

W/B-18

R. J. Robinson

W/B-86

D. P. Schively

$W / B-48$

L. K. Severud

E. M. Sheen

$W / C-99$

W/A-56

D. E. Simpson

$W / C-80$

D. D. Stepnewski W/C-75

J. L. Stringer (6) W/A-56

W. L. Thorne

J. C. Tobin

R. P. Warrick

$W / A-11$

W/B-33

$W / D-56$

$W / D-56$

W. R. Wyckoff

M. W. Young Central Files (10)

W/B-106

Publications and Services (2) 